\title{
Epidemiology of HIV-1 subtypes among men who have sex with men in Cape Town, South Africa
}

\author{
By \\ Keren Middelkoop \\ (JNSKER001) \\ Thesis presented for partial fulfillment of the requirements \\ for the degree of \\ MASTERS IN PUBLIC HEALTH \\ in the School of Public Health and Family Medicine \\ at the \\ UNIVERSITY OF CAPE TOWN
}

November 2013

Supervisors:

Landon Myer, School of Public Health \& Family Medicine, University of Cape

Town

Linda-Gail Bekker, Desmond Tutu HIV Centre, Department of Medicine, University of Cape Town 
The copyright of this thesis vests in the author. No quotation from it or information derived from it is to be published without full acknowledgement of the source. The thesis is to be used for private study or noncommercial research purposes only.

Published by the University of Cape Town (UCT) in terms of the non-exclusive license granted to UCT by the author. 


\section{DECLARATION}

I, Keren Middelkoop, hereby declare that the work on which this dissertation is based is my original work (except where acknowledgements indicate otherwise) and that neither the whole work nor any part of it has been, is being, or is to be submitted for another degree in this or any other university.

I empower the university to reproduce for the purpose of research either the whole or any portion of the contents in any manner whatsoever.

Signature:

Date: 08 November 2013 


\section{Acknowledgements}

I owe my supervisors a huge debt of gratitude: to Landon for encouraging me to pursue my studies and for your ongoing support; to Linda-Gail, my mentor, you continue to teach me in the ways of research and academia, and inspire me to always remain mindful of why we do this work. Thank you both for your time, patience and guidance on this journey.

My heartfelt appreciation and thanks also go to my co-authors on this paper. This study was a rewarding collaboration between clinicians, epidemiologists and virologists. In particular I would like to thank Celia Rademeyer for her tireless patience in answering my numerous questions regarding the laboratory techniques and for her assistance with the laboratory component of the study methodology. 


\section{Contents}

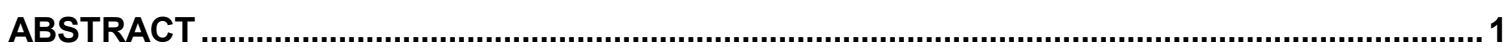

ABBREVIATIONS AND ACRONYMS

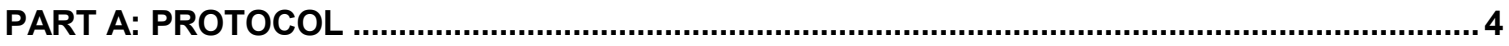

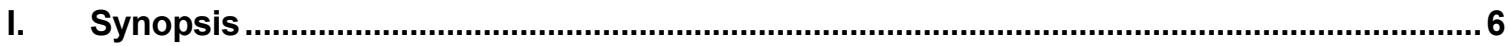

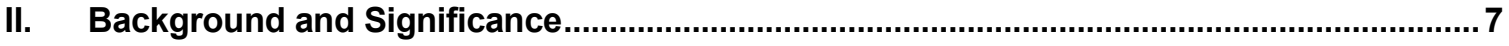

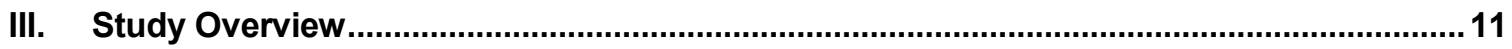

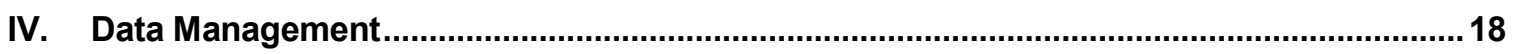

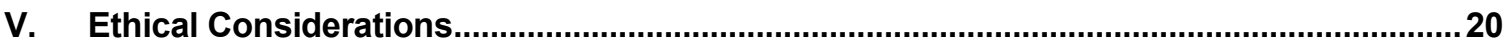

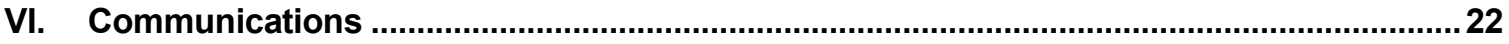

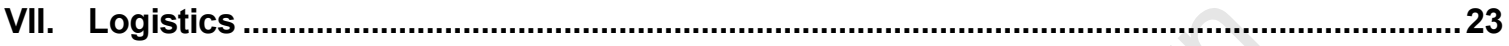

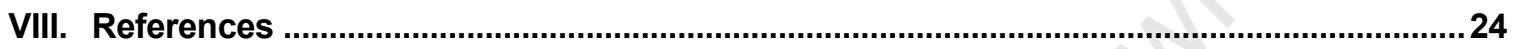

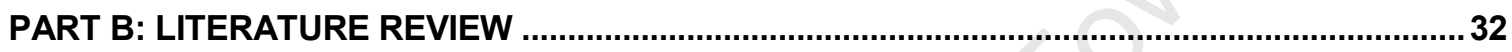

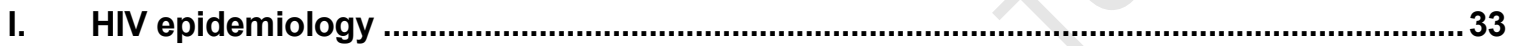

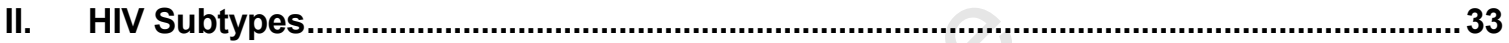

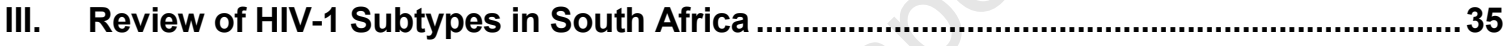

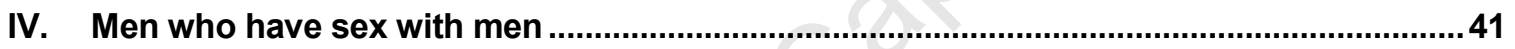

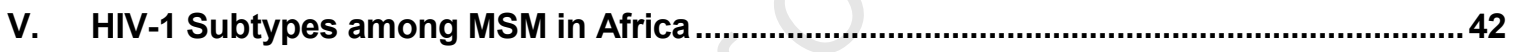

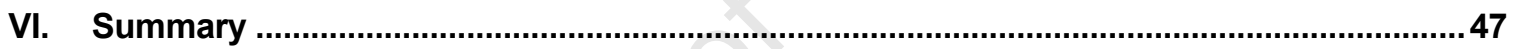

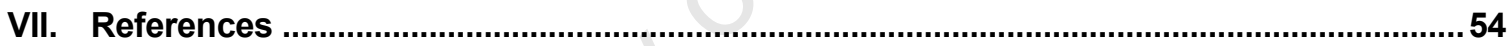

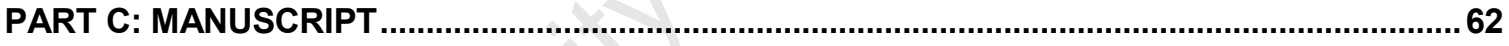

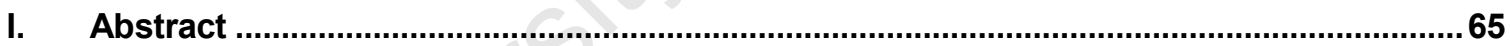

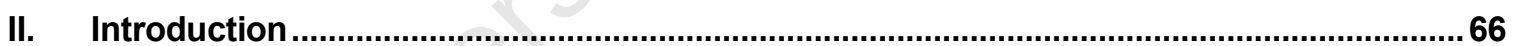

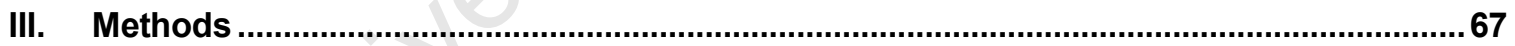

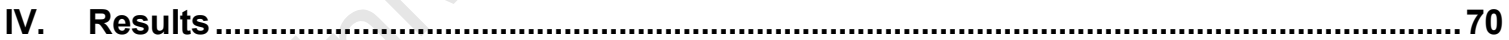

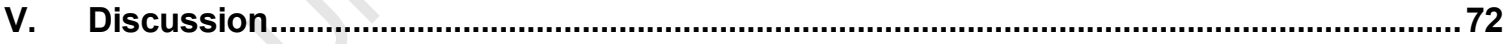

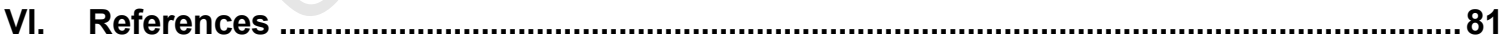

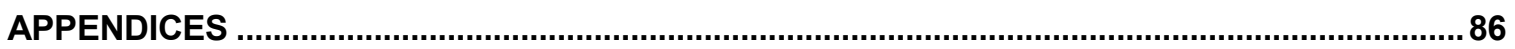

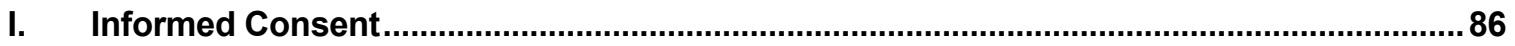

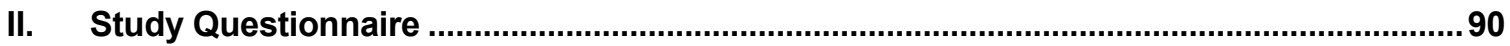

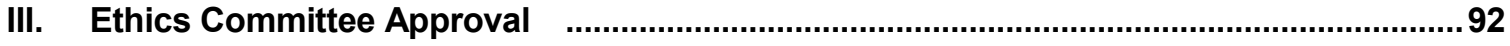

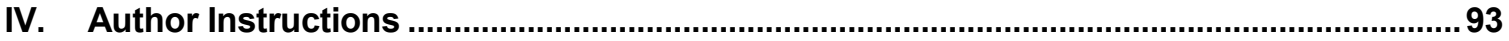




\section{Abstract}

Background: There are few data describing the HIV epidemic among men who have sex with men (MSM) in South Africa, and thus little information is available to inform appropriate public health response strategies for this high-risk group. One such existing knowledge gap is an understanding of HIV transmission patterns between different MSM communities and between MSM and the heterosexual population. Studies in the early 1990s identified two independent HIV-1 epidemics in Cape Town: a predominantly subtype B epidemic among white MSM and the mainly subtype $\mathrm{C}$ epidemic among the predominantly black heterosexual epidemic. While the heterosexual epidemic remains primarily due to subtype $\mathrm{C}$ virus, few recent HIV-1 subtype data are available for MSM in South Africa. This study examined circulating HIV-1 subtypes among MSM in Cape Town.

Methods: Self-identified MSM were recruited from geographically and racially disparate communities across Cape Town. A trained interviewer administered a study questionnaire, eliciting information on demographic characteristics, sexual orientation, and sexual partners. Participants underwent HIV counselling and testing, and CD4 T-cell count and HIV subtype testing was performed on HIV-infected participants. Subtyping was performed by DNA amplification followed by nucleotide sequencing of the complete env gp160 gene. HIV-1 subtypes were assigned via phylogenetic analysis.

Results: In total 194 HIV-infected MSM were enrolled: 52\% were from communities that were historically designated as black African and/or coloured communities. The majority of the participants were black African (67\%), with $24 \%$ coloured, and $9 \%$ white men. More black African men identified as bisexual or heterosexual compared to other races. Overall $40 \%$ of men reported a recent partner of a different race. HIV-1 subtypes were confirmed for 143 participants: $81 \%$ were subtype $C, 14 \% \mathrm{~B}, 1 \% \mathrm{~A} 1,1 \% \mathrm{~F} 2$, and three recombinant viruses. Subtype $C$ virus was associated with black African race $(p=0.003$ compared to coloured; $p<0.001$ compared to white), men who identified as bisexual/heterosexual $(p=0.01)$, and who reported a female sexual partner in the last year $(p=0.02)$. Compared to previous studies, an increasing prevalence of subtype $C$ virus was noted among white MSM. 
Conclusions: This molecular epidemiological study provides novel evidence of sexual network links between the heterosexual and MSM epidemics and between previously racially disparate communities in Cape Town. These data concur with behavioural evidence of links between these epidemics and communities. This study provides insights into the drivers of HIV epidemics in different population groups and may have implications for prevention strategies and research, particularly the development of locally efficacious HIV vaccines. 


\section{Abbreviations and Acronyms}

$\begin{array}{ll}\text { AIDS } & \text { Acquired Immune Deficiency Syndrome } \\ \text { ANC } & \text { Antenatal Clinic } \\ \text { ARV } & \text { Antiretroviral } \\ \text { CBD } & \text { Central Business District } \\ \text { CDC } & \text { Center for Disease Control } \\ \text { cDNA } & \text { Complementary deoxyribonucleic acid } \\ \text { CI } & \text { Confidence interval } \\ \text { CRF } & \text { Circulating recombinant forms } \\ \text { DCFAR } & \text { Developmental Center for AIDS Research } \\ \text { DNA } & \text { Deoxyribonucleic acid } \\ \text { DTHF } & \text { Desmond Tutu HIV Foundation } \\ \text { EDTA } & \text { Ethylenediaminetetraacetic acid } \\ \text { ELISA } & \text { Enzyme-linked immunosorbent assay } \\ \text { FSW } & \text { Female Sex Workers } \\ \text { GCP } & \text { Good Clinical Practice } \\ \text { HCT } & \text { HIV counselling and testing } \\ \text { HIV } & \text { Human Immunodeficiency Virus } \\ \text { HMA } & \text { Heteroduplex mobility assay } \\ \text { HREC } & \text { Human Research Ethics Committee } \\ \text { IAVI } & \text { International AIDS Vaccine Initiative } \\ \text { IQR } & \text { Interquartile range } \\ \text { jpHMM } & \text { Jumping profile Hidden Markov Model } \\ \text { LGBT } & \text { Lesbian, gay, bisexual, and transgender } \\ \text { MSM } & \text { Men who have sex with men } \\ \text { MTCT } & \text { Mother to child transmission } \\ \text { NGO } & \text { Non-governmental organisation } \\ \text { NNRTI } & \text { Non-nucleoside reverse transcriptase inhibitors } \\ \text { NRTI } & \text { Nucleoside reverse transcriptase inhibitors } \\ \text { OR } & \text { Odds ratio } \\ \text { PCR } & \text { Polymerase chain reaction } \\ \text { PI } & \text { Protease inhibitors } \\ \text { RNA } & \text { Ribonucleic acid } \\ \text { SA } & \text { South Africa } \\ \text { SCO } & \text { Study coordinator } \\ \text { STI } & \text { Sexually transmitted infection } \\ \text { TB } & \text { Tuberculosis } \\ \text { UNAIDS } & \text { Joint United Nations Programme on HIVIAIDS } \\ \text { UCT } & \text { University of Cape Town } \\ \text { VCT } & \text { Voluntary Counselling and Testing } \\ \text { WC } & \text { Western Cape Province } \\ & \end{array}$




\section{PART A: PROTOCOL}




\section{Epidemiology of HIV-1 Subtypes among Men Who Have Sex With Men in Cape Town, South Africa:}

An Exploratory Study to Determine Identity, Social Networks and Circulating HIV Subtypes Among Men Who Have Sex With Men in Cape Town

\section{Table of Contents}

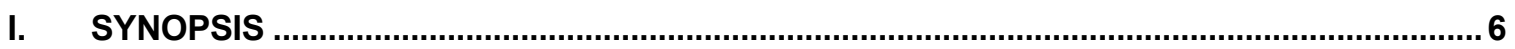

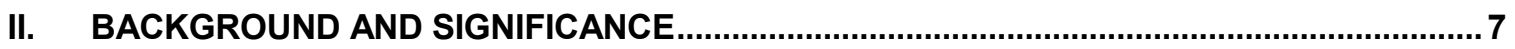

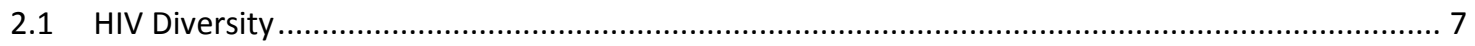

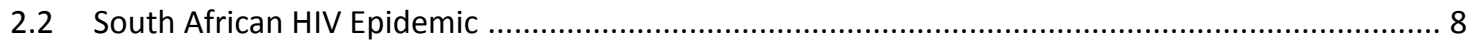

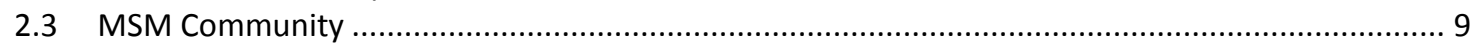

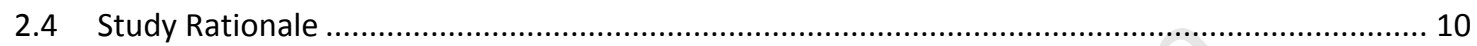

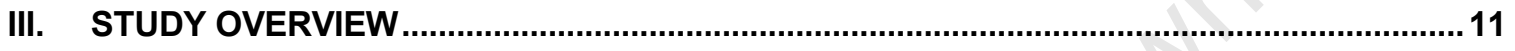

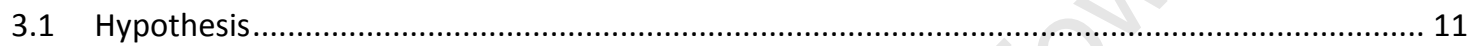

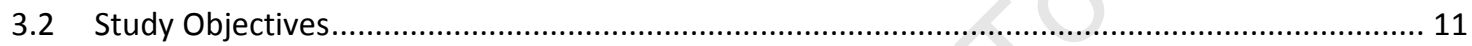

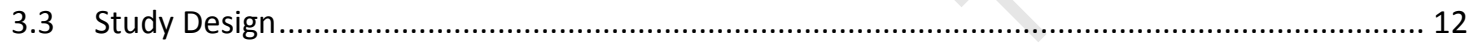

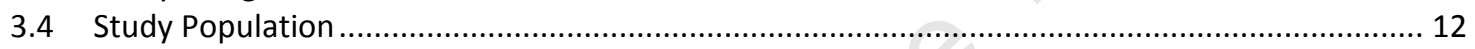

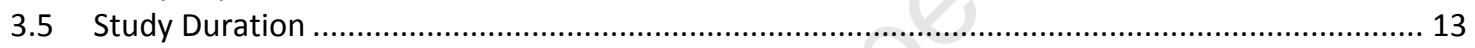

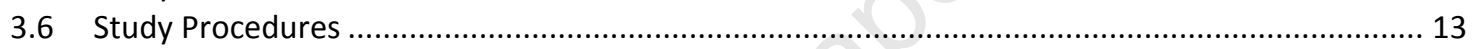

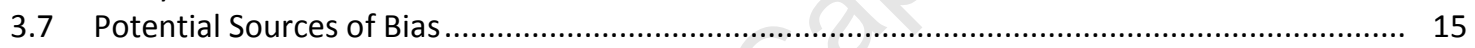

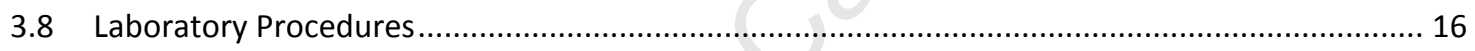

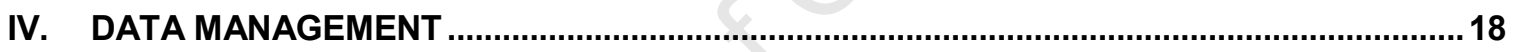

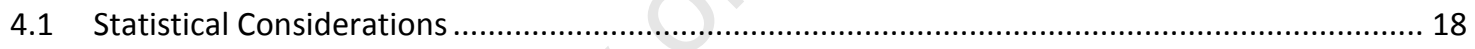

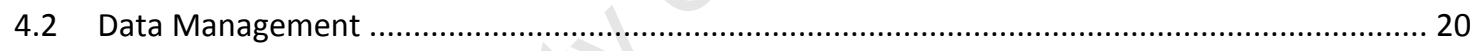

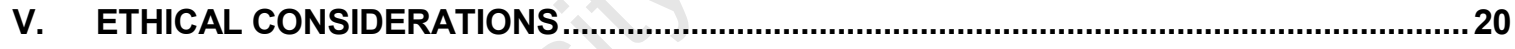

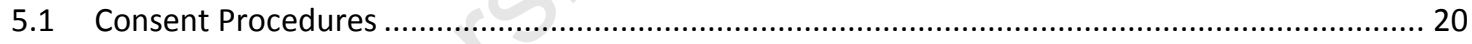

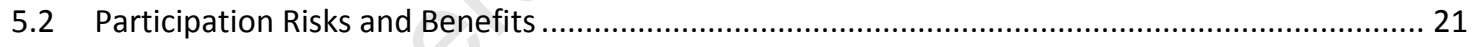

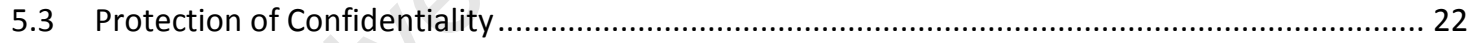

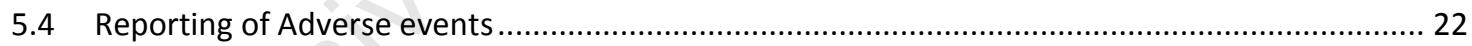

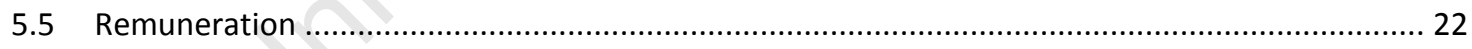

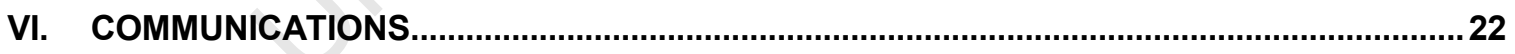

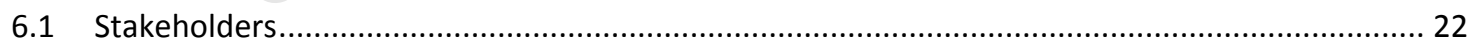

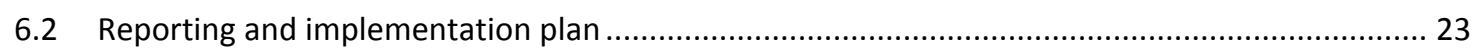

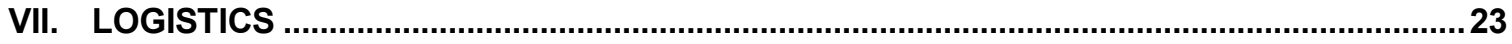

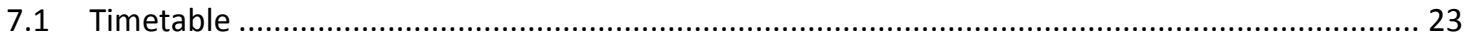

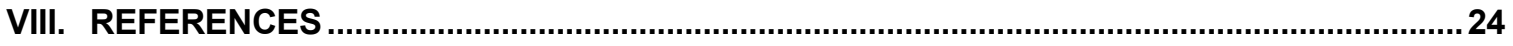




\section{Synopsis}

Protocol for epidemiological study of HIV-1 subtypes among Cape Town MSM

Design:

Duration:

Sample Size:

Population:

Primary Study Objective:
Cross-sectional survey

9 months: Clinical component: Recruitment and enrolment

6 months: Laboratory component: Sequencing and sequence analysis

200 HIV-infected participants

Self-identified MSM, 16 years or older, resident in urban and peri-urban Cape Town and sexually active with a male partner in the last 12 months. Participants must be willing and able to provide written informed consent and undergo HIV testing.

To identify HIV-1 subtypes present among HIVinfected MSM in historically racially defined geographical areas (urban and peri-urban) in the greater Cape Town area.

Secondary Study Objectives: To investigate associations between race and HIV-1 subtypes among MSM in the greater Cape Town area.

To determine the extent of possible sexual network links between urban and peri-urban MSM populations in the greater Cape Town area

To determine the extent of possible sexual network links between the MSM population and the general heterosexual population in the greater Cape Town area. 


\section{Background and Significance}

Nearly three decades after the discovery of HIV, this pathogen remains a major cause of morbidity and mortality worldwide. The UNAIDS estimated that globally 34 million people were living with HIV by the end of 2010 , with a further 2.7 million people newly infected in the same year [1].

A key characteristic of HIV is the genetic diversity of the virus, which is classified into a number of groups and subtypes. The global pandemic is comprised predominantly of HIV-1 Group M infections. Group M is further divided into a number of subtypes or clades [2,3], of which HIV-1 subtype $\mathrm{C}$ is responsible for the bulk of infections globally [4].

\subsection{HIV Diversity}

To date nine subtypes of HIV-1 group $M$ have been identified: A-D, F-H, J and K [4], as well as a large number of recombinant viruses and circulating recombinant forms (CRF) $[4,5]$. The genetic diversity between subtypes and recombinant viruses of HIV-1 may have several important implications for patient care.

Genetic diversity has shown to affect the validity of HIV-1 serology tests [6] as well as certain viral load tests [7,8]. HIV-1 subtypes may vary in transmissibility [9], in proficiency of spread by specific routes [10-12], and in progression to AIDS [13-17].

There is a growing body of evidence that HIV genetic variability has the potential to impact on susceptibility and response to antiretroviral (ARV) drugs [13], including nonnucleoside reverse transcriptase inhibitors (NNRTIs) [18] and protease inhibitors (PIs) $[19,20]$. Subtype diversity may be an important factor in the effectiveness of new classes of ARV drugs, targeting viral attachment or cell entry. Subtypes are associated with different co-receptor phenotype strains $[21,22]$ and these variations may mean that new drugs such as CCR5 antagonists have limited benefit in some viral subtypes [23]. In addition, these findings support the hypothesis that subtypes may differ with regards to virulence and transmissibility [21]. HIV-1 diversity may also impact the type of drug resistance mutations, the rate of resistance emergence as well as cross-resistance to ARVs within drug classes [24]. There is strong evidence that subtypes acquire different ARV drug resistance patterns [25], including resistance mutations to nucleoside reverse transcriptase inhibitors (NRTIs) [26,27], NNRTIs [27-32] and PIs [33-35]. 
Furthermore, in the field of HIV prevention HIV subtypes may play an important role, specifically with regards to vaccine development. The substantial genetic diversity between subtypes [36] may limit the cross-reactivity of vaccine-induced immune responses $[37,38]$. In order to determine the implications of HIV subtype for vaccine design, vaccines constructed from a variety of subtypes need to be tested in different areas or populations, where the subtype distributions are known.

\subsection{South African HIV Epidemic}

With an estimated 5.6 million South Africans living with HIV, South Africa has the largest HIV epidemic in the world [39]. The history of HIV in South Africa is fascinating, with two independent epidemics noted in early reports.

The first cases of Acquired Immune Deficiency Syndrome (AIDS) in South Africa were documented in homosexual men in 1982 [40]. Throughout the 1980s the HIV epidemic was concentrated mainly in white homosexual males [41]. However, in 1987 the first cases of AIDS in heterosexual patients were reported [42] and by the early 1990s the demographic profile of the HIV epidemic was changing, with an increasing number of black African, heterosexual patients attending South African HIV clinics $[41,43]$. By the mid-1990s the homosexual epidemic had been eclipsed by the far larger heterosexual epidemic, the face of which was predominantly black [43]. In the early 1990s the country's focus had shifted to the growing heterosexual epidemic, as epitomised by national HIV surveillance being performed in antenatal clinics [42,44].

A molecular epidemiological study of circulating HIV strains in Cape Town in the mid1990s suggested that the epidemics among men-who-have-sex-with-men (MSM) and heterosexual individuals were independent of one another. The homosexual epidemic was comprised almost exclusively of HIV-1 subtype B [45,46], and was strongly associated with travel history to the United States of America and Europe [41], regions in which this subtype was and remains the dominant virus. The heterosexual epidemic, by contrast, comprised predominantly of HIV-1 subtype $C[45,46]$. This is the most prevalent HIV-1 subtype in Southern Africa, and most likely spread to South Africa through regional travel [46]. 
Ongoing surveillance of predominantly heterosexual populations in South African townships, including communities in Cape Town, from the late 1990s through the 2000s have shown that despite the introduction of other HIV-1 subtypes [47-49], subtype C remains responsible for more than $90 \%$ of this epidemic [49-53]. While much data are available on the general heterosexual HIV epidemic in peri-urban communities, recent data on the MSM HIV subtypes and infection patterns are lacking.

\subsection{MSM Community}

The phenomenon of MSM includes any male who engages in sexual activity with another male. This is a varied group that includes men who identify as homosexual, bisexual and even self-identified heterosexual men. MSM have a high risk of HIV acquisition, due to a number of biological, behavioural and social risk factors [54-56].

During the apartheid era, homosexuality was illegal in South Africa under Common Law and punishable by imprisonment. Despite the decriminalisation of homosexuality in 1994 [57], stigma, social prejudices and human rights abuses remain prevalent [56,58], particularly in black African townships where cultural norms are typically not accepting of MSM activity. As a result of this social vulnerability black African MSM are less likely to be open about their sexual preferences [58] and frequently go to considerable lengths to avoid being identified as homosexuals. Even among self-identified MSM, South African studies have reported that $4-32 \%$ of participants identify as heterosexual or straight [5961]. In one study among black African MSM in Cape Town only $1 \%$ identified as bisexual, but $8 \%$ reported being married [56].

In addition, two apartheid legislations, Group Areas Act [62] and the Immorality Act [63] enforced racial segregation of the population by delineating residential areas by race, and prohibiting inter-race sexual relations, respectively. These acts were abolished in the transition to a democratic constitution, allowing for increased socialisation across previous geographical and racial divides. However, there are limited data on the impact of these legislative, and consequently social, changes on the HIV epidemics among different population groups. 


\subsection{Study Rationale}

Despite the world's largest HIV treatment programme, HIVIAIDS was still responsible for 314,000 deaths in South Africa in 2010 [39]. The South African Government, private and public sectors have placed a high priority on the development of novel interventions that are effective in preventing the transmission of HIV and the provision of timely access to antiretroviral treatment when indicated. While programmes that focus on the general South African epidemic are important, the emphasis of HIV programmes on heterosexual transmission of HIV has culminated in the neglect of the MSM epidemic over the past two decades. There is growing evidence that HIV prevalence remains high in MSM groups in South Africa [60,61], and while the impact of homosexual transmission of HIV on the South African epidemic overall is likely minor, these transmission patterns may constitute a significant proportion of incident HIV infections among males generally $[64,65]$. Therefore, it is not only unethical but also shortsighted to neglect this vulnerable population in national plans for HIV prevention and treatment.

Over the last few years there has been an increasingly loud call for improved surveillance and access to safe, appropriate HIV care for MSM in Africa [66], including South Africa [60,61]. The South African government has identified MSM as a key population for targeted interventions in the current National Strategic Plan on HIV, STIs and TB [64]. However, the maxim "Know your epidemic, know your response" [67] is particularly apt in this context. Little data are available on the dynamics of the MSM epidemics in South Africa, and governments are left to plan HIV response strategies in this void.

Given the potential impact of genetic diversity on HIV-1 transmission [9] and disease progression [13-17], response to ART [13,19,20], development of ARV drug resistance [25-35] and the efficacy of biomedical HIV prevention interventions [37,38], ongoing surveillance of HIV subtype distribution in the South African epidemic is essential.

In South Africa, both the historic, geographical segregation of communities based on race and the different cultural backgrounds of these communities may have influenced how different MSM groups identified, engaged in MSM activity and interacted both across these communities and with the general population [68]. The introduction of 
democracy, and the legalization of homosexual activity in the South African constitution, may have modified these interactions.

An improved understanding of HIV transmission patterns among MSM as well as the presence of possible bridging of the epidemics both between the different MSM communities and between this population group and the heterosexual population is required. This knowledge together with accurate data on HIV subtype distribution may increase our understanding of the drivers of our local epidemic, and inform local policy and resource allocation and guide HIV prevention initiatives.

This protocol aims to describe the HIV-1 epidemic among MSM in Cape Town, to determine if this epidemic remains predominantly due to HIV-1 subtype B and to investigate for evidence of bridging between the two previously distinct HIV epidemics in Cape Town.

\section{Study Overview}

\subsection{Hypothesis}

The HIV-1 epidemic among urban MSM is comprised of predominantly subtype B virus, while the HIV-1 epidemic among peri-urban MSM is comprised of predominantly subtype C virus.

\subsection{Study Objectives}

Primary Objective:

1) To identify HIV-1 subtypes present among HIV-infected MSM in historically racially defined geographical areas (urban and peri-urban) in the greater Cape Town area.

\section{Secondary Objective:}

1) To investigate associations between race and HIV-1 subtypes among MSM in the greater Cape Town area.

2) To determine the extent of possible sexual network links between urban and periurban MSM populations in the greater Cape Town area

3) To determine the extent of possible sexual network links between MSM population and the general heterosexual population in Cape Town. 


\subsection{Study Design}

A cross-sectional survey among self-identified MSM resident in the greater Cape Town area. This study will be nested within a parent study that aims to explore HIV knowledge and risk behaviours among HIV-positive and HIV-negative MSM in the greater Cape Town area.

\subsection{Study Population}

200 HIV-infected MSM, resident in urban and peri-urban Cape Town.

Urban areas are defined as Cape Town's Central Business District (CBD) and surrounding communities that were historically designated as white areas, such as Claremont and Belville.

Peri-urban areas are defined as township or low-income areas that were historically designated as black and/or coloured areas, such as Khayelitsha and Mitchell's Plain.

By recruiting from these two areas, we anticipate enrolment of MSM across the three main racial groups in Cape Town: black African, coloured and white. These racial categories are in keeping with the terms employed in the 2011 South African census [69].

\section{$\underline{\text { Inclusion Criteria }}$}

Participants must meet the following inclusion criteria:

- Male sex (at birth)

- Age 16 years or older

- Reside in the greater Cape Town area

- Have had anal intercourse with another male in the previous 12 months

- Willing and able to provide written informed consent to participate in the study

\section{Exclusion Criteria}

Participants are ineligible for the study if they are:

- Unwilling to undergo HIV testing

- Unable to give informed consent to participate in the study. 


\subsection{Study Duration}

Recruitment and enrolment will occur over a nine month period. Participation will involve one or two study visits, not more than one month apart. The subtyping component will commence once all specimens are collected, and will be completed in a further six months.

\subsection{Study Procedures}

\subsubsection{Recruitment of Participants}

Preliminary background exploration has been conducted by the Desmond Tutu HIV Foundation (DTHF) to identify lesbian, gay, bisexual and transgender (LGBT) venues and methods for recruiting research participants into cross-sectional surveys. Sources of information include key informant interviews with local leaders, non-governmental organizations (NGOs), and discussions with community advisory boards.

The recruitment strategy for this study will include two components:

- Fieldworker community-based recruitment

- Identification during screening for other studies

\section{Fieldworker community-based recruitment}

As MSM are a hard-to-reach population for research, especially in peri-urban communities, recruitment strategies previously shown to be successful in such populations, will be utilized [70].

Trained recruiters will visit different organizations and venues frequented by MSM for facility-based recruitment. Peer recruiters will provide presentations to the organizations' staff and potential participants, including an explanation of the study and an invitation to participate. Examples of venues for recruitment activity are saunas, adult movie theaters, adult video arcades, areas for commercial sex work (streets, parks, and avenues), discotheques, MSM-friendly bars/shebeens (informal township taverns), beauty parlors/houses, athletic facilities, open houses, open community meetings and entertainment events. At appropriate venues, recruiters will request the manager's permission to post notices, distribute flyers, and leave educational and informational 
material for customers and organize meetings to publicize the study. Study recruitment may also be done via the internet and social media.

Fieldworker recruitment will utilize a quasi-snowballing recruitment methodology, in which MSM participants will be asked to refer other known MSM individuals to join the study. This method of sampling is well established in the literature as a tool to recruit hard-toreach or marginalized populations, including MSM communities [71-73].

\section{Other studies}

The DTHF study sites are involved in multiple research projects. Individuals who screen for other studies are offered the opportunity to sign an informed consent that authorizes investigators to contact them for future research. Locator information will be available for those who gave permission for future contact and recruiters will contact potentially eligible participants by telephone or email as specified in the consent.

\subsubsection{Screening and Enrolment}

Before written informed consent is sought, all participants will be given information regarding the study objectives, procedures, and outcomes. Any issues will be discussed and all questions about the study will be answered. After the informed consent form has been read by the participant, written consent to enrol in the study will be sought. The informed consent form will be available in English, Xhosa and Afrikaans. Those participants who are unable to read the form will have it read to them by an independent witness. Two copies of the informed consent form will be signed: one copy will be given to the participant and a copy will remain in the study site file.

\subsubsection{Study Procedures}

\section{Questionnaire Completion}

A trained interviewer will administer the study questionnaire in the participant's home language. The questionnaire will include questions on:

- Demography, including race

- Sexual orientation

- Sexual history and partners 


\section{Validation and reliability}

The questionnaire is not a validated tool. However, the questions were chosen to allow for comparability between other, venue-based MSM surveys completed by the DTHF. The questions have been reviewed for appropriateness and language by MSM staff and representatives of the MSM communities with which the DTHF engage.

As this study will be nested within a parent study that aimed to enroll both HIV-negative and HIV-positive patients HIV status is not an inclusion criterion. The questionnaire will be completed prior to HIV testing, to ensure participant answers were not influenced by the HIV test result.

\section{HIV testing:}

Participants will have an HIV test using finger-prick rapid antibody screening tests. See testing algorithm in Section II:7. All participants will receive appropriate HIV-testing counselling. Participants who test HIV-infected will be referred to the closest HIV care clinic or to an appropriate MSM-friendly clinic of their choice.

\section{Blood Draw}

Blood draw via venipuncture will be performed by a trained health worker. Blood will be drawn for HIV sequencing and subtyping, CD4 T-cell count and, when necessary, confirmation of HIV status.

Blood samples from HIV-infected patients will be sent for the following:

- CD4 T-cell count

- Plasma extraction and storage for HIV subtyping.

Results of the CD4 T-cell count will be made available to the patient as soon as possible via the contact information provided.

\subsection{Potential Sources of Bias}

This is a cross-sectional survey and as such we are more likely to sample prevalent, rather than incident cases of HIV-1. This may introduce length-bias sampling, limiting our ability to make inferences about currently circulating HIV-1 strains. 
MSM is a typically hard to reach population, necessitating innovative recruitment strategies. However, in these typically non-random sampling approaches there is a risk of oversampling some sexual networks while missing hidden sub-groups, such as married MSM. In order to avoid oversampling a few select sexual networks, we will recruit widely from a number of different venues, as well as from different types of venues. Having identified MSM from a variety of locations, we will then employ a quasisnowballing recruitment methodology: in this method enrolled participants recruit new participants who then in turn recruit further participants and so on. This is a recognized method for attempting to reach more hidden sub-groups within a population. It should be noted that the relatively small study sample size may limit our ability to access hidden sub-groups in our areas.

The offer of an incentive, although small, may influence men who do not have sex with men to enroll in the study, particularly from the lower socio-economic, peri-urban areas. While it is not possible to negate this risk entirely, we hope to mitigate the risk by utilising recruiters employed from the MSM communities and by predominantly recruiting from MSM-frequented venues.

Data on sexual orientation, sexual history and partners will be obtained by self-report. Questionnaires will be administered prior to the HIV test and questions regarding recent sexual partners will be limited to the past 6 months in order to reduce recall bias. Interviewers will be trained in MSM sensitivity and in appropriate administration of questionnaires, to ensure an open, non-judgmental environment, to reduce social desirability bias in participants' responses.

\subsection{Laboratory Procedures}

\subsubsection{HIV Testing}

Patients will be tested using the standard procedures outlined in the National HIV Counselling and Testing policy [74]:

- Following appropriate counselling, a rapid HIV test (Abbott Determine $®$ HIV1/2) will be performed.

- If the result is negative, the participant shall be considered HIV-uninfected and receive appropriate post-test counselling 
- If the test is positive a confirmatory test will be performed using a second rapid HIV test (SD Bio-Line HIV 1/2)

- If the second test is positive, the participant will be considered HIV-infected. He will receive appropriate post-test counselling.

- If the confirmatory test is negative or indeterminate, a $2.5-5 \mathrm{ml}$ venipuncture blood draw will be performed to conduct an enzymelinked immunosorbent assay (ELISA) test to confirm HIV status

\subsubsection{CD4 T-Cell Count}

A $2.5-5 \mathrm{ml}$ specimen of blood will be collected in a sterile tube. CD4 T-cell counts will be performed at the National Health Laboratory Services in accordance with standard practices. The study site will inform participants of the test results.

\subsubsection{Viral Diversity Assay}

The diversity testing will be performed at the Institute of Infectious Disease and Molecular Medicine's virology laboratory, at the University of Cape Town.

A $10 \mathrm{ml}$ specimen will be collected from HIV-infected participants in an EDTA tube. Plasma will be extracted from the sample and stored at $-70 \mathrm{C}$. Viral loads will be performed on these specimens when required to inform the PCR analysis.

RNA will be extracted from plasma samples and reverse transcribed. To ensure that single genomes are amplified, the cDNA will be diluted to end-point. To identify infecting subtype, complete sequencing of the gp160 region will be performed. Env gene will be amplified from cDNA by nested PCR and amplicons will be directly sequenced.

Studies describing HIV subtypes in different populations in South Africa in the 1990s utilized different subtyping techniques. Predominantly proviral HIV-1 DNA was subtyped by a PCR-based method, heteroduplex mobility assay (HMA), based on the V3-V5 region of the env gene and/or by sequence analysis of the p17 region of the gag gene [46,50]. This study will utilize sequencing of the gp160 env region from RNA-derived cDNA. While sequencing is the most accurate approach to subtyping [75], HMA allows for more rapid and cheaper subtype determination. However, recombinants may be missed in the HMA approach [75], hence the need for confirmatory sequencing of the p17 region in the earlier studies. Overall, the comparison of HIV-1 subtypes as identified by these different 
technologies is unlikely to have significant limitations.

\subsubsection{Phylogenetic analysis}

Phylogenetic analysis will be conducted to assign HIV subtypes. The participants' sequences will be aligned using CLUSTAL W [76], and subtypes will be assigned by inferring gp160 phylogenetic relatedness of participant sequences to an HIV-1 subtype reference set from the HIV Sequence Database [4]. Maximum Likelihood phylogenetic trees will be constructed from the study samples using the MEGA v5.04 software [77], and will include reference subtypes and CRFs from the study region [4]. A reference subtype tree will be constructed to visualise clustering of all the sequences. If required phylogenetic clusters may be confirmed by sequencing of alternate viral genes, such as gag p17p24.

To identify inter-subtype recombinants from the env sequences sampled from the participants, we will use independent recombination identification programmes including: the Recombination Identification Program (RIP 3.0) (http://www.hiv.lanl.gov/content/sequence/RIP/RIP.html), REGA HIV-1 Subtyping ToolVersion 2.0 (http://www.bioafrica.net/rega-genotype/html/subtypinghiv.html) and jumping profile Hidden Markov Model (jpHMM)(http://jphmm.gobics.de/) [78]. Recombinant viruses will be analyzed for subtype assignment and breakpoint identification by SimPlot software v3.5.1 (http://sray.med.som.jhmi.edu/SCRoftware).

\section{Data Management}

\subsection{Statistical Considerations}

\subsubsection{Sample size}

The required sample size to show a difference in subtypes between the urban and periurban communities is dependent on the proportional representation of the subtypes in these two populations. Sample size calculations are shown below for varying proportions of subtype $C$ in the two populations. All sample sizes are calculated at $90 \%$ power, alpha $=0.05$, and a ratio of $1: 1$ enrolment in both arms. 


\begin{tabular}{|l|l|l|}
\hline $\begin{array}{l}\text { Proportion subtype C } \\
\text { in peri-urban } \\
\text { population }\end{array}$ & $\begin{array}{l}\text { Proportion subtype C } \\
\text { in urban population }\end{array}$ & $\begin{array}{l}\text { Sample } \\
\text { size }\end{array}$ \\
\hline $65 \%$ & $5 \%$ & 30 \\
\hline $65 \%$ & $10 \%$ & 36 \\
\hline $65 \%$ & $20 \%$ & 56 \\
\hline $65 \%$ & $40 \%$ & 180 \\
\hline $65 \%$ & $50 \%$ & 480 \\
\hline $75 \%$ & $5 \%$ & 22 \\
\hline $75 \%$ & $10 \%$ & 26 \\
\hline $75 \%$ & $20 \%$ & 38 \\
\hline $75 \%$ & $40 \%$ & 92 \\
\hline $75 \%$ & $50 \%$ & 170 \\
\hline $90 \%$ & $5 \%$ & 14 \\
\hline $90 \%$ & $10 \%$ & 18 \\
\hline $90 \%$ & $20 \%$ & 22 \\
\hline $90 \%$ & $40 \%$ & 42 \\
\hline $90 \%$ & $50 \%$ & 40 \\
\hline
\end{tabular}

Based on relatively conservative estimates of $75 \%$ and $50 \%$ representation of subtype C in the peri-urban and urban respectively, a total sample size of 170 (85 from each geographical population) is required. Allowing for loss of specimens due to difficulties in amplification of CDNA or indeterminate sequencing results, a total sample size of 200 HIV-infected participants will be recruited (100 from each geographical population).

\subsubsection{Data Analysis}

Data analysis will be performed in the statistical programme STATA (Stata Corp. LP, College Station, TX, United States of America). Descriptive statistics will be employed for basic characterization of both predictor and outcome variables. Bivariate comparisons (using Student's t-test, Wilcoxon rank-sum, chi-squared and Fisher exact tests as appropriate) will be used to identify basic associations. Multivariate logistical regression models will be developed to examine the possible associations between with HIV-subtypes and location (urban vs peri-urban) and race. All tests will be two-sided. 


\subsection{Data Management}

The study coordinator and study nurse will review all data sheets and questionnaires for completeness and legibility. Study staff will ensure that standard operating procedures for Good Clinical Practice (GCP) are adhered to. Study data will be entered into a Microsoft Excel database designed for this study. Data entry will be performed by a trained staff member, and $15 \%$ of data entry will be checked for quality control purposes. The site investigator will make study documents readily available for inspection by the local Research Ethics Committee for confirmation of the study data and procedures.

Study files will be kept at the study site. Study files will be stored by the site staff in a locked cupboard, and signed consent forms will be kept separate from questionnaires and laboratory test results. Access will be restricted to study personnel authorized to handle research documents and site monitors.

\section{Ethical Considerations}

The study protocol and all study procedures will be implemented in accordance with national GCP standards [79] and the Declaration of Helsinki 2008 [80].

The study protocol and all study instruments will be reviewed by the Faculty of Health Sciences' Human Research Ethics Committee (HREC) of the University of Cape Town (UCT).

\subsection{Consent Procedures}

Eligible subjects will be identified by the process outlined in Section II:6. Trained research staff will explain the study objectives and procedures to all potential participants, including possible risks associated with participation, and the right to refuse study participation or to withdraw. Participants will receive the informed consent form to read and consider. Any issues will be discussed and all questions about the study will be answered. Written informed consent will be sought from all study participants, in their home language. Before signing the consent form, all participants will be questioned for comprehension of the consent form and study.

The informed consent form will explain:

- The aims of the study 
- What is involved in participating, including the number and duration of clinic visits

- The risk and benefits of participation

- That all information provided will be treated as confidential and will not be stored with participants' names

- The voluntary nature of participation

- The participant's right to decide not to participate, to refuse to answer any question, or to withdrawal from the study at any time without consequence.

The informed consent form will be translated into Xhosa (local African language) and Afrikaans, and back translated into English to verify content.

Participants must be self-identified MSM, and given the sensitive nature of this disclosure, we will apply to the ethics committee for a waiver of parental consent in participants less than 18 years of age. We believe this is an acceptable request, as the research has no more than minimal risk and requiring adult consent may preclude some individuals from participation if they have not disclosed their sexual preferences to their parents, thus potentially introducing a selection bias.

\subsection{Participation Risks and Benefits}

There is a slight risk associated with venipuncture for the laboratory tests. Participants will probably experience pain and may experience some bruising at the venipuncture site. Very rarely, a participant may develop an infection at the venipuncture site. All of these potential medical risks will be addressed appropriately at the clinic site.

Participants may also become embarrassed, worried, or anxious when receiving HIV counselling and testing.

Participants will experience emotional distress if diagnosed as HIV-infected. Counsellors who have received training in MSM-appropriate counselling and who have extensive experience in HIV education and counselling, will be available on site. These counsellors will provide the pre- and post-test counselling for the study. All HIV-infected participants will be referred to the closest HIV care clinic or to an appropriate MSMfriendly clinic of their choice.

There is a small risk of loss of confidentiality, however all reasonable efforts will be made to preserve confidentiality (see Section IV:3 below). 
Participants will benefit from study participation by learning their HIV status and receiving risk-reduction counselling. Participants who test HIV-infected will receive their CD4 T-cell count as well as appropriate medical referrals.

\subsection{Protection of Confidentiality}

Each participant will be assigned a unique study number and all questionnaires, laboratory specimens and laboratory data will be identified by this number, not by participant name. The participant's number will also be used in the database to further ensure confidentiality. All study documentation, including informed consent forms, demographic information, questionnaires and laboratory results will be kept in a locked cupboard. Access will be restricted to study personnel authorized to handle research documents, sponsor or UCT HREC representatives and site monitors.

No individual identifying information will be disclosed in reports, publications, or presentations.

\subsection{Reporting of Adverse events}

No drug or other medical intervention is being administered in this study and thus no experimental product-related adverse events are anticipated. The researchers will record any reported social harms occurring as a result of participation in the study. All adverse events will be reported to the Faculty of Health Sciences' HREC in accordance with GCP guidelines [79].

\subsection{Remuneration}

Participants will receive R100 as reimbursement for their time and transport costs.

\section{Communications}

\subsection{Stakeholders}

MSM communities are well represented in South Africa, and particularly in Cape Town which is known as Africa's "Pink City". Several active LGBT advocacy and research groups, as well as groups providing clinical services to LGBT, exist in Cape Town making it an ideal site in which to conduct HIV research among MSM. The researchers will inform these groups of the study and request assistance with recruitment (where appropriate). Study results will be reported back to these key stakeholders. 
Other important stakeholders include City Department of Health, the Provincial Health Authorities, as well as fellow researchers in the field of HIV and MSM.

\subsection{Reporting and implementation plan}

The DTHF has built a good partnership with the MSM community in Cape Town. The Foundation has established weekly or biweekly community meetings within five township communities in greater Cape Town. This programme provides safe spaces for MSM to meet and engage in educational, social, and research activities. These spaces also provide access to hard to reach MSM and offer opportunities to solicit feedback directly from the MSM community with regards to new or on-going research activities. This protocol will be discussed in these forums prior to implementation and the study findings will be presented to these groups in a language-appropriate document and presentation.

The DTHF also has an excellent relationship with the City Department of Health and the Provincial Health Authorities. We will engage with the health authorities regarding the possible implications of research findings to influence public health policy in this area.

Results will also be submitted to relevant local and international conferences, to increase dissemination of information. A manuscript will be submitted to a peer-review journal and all journal publications would be registered on PubMed Central.

\section{Logistics}

\subsection{Timetable}

\begin{tabular}{|c|c|c|c|c|c|c|c|c|c|c|c|c|c|c|c|c|c|c|c|}
\hline \multirow[b]{2}{*}{ Month } & \multicolumn{3}{|c|}{ Quarter 1} & \multicolumn{3}{|c|}{ Quarter 2} & \multicolumn{3}{|c|}{ Quarter 3} & \multicolumn{3}{|c|}{ Quarter 4} & \multicolumn{3}{|c|}{ Quarter 5} & \multicolumn{3}{|c|}{ Quarter 6} & \multirow[b]{2}{*}{19} \\
\hline & 1 & 2 & 3 & 4 & 5 & 6 & 7 & 8 & 9 & 10 & 11 & 12 & 13 & 14 & 15 & 16 & 17 & 18 & \\
\hline \multicolumn{20}{|l|}{ Ethics submission } \\
\hline \multicolumn{20}{|l|}{ Staff training } \\
\hline \multicolumn{20}{|l|}{$\begin{array}{l}\text { Recruitment and } \\
\text { enrolment }\end{array}$} \\
\hline \multicolumn{20}{|l|}{ Study procedures } \\
\hline \multicolumn{20}{|l|}{$\begin{array}{l}\text { Data entry and } \\
\text { cleaning }\end{array}$} \\
\hline \multicolumn{20}{|l|}{ Sequencing } \\
\hline \multicolumn{20}{|l|}{ Data analysis } \\
\hline $\begin{array}{l}\text { Dissemination of } \\
\text { results }\end{array}$ & & & & & & & & & & & & & & & & & & & \\
\hline
\end{tabular}




\section{References}

1. UNAIDS. Global HIVIAIDS Response. Epidemic update and health sector progress towards Universal Access. 2011. 2011.

http://www.who.int/hiv/pub/progress report2011/hiv full report 2011.pdf

2. Robertson DL, Anderson JP, Bradac JA, Carr JK, Foley B, Funkhouser RK et al. HIV-1 nomenclature proposal. Science 2000; 288: 55-56.

3. Virology. In: Handbook of HIV Medicine. Wilson D, Naidoo S, Bekker LG, Cotton MF, Maartens G (eds) Oxford University Press. 2002: 15-21.

4. Los Alamos National Laboratory. HIV Database. 2012. http://www.hiv.lanl.gov/

5. Robertson DL, Anderson JP, Bradac JA, Carr JK, Foley B, Funkhouser RK et al. HIV-1 nomenclature proposal. Science 2000; 288: 55-56

6. Sullivan PS, Schable C, Koch W, Do AN, Spira T, Lansky A et al. Persistently negative HIV-1 antibody enzyme immunoassay screening results for patients with HIV-1 infection and AIDS: serologic, clinical, and virologic results. Seronegative AIDS Clinical Study Group. AIDS 1999; 13: 89-96.

7. Kim JE, Beckthold B, Chen Z, Mihowich J, Malloch L, Gill MJ. Short communication: identification of a novel HIV type 1 subtype $\mathrm{H} / \mathrm{J}$ recombinant in Canada with discordant HIV viral load (RNA) values in three different commercial assays. AIDS Res Hum Retroviruses 2007; 23: 1309-1313.

8. Parekh B, Phillips S, Granade TC, Baggs J, Hu DJ, Respess R. Impact of HIV type 1 subtype variation on viral RNA quantitation. AIDS Res Hum Retroviruses 1999; 15: 133142

9. Arien KK, Abraha A, Quinones-Mateu ME, Kestens L, Vanham G, Arts EJ. The replicative fitness of primary human immunodeficiency virus type 1 (HIV-1) group M, HIV-1 group O, and HIV-2 isolates. J Virol 2005; 79: 8979-8990.

10. Kanki PJ, Travers KU, MBoup S, Hsieh CC, Marlink RG, Gueye-NDiaye A et al. Slower heterosexual spread of HIV-2 than HIV-1. Lancet 1994; 343: 943-946. 
11. Kiwanuka N, Laeyendecker O, Quinn TC, Wawer MJ, Shepherd J, Robb M et al. HIV-1 subtypes and differences in heterosexual HIV transmission among HIV-discordant couples in Rakai, Uganda. AIDS 2009; 23: 2479-2484.

12. Renjifo B, Gilbert $P$, Chaplin B, Msamanga G, Mwakagile D, Fawzi W et al. Preferential in-utero transmission of HIV-1 subtype $\mathrm{C}$ as compared to HIV-1 subtype A or D. AIDS 2004; 18: 1629-1636.

13. Easterbrook PJ, Smith M, Mullen J, O'Shea S, Chrystie I, de Ruiter A et al. Impact of HIV1 viral subtype on disease progression and response to antiretroviral therapy. $J$ Int AIDS Soc 2010; 13: 4.

14. Kiwanuka N, Laeyendecker O, Robb M, Kigozi G, Arroyo M, McCutchan F et al. Effect of human immunodeficiency virus Type 1 (HIV-1) subtype on disease progression in persons from Rakai, Uganda, with incident HIV-1 infection. J Infect Dis 2008; 197: 707713.

15. Kaleebu P, French N, Mahe C, Yirrell D, Watera C, Lyagoba F et al. Effect of human immunodeficiency virus (HIV) type 1 envelope subtypes $A$ and $D$ on disease progression in a large cohort of HIV-1-positive persons in Uganda. J Infect Dis 2002; 185: 1244-1250.

16. Baeten JM, Chohan B, Lavreys L, Chohan V, McClelland RS, Certain L et al. HIV-1 subtype $D$ infection is associated with faster disease progression than subtype $A$ in spite of similar plasma HIV-1 loads. J Infect Dis 2007; 195: 1177-1180.

17. Vasan A, Renjifo B, Hertzmark E, Chaplin B, Msamanga G, Essex M et al. Different rates of disease progression of HIV type 1 infection in Tanzania based on infecting subtype. Clin Infect Dis 2006; 42: 843-852.

18. Apetrei C, Descamps D, Collin G, Loussert-Ajaka I, Damond F, Duca M et al. Human immunodeficiency virus type 1 subtype $F$ reverse transcriptase sequence and drug susceptibility. J Virol 1998; 72: 3534-3538.

19. Descamps D, Apetrei C, Collin G, Damond F, Simon F, Brun-Vezinet F. Naturally occurring decreased susceptibility of HIV-1 subtype $\mathrm{G}$ to protease inhibitors. AIDS 1998; 12: $1109-1111$.

20. Kinomoto M, Appiah-Opong R, Brandful JA, Yokoyama M, Nii-Trebi N, Ugly-Kwame E et al. HIV-1 proteases from drug-naive West African patients are differentially less susceptible to protease inhibitors. Clin Infect Dis 2005; 41: 243-251. 
21. Tscherning C, Alaeus A, Fredriksson R, Bjorndal A, Deng H, Littman DR et al. Differences in chemokine coreceptor usage between genetic subtypes of HIV-1. Virology 1998; 241: 181-188.

22. Kaleebu P, Nankya IL, Yirrell DL, Shafer LA, Kyosiimire-Lugemwa J, Lule DB et al. Relation between chemokine receptor use, disease stage, and HIV-1 subtypes A and D: results from a rural Ugandan cohort. J Acquir Immune Defic Syndr 2007; 45: 28-33.

23. Wambui V, Kiptoo MK, Kinyua JG, Odera I, Muiruri P, Muge E et al. Predicted HIV-1 coreceptor usage among Kenya patients shows a high tendency for subtype $d$ to be cxcr4 tropic. AIDS Res Ther 2012; 9: 22.

24. Martinez-Cajas JL, Pai NP, Klein MB, Wainberg MA. Differences in resistance mutations among HIV-1 non-subtype B infections: a systematic review of evidence (1996-2008). J Int AIDS Soc 2009; 12: 11.

25. Wainberg MA, Brenner BG. The Impact of HIV Genetic Polymorphisms and Subtype Differences on the Occurrence of Resistance to Antiretroviral Drugs. Mol Biol Int 2012; 2012: 256982.

26. Doualla-Bell F, Avalos A, Brenner B, Gaolathe T, Mine M, Gaseitsiwe S et al. High prevalence of the K65R mutation in human immunodeficiency virus type 1 subtype $C$ isolates from infected patients in Botswana treated with didanosine-based regimens. Antimicrob Agents Chemother 2006; 50: 4182-4185.

27. Novitsky V, Wester CW, DeGruttola V, Bussmann H, Gaseitsiwe S, Thomas A et al. The reverse transcriptase $67 \mathrm{~N} 70 \mathrm{R} 215 \mathrm{Y}$ genotype is the predominant TAM pathway associated with virologic failure among HIV type 1C-infected adults treated with ZDV/ddlcontaining HAART in southern Africa. AIDS Res Hum Retroviruses 2007; 23: 868-878.

28. Flys TS, Chen S, Jones DC, Hoover DR, Church JD, Fiscus SA et al. Quantitative analysis of HIV-1 variants with the $\mathrm{K} 103 \mathrm{~N}$ resistance mutation after single-dose nevirapine in women with HIV-1 subtypes A, C, and D. J Acquir Immune Defic Syndr 2006; 42: 610-613.

29. Eshleman SH, Hoover DR, Chen S, Hudelson SE, Guay LA, Mwatha A et al. Nevirapine (NVP) resistance in women with HIV-1 subtype $C$, compared with subtypes $A$ and $D$, after the administration of single-dose NVP. J Infect Dis 2005; 192: 30-36. 
30. Eshleman SH, Guay LA, Mwatha A, Brown ER, Cunningham SP, Musoke P et al. Characterization of nevirapine resistance mutations in women with subtype A vs. D HIV-1 6-8 weeks after single-dose nevirapine (HIVNET 012). J Acquir Immune Defic Syndr 2004; 35: 126-130.

31. Grossman Z, Istomin V, Averbuch D, Lorber M, Risenberg K, Levi I et al. Genetic variation at NNRTI resistance-associated positions in patients infected with HIV-1 subtype C. AIDS 2004; 18: 909-915.

32. Marconi VC, Sunpath H, Lu Z, Gordon M, Koranteng-Apeagyei K, Hampton J et al. Prevalence of $\mathrm{HIV}-1$ drug resistance after failure of a first highly active antiretroviral therapy regimen in KwaZulu Natal, South Africa. Clin Infect Dis 2008; 46: 1589-1597.

33. Abecasis AB, Deforche K, Snoeck J, Bacheler LT, McKenna P, Carvalho AP et al. Protease mutation M89I/V is linked to therapy failure in patients infected with the HIV-1 non-B subtypes C, F or G. AIDS 2005; 19: 1799-1806.

34. Doualla-Bell F, Avalos A, Gaolathe T, Mine M, Gaseitsiwe S, Ndwapi N et al. Impact of human immunodeficiency virus type 1 subtype $C$ on drug resistance mutations in patients from Botswana failing a nelfinavir-containing regimen. Antimicrob Agents Chemother 2006; 50: 2210-2213.

35. Grossman Z, Paxinos EE, Averbuch D, Maayan S, Parkin NT, Engelhard D et al. Mutation D30N is not preferentially selected by human immunodeficiency virus type 1 subtype $C$ in the development of resistance to nelfinavir. Antimicrob Agents Chemother 2004; 48: 2159-2165.

36. Korber B, Gaschen B, Yusim K, Thakallapally R, Kesmir C, Detours V. Evolutionary and immunological implications of contemporary HIV-1 variation. Br Med Bull 2001; 58: 19-42.

37. Gaschen B, Taylor J, Yusim K, Foley B, Gao F, Lang D et al. Diversity considerations in HIV-1 vaccine selection. Science 2002; 296: 2354-2360.

38. van der GG, Nyambi PN, Beirnaert E, Davis D, Fransen K, Heyndrickx L et al. Genetic variation of HIV type 1: relevance of interclade variation to vaccine development. AIDS Res Hum Retroviruses 1998; 14 Suppl 3: S211-S221.

39. UNAIDS. Country Fact Sheet. South Africa. 2011. http://www.unaids.org/en/regionscountries/countries/southafrica/ 
40. Ras GJ, Simson IW, Anderson R, Prozesky OW, Hamersma T. Acquired immunodeficiency syndrome. A report of 2 South African cases. S Afr Med J 1983; 64: 140-142.

41. Sher R. HIV infection in South Africa, 1982-1988--a review. S Afr Med J 1989; 76: 314318.

42. Kustner HG, Swanevelder JP, van Middelkoop A. National HIV surveillance in South Africa--1993-1995. S Afr Med J 1998; 88: 1316-1320.

43. Wood R, O'Keefe EA, Maartens $\mathrm{G}$. The changing pattern of transmission and clinical presentation of HIV infection in the Western Cape region of South Africa (1984-1995). Southern African Journal of Epidemiology and Infection 1996; 11: 96-98.

44. Kustner HG, Swanevelder JP, van Middelkoop A. National HIV surveillance--South Africa, 1990-1992. S Afr Med J 1994; 84: 195-200.

45. Williamson C, Engelbrecht S, Lambrick M, van Rensburg EJ, Wood R, Bredell W et al. HIV-1 subtypes in different risk groups in South Africa. Lancet 1995; 346: 782.

46. van Harmelen J, Wood R, Lambrick M, Rybicki EP, Williamson AL, Williamson C. An association between HIV-1 subtypes and mode of transmission in Cape Town, South Africa. AIDS 1997; 11: 81-87.

47. Bredell H, Hunt G, Casteling A, Cilliers T, Rademeyer C, Coetzer M et al. HIV-1 Subtype $A, D, G, A G$ and unclassified sequences identified in South Africa. AIDS Res Hum Retroviruses 2002; 18: 681-683.

48. Engelbrecht S, Laten JD, Smith TL, van Rensburg EJ. Identification of env subtypes in fourteen HIV type 1 isolates from south Africa. AIDS Res Hum Retroviruses 1995; 11 : 1269-1271.

49. Jacobs GB, Loxton AG, Laten A, Robson B, van Rensburg EJ, Engelbrecht S. Emergence and diversity of different HIV-1 subtypes in South Africa, 2000-2001. J Med Virol 2009; 81: 1852-1859.

50. Van Harmelen JH, Van der RE, Loubser AS, York D, Madurai S, Lyons S et al. A predominantly HIV type 1 subtype C-restricted epidemic in South African urban populations. AIDS Res Hum Retroviruses 1999; 15: 395-398. 
51. Bredell H, Williamson C, Sonnenberg P, Martin DJ, Morris L. Genetic characterization of HIV type 1 from migrant workers in three South African gold mines. AIDS Res Hum Retroviruses 1998; 14: 677-684.

52. Engelbrecht S, Smith TL, Kasper P, Faatz E, Zeier M, Moodley D et al. HIV type 1 V3 domain serotyping and genotyping in Gauteng, Mpumalanga, KwaZulu-Natal, and Western Cape Provinces of South Africa. AIDS Res Hum Retroviruses 1999; 15: 325328.

53. Jacobs GB, de Beer C, Fincham JE, Adams V, Dhansay MA, van Rensburg EJ et al. Serotyping and genotyping of HIV-1 infection in residents of Khayelitsha, Cape Town, South Africa. J Med Virol 2006; 78: 1529-1536.

54. Sanders EJ, Graham SM, Okuku HS, van der Elst EM, Muhaari A, Davies A et al. HIV-1 infection in high risk men who have sex with men in Mombasa, Kenya. AIDS 2007; 21: 2513-2520.

55. Kajubi P, Kamya MR, Raymond HF, Chen S, Rutherford GW, Mandel JS et al. Gay and bisexual men in Kampala, Uganda. AIDS Behav 2008; 12: 492-504.

56. Baral S, Burrell E, Scheibe A, Brown B, Beyrer C, Bekker LG. HIV risk and associations of HIV infection among men who have sex with men in peri-urban Cape Town, South Africa. BMC Public Health 2011; 11: 766.

57. Louw R. Advancing human rights through constitutional protection for gays and lesbians in South Africa. J Homosex 2005; 48: 141-162.

58. Sandfort TG, Nel J, Rich E, Reddy V, Yi H. HIV testing and self-reported HIV status in South African men who have sex with men: results from a community-based survey. Sex Transm Infect 2008; 84: 425-429.

59. Burrell E, Mark D, Grant R, Wood R, Bekker LG. Sexual risk behaviours and HIV-1 prevalence among urban men who have sex with men in Cape Town, South Africa. Sex Health 2010; 7: 149-153.

60. Rispel LC, Metcalf CA, Cloete A, Reddy V, Lombard C. HIV prevalence and risk practices among men who have sex with men in two South African cities. J Acquir Immune Defic Syndr 2011; 57: 69-76. 
61. Lane T, Raymond HF, Dladla S, Rasethe J, Struthers H, McFarland W et al. High HIV prevalence among men who have sex with men in Soweto, South Africa: results from the Soweto Men's Study. AIDS Behav 2011; 15: 626-634.

62. Group Areas Act, No.41 of. 1950. Cape Town. Parliament of South Africa.

63. Immorality Act, No.21 of. 1950. Cape Town. Parliament of South Africa.

64. Department of Health. National Strategic Plan on HIV, STIs and TB. 2011. http://www.doh.gov.za/docs/stratdocs/2012/NSPfull.pdf

65. South African Centre for Epidemiological Modelling and Analysis (commissioned for SA National AIDS Council). The Modes of Transmission of HIV in South Africa. 2009.

66. Millett GA, Jeffries WL, Peterson JL, Malebranche DJ, Lane T, Flores SA et al. Common roots: a contextual review of HIV epidemics in black men who have sex with men across the African diaspora. Lancet 2012; 380: 411-423.

67. UNAIDS. Practical Guidelines for Intensifying HIV Prevention:Towards Universal Access. 2007. http://data.unaids.org/pub/Manual/2007/20070306 Prevention Guidelines Towards Uni versal Access en.pdf

68. Tucker A. Queer Visibilities: Space, Identity and Interaction in Cape Town. WileyBlackwell. 2009.

69. Statistics South Africa. South African Census Questionnaire. 2011. https://www.statssa.gov.za/census2011/CensusQuestionnaire.asp

70. Magnani R, Sabin K, Saidel T, Heckathorn D. Review of sampling hard-to-reach and hidden populations for HIV surveillance. AIDS 2005; 19 Suppl 2: S67-S72.

71. Razzaghi EM, Movaghar AR, Green TC, Khoshnood K. Profiles of risk: a qualitative study of injecting drug users in Tehran, Iran. Harm Reduct J 2006; 3: 12.

72. Wade AS, Kane CT, Diallo PA, Diop AK, Gueye K, MBoup S et al. HIV infection and sexually transmitted infections among men who have sex with men in Senegal. AIDS 2005; 19: 2133-2140. 
73. Parry C, Petersen P, Dewing S, Carney T, Needle R, Kroeger K et al. Rapid assessment of drug-related HIV risk among men who have sex with men in three South African cities. Drug Alcohol Depend 2008; 95: 45-53.

74. Department of Health RoSA. National HIV Counselling and Testing (HCT) Policy Guidelines. 2010.

http://www.uj.ac.za/EN/CorporateServices/ioha/Documentation/Documents/hct policy gu idelines\%202010.pdf

75. Peeters M, Sharp PM. Genetic diversity of HIV-1: the moving target. AIDS 2000; 14 Suppl 3: S129-S140.

76. Thompson JD, Higgins DG, Gibson TJ. CLUSTAL W: improving the sensitivity of progressive multiple sequence alignment through sequence weighting, position-specific gap penalties and weight matrix choice. Nucleic Acids Res 1994; 22: 4673-4680.

77. Tamura K, Peterson D, Peterson N, Stecher G, Nei M, Kumar S. MEGA5: molecular evolutionary genetics analysis using maximum likelihood, evolutionary distance, and maximum parsimony methods. Mol Biol Evol 2011; 28: 2731-2739.

78. Schultz AK, Zhang M, Leitner T, Kuiken C, Korber B, Morgenstern B et al. A jumping profile Hidden Markov Model and applications to recombination sites in HIV and HCV genomes. BMC Bioinformatics 2006; 7: 265.

79. Department of Health. Guidelines for Good Practice in the Conduct of Clinical Trials with Human Participants in South Africa. 2006; 2nd edition. Department of Health: Pretoria, South Africa.

http://www.witshealth.co.za/Documents/South\%20African\%20Good\%20Clinical\%20Guid elines.pdf

80. World Medical Association. Declaration of Helsinki. 2008. http://www.wma.net/en/30publications/10policies/b3/17c.pdf 


\section{PART B: LITERATURE REVIEW}


The focus of this literature review is to provide a brief overview of the current HIV epidemic, to review the concept of HIV subtypes and to describe the distribution of HIV-1 subtypes in South Africa. In addition, the literature review will describe the at-risk group of men who have sex with men and review the current knowledge of HIV-1 subtypes among MSM in Africa. A formal structured review will be used to describe HIV-1 subtypes both in South Africa and among MSM in Africa, as this is the key subject of this thesis and no recent published reviews on the topic are available.

\section{HIV epidemiology}

In the early 1980s doctors in Eastern and Central Africa were facing a surge of patients with severe wasting and opportunistic infections, locally named "slim disease" [1], while in America increasing reports of unexplained cases of Pneumocystis carinii pneumonia and Kaposi's sarcoma were emerging from hospitals in Los Angeles [2,3]. However, the connection between these two new epidemics was only recognized after the aetiological agent of the CDC-named "Acquired Immune Deficiency Syndrome" (AIDS) [4] was isolated in 1983 [5], and the first confirmed case of Human Immunodeficiency Virus (HIV) infection was identified in a stored sample, collected in the Congo in 1959 [6].

Despite international efforts to understand and halt the spread of this disease, HIV has subsequently resulted in one of the largest pandemics known to mankind. In 201034 million people were estimated to be living with HIV globally, with 2.7 million new infections and 1.8 million AIDS-related deaths occurring in the same year [7].

Sub-Saharan Africa remains the most heavily affected region. Two thirds of all HIVinfected people live in sub-Saharan Africa, 70\% of new infections in 2010 occurred in this region and it is estimated that 1.2 million sub-Saharan Africans died from AIDS in 2010 [7]. However there is some hope in the midst of this devastation: sub-Saharan Africa boasts the largest scale-up of ART access, with $49 \%$ coverage being achieved by 2010 [7], and as a result, over the past five years there has been a decreasing trend in both HIV-related mortality and incident infections.

\section{HIV Subtypes}

HIV is a retrovirus, belonging to the genus Lentivirus, and is divided into two strains: HIV Type 1 and 2. HIV-1 originated from zoonotic transmission of a simian immunodeficiency 
virus (SIV) from chimpanzees (Pan troglodytes troglydytes) [8], occurring in the 1930s [9]. Similarly, HIV-2 is thought to originate from SIV found in sooty mangabey monkeys (Cercocebus atys atys) [10], in the 1940s [11].

The global pandemic is comprised predominantly of HIV-1 infections, while HIV-2 is largely restricted to West Africa [12,13]. Since its zoonotic transmission to humans, HIV1 has diversified extensively due to the high rates of viral replication, high frequency of reverse transcriptase errors [14] and recombination, the large pool of infected individuals and prolonged period of infection [15]. Based on this diversity, HIV-1 is further classified into three distinct lineages: Groups $\mathrm{M}, \mathrm{N}$ and $\mathrm{O}$ [16]. Groups $\mathrm{N}$ and $\mathrm{O}$ are relatively rare, and are largely confined to central Africa and Cameroon [17,18]. HIV-1 Group M is the dominant virus globally, and is further classified into a number of subtypes or clades $[16,19]$. To date nine subtypes of group $M$ have been identified: $A-D, F-H, J$ and $K$ [20]. In addition to these subtypes, there are also recombinant viruses, that is novel viruses arising when "co-infecting viruses exchange genetic information" [21]. Recombinant viruses that are epidemic strains are called circulating recombinant forms (CRFs) [22], of which approximately 52 have been identified [20].

\subsection{Geographic Distribution of Subtypes}

The high degree of genetic diversity of HIV-1 has enabled scientists to study and monitor spread of the virus around the globe. Central Africa has the greatest diversity of HIV-1 subtypes and the highest representation of recombinant viruses [15,23], as one would expect at the source of the pandemic. The global distribution of HIV-1 subtypes and recombinant viruses is summarized in Figure 1.

The most prevalent subtypes globally are A, B, C and the recombinant virus CFR02_AG [15]. Subtype A occurs predominantly in Central and East Africa, Eastern Europe and in Central Asia. CFR02_AG is concentrated in West Africa and parts of Central Africa. Subtype $B$ is one of the most widely spread subtypes, and is the dominant virus in the Americas, West and Central Europe and Australia. It is also common in Asia, North Africa and the Middle East. Of interest is that subtype $B$ is rare in sub-Saharan Africa $[15,24]$. Subtype $C$ is the most prevalent subtype in China, India and East and southern Africa [20], most notably in Zimbabwe [25], Malawi [26], Mozambique [27] and South Africa [28,29]. 


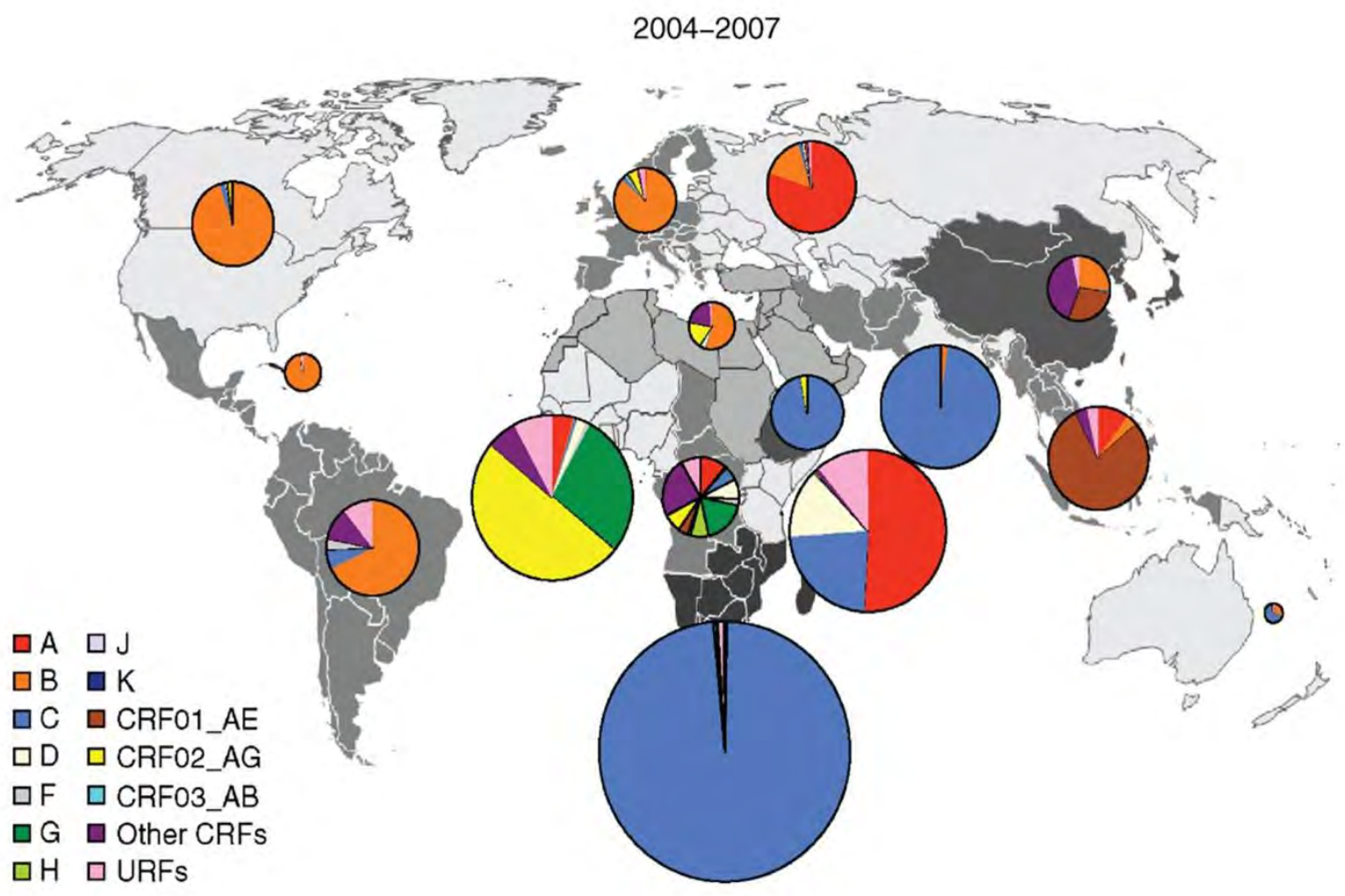

Figure 1: Global distribution of HIV-1 subtypes (from Hemelaar et al, 2011 [24])

\section{Review of HIV-1 Subtypes in South Africa}

A structured literature review was performed in order to describe HIV-1 subtypes identified among infected patients in South Africa, from the 1980s to date.

\subsection{Methods}

Included in the review were all epidemiological studies that described the HIV-1 subtype distribution within a South African-based cohort. Samples could be derived from community or clinic based studies, antenatal surveys or from sample banks, such as blood bank specimens.

The following studies were excluded: a) studies of selected strains performed to assess different HIV subtyping methodologies, to investigate specific phenotypic, genotypic, disease or immune response characteristics, or to investigate phenotypic or genotypic differences between strains; b) studies of non-South African based cohorts, or cohorts that did not include samples from South Africa; and c) review articles. 
There were no exclusions based on participant age, sexual orientation, method of HIV acquisition or subtyping methodology.

The PubMed and Africa-Wide Information electronic databases were searched. The following search terms were used in the PubMed search: ("HIV-1/classification" [MeSH term] OR "HIV-1/genetics" [MeSH term] OR "Phylogeny" [MeSH term]) AND ("subtype" OR "clade") AND "South Africa". A filter for "human" studies was added. For the AfricaWide Information database, the following search terms were used: [HIV-1 classification OR HIV-1 genetics] AND HIV subtype AND "South Africa". The Africa-Wide Information search was restricted to peer-reviewed journals. Titles and abstracts identified by the search terms were screened for inclusion/exclusion criteria. Full paper review was performed on the remaining papers, and the reference lists were reviewed for additional papers.

An electronic data extraction form was developed and relevant data from the selected studies were captured on this form. Where possible, authors were contacted to clarify information.

\subsection{Results}

\subsubsection{Identification of studies}

The electronic database searches were performed on 09 June 2013. The PubMed yielded 196 results. Title and abstract review excluded 175 papers. Full review of the remaining 21 papers resulted in the exclusion of two studies in which specific strains had been selected for the analysis.

The Africa-Wide Information database search yielded 106 results, of which all but one were excluded on title and abstract review as ineligible or duplicates of the PubMed search. The additional paper was included in the structured review, following full paper review. Review of paper references yielded a further two papers that had been missed by the electronic search. Therefore the final literature review was performed on 22 studies (Table 1).

\subsubsection{Overview of studies}

\subsubsection{Study Populations}

The 22 studies spanned nearly two and a half decades, with specimens collected from 1984 to 2008 . Geographically they cover six of the country's nine provinces. Nine 
studies involving patients from the Western Cape, all of which were based in Cape Town. The majority of the studies did not report on participant nationalities, but two specifically noted that all the participants were South African [30,31]. Two studies included participants from outside of South Africa, and reported on the representation of South African participants [32,33], and Romani et al noted that only one participant in their study was from a country other than South Africa [34].

Populations sampled were predominantly patients from the South African public health sector, including patients identified as HIV-positive at VCT clinics (two studies), HIV care clinics and hospitals (nine studies), antiretroviral treatment clinics (four studies) and antenatal clinics (three studies). Less frequently sampled populations were patients from private hospitals (three studies), Western Province Blood Transfusion service donors (two studies), members of an HIV support group (one study), miners (one study), and participants from a cohort of sex workers (two studies) and of HIV-positive patients (one study). Some studies obtained samples from more than one patient source.

\subsubsection{Study Designs}

All 22 studies were cross-sectional surveys.

\subsubsection{Sampling}

Sampling methods were poorly described and eight studies did not report sampling methodology at all. Sampling methodology entailed attempted recruitment of all eligible clients testing HIV-positive at VCT (two studies), attending an HIV Wellness clinic (one study), initiating ARV treatment (one study), participating in an antenatal survey (one study), enrolled in an HIV positive cohort (one study) or presenting at study clinics (one study) during the study periods. No data were provided on the proportion of patients that declined study participation. Convenience sampling was utilized in at least two studies. Becker et al utilized specimens selected based on patients' race, gender and sexual orientation [33], van Harmelen et al (1997) selected specimens based on likely mode of HIV transmission [35] and Bredell et al selected participants based on proportional representation of nationalities working in the mines [32].

Naidoo et al and Papathanasopoulos et al were the only studies in which specimens were obtained from a random selection of eligible patients [36] and cohort participants [29] respectively. 
Sample sizes ranged from 13 to 320 participants, with an average of 98 participants per study.

\subsubsection{Demographics}

Participant race was not reported in 12 studies. In two studies $100 \%$ of participants were black Africans, and in six other studies black Africans comprised the majority of participants (36\%-97\%). In only one study were the majority of participants (78\%) white South Africans. Six studies included coloured participants with their proportional representation ranging from $5 \%$ to $31 \%$.

Gender distribution of participants was not reported in five studies. Two studies were performed exclusively in females, and two studies exclusively in men. Two studies were comprised of majority male participants, and in the remaining 11 studies, women comprised the majority of participants (52\%-90\%).

Overall 15 studies included men, of which five did not report on sexual orientation. One study comprised 100\% heterosexual individuals [31], a second study included $99 \%$ heterosexuals and $1 \%$ of participants who acquired HIV infection through mother to child transmission (MTCT) [37], and a third reported $97 \%$ heterosexual and the remaining 3\% unknown [38]. The remaining seven studies included heterosexual, bisexual and homosexual participants. An eighth study did not report gender distribution, but did report sexual orientation. Among these eight studies, Jacobs et al (2008) reported a mix of heterosexual, homosexual and bisexual individuals and MTCT-infected individuals, but did not report their proportional representation [39]. Engelbrecht et al (1995) reported $50 \%$ homosexual participants and $21 \%$ bisexuals [40]; and in the remaining six studies MSM orientation accounted for $3 \%-43 \%$ of participants.

\subsubsection{HIV Infection}

None of the reviewed studies were able to report when participants acquired their HIVinfection. However, Nwobegahay et al reported that all participants in a 2008 study were likely to have been infected after 1999 [41], and Iweriebor reported that none of the participants in their study were likely to have been recently infected (in the past six months) [37]. Pillay et al recruited participants through an antenatal survey, and 
attempted to obtain specimens from recently infected women by restricting eligibility to women in their first pregnancy [42].

\subsubsection{HIV-1 Subtypes}

Two studies included non-South Africans but provided data by nationality, for these studies only the data from South Africans were included. Therefore, in total, 2158 participants were enrolled in the 22 studies.

Overall, 94\% (95\% Confidence interval [Cl]: 93-95\%) of participants were infected with subtype $C$ virus, but the proportions varied across studies, predominantly influenced by when samples were collected, and from which population groups. Studies in which samples were collected in 1990s (five studies in total) tended to have a wider range of population groups, with heterosexual and MSM participants enrolled and greater variation in the proportion of infections attributed to subtype C $[33,35,40]$. Studies performed from 2002 onwards (12 studies) sampled largely from the general population. Only two of these studies reported on participants' sexual orientation and in both studies heterosexual participants accounted for $>90 \%$ of the sample $[34,43]$. All but one of these 12 studies reported $\geq 94 \%$ subtype C virus, with five studies reporting $100 \%$ subtype C virus $[36,37,42,44,45]$.

Overall, subtype B virus accounted for $4 \%$ (95\% CI: 3-5\%) of South African HIV infections, but the contributing proportion of subtype B decreased from $\pm 50 \%$ in some earlier studies $[35,40]$ to less than $4 \%$ in later studies with general population samples. Subtype B was found in predominantly MSM participants, with only four studies reporting subtype B virus in heterosexual participants, and always in low prevalence.

Other subtypes reported included subtype D (reported in early studies [35,40]), subtype A ( $1 \%$ of all participants), and occasional reports of subtypes $F 1, G, J, U$, and CRF_AG, $\mathrm{DC}, \mathrm{BC}, \mathrm{AB}, \mathrm{A} 1 / \mathrm{C}, \mathrm{CJ}$ and $\mathrm{CH}$ recombinants.

Further details on subtypes among MSM are reported in the literature review of HIV-1 subtypes among MSM in Africa. 


\subsection{Limitations}

Only English language papers were included in this review, and as such studies reported in French from Francophone African countries may have been missed.

All these studies were cross-sectional surveys and as such described the HIV-1 subtypes among prevalent, rather than incident HIV-1 cases (length-bias sampling). This may hamper our understanding of currently circulating HIV-1 strains.

The heavy reliance on non-random, convenience sampling of populations may have resulted in considerable selection bias in these data. Furthermore, as data are largely restricted to those patients utilizing public health services, and those who were prepared to provide blood samples for research purposes, the generalizability of these data may be limited.

Furthermore, paucity of data on nationality of participants gives rise to difficulties in interpreting the presence of rare strains, which may have been detected in immigrants or refugees, or introduced into the South African epidemic through international travel. Similarly, the limited data on HIV transmission routes restricts our ability to determine the trend of strains in the different at-risk population sub-groups

\subsection{Discussion}

The dominant HIV-1 virus in South Africa is subtype C. Studies in largely black African, heterosexual populations show an overwhelming subtype $C$ epidemic, and despite some evidence of increased viral diversity this finding remained consistent across the review period. Genotyping studies have shown that the South African HIV-1 C epidemic most likely resulted from multiple introductions of this subtype into the general population $[35,46]$. Subtype $C$ is the most prevalent subtype in southern Africa [20] and likely spread to South Africa via regional travel $[33,35,47]$, particularly through mobile groups such as migrant workers [48-50], immigrants [47], refugees [47], and truck drivers $[33,51]$. This spread was facilitated by urbanisation [52] and well established transportation infrastructure [53]. 
In contrast, studies including MSM in South Africa reported largely subtype B virus in this population group. These early subtype B infections were associated with travel history to the United States of America, Europe, Australia and Thailand [35,54], regions in which this subtype was and remains the dominant virus [20].

\section{Men who have sex with men}

The phenomenon of men-who-have-sex-with-men (MSM) includes any male who engages in sexual activity with another male, including men who identify as homosexual, bisexual or heterosexual.

MSM are a high risk group for HIV acquisition. This is due, in part, to biology risk factors, with unprotected receptive anal intercourse carrying the highest sexual intercourserelated risk [55-57], as well as prevalent behavioural risk factors including multiple partners [58] and low use of condoms and appropriate lubricant [57,59]. In addition there are social constructs that may place MSM at a higher risk for HIV infection. In many African countries MSM activity is criminalized, driving this population underground, and restricting access to adequate health care and HIV preventative services. Even in countries in which MSM activity is legal, such as South Africa, stigma, social prejudice and human rights abuses are all too common [60].

Consequently, HIV prevalence in MSM groups is consistently higher than in general population epidemics [57,61]. A systematic review and meta-analysis of HIV prevalence in MSM compared to background populations reported that MSM have 11 times the odds of HIV infection in countries with generalised epidemics, and nearly four times the risk in African countries [61]. Similarly, the HIV prevalence among South African MSM has consistently been reported as higher than that of the overall age-matched, male population. The generalised HIV prevalence in South Africa is estimated to be $18 \%$ [62], compared to prevalence among MSM ranging from 13 to $44 \%[59,63,64]$ in different cities. In addition MSM who self-identified as "gay" or "homosexual" had a higher risk of HIV infection compared to those who identified as "bisexual" [64,65]. One study reported that HIV prevalence in bisexual and straight men was the same as the background population, while gay-identified men had twice the prevalence [63]. 
There is strong behavioural evidence of bridging between MSM and heterosexual populations. A study conducted in Botswana, Malawi, and Namibia reported high levels of female sexual partners among self-identified MSM. While $38 \%$ of participants described their sexual orientation as "bisexual", 54\% reported female sexual partners in preceding 6 months. Overall, $17 \%$ of participants reported ongoing concurrent relationships with a man and a woman [60]. Similarly, 18\% of MSM in Senegal reported recent intercourse with a female partner [58], and in Kenya 12\% of MSM surveyed were married, and $60 \%$ reported sex with both male and female partners [57].

The findings from South African studies have been consistent with those in other African countries, with $9-30 \%$ of self-identified MSM surveyed describing their sexual orientation as "bisexual" $[59,63,65]$ and in one study as many as $32 \%$ identified as "straight" [63]. In a Cape Town based study, $1 \%$ of MSM participants identified as heterosexual, but $8 \%$ reported that they were married [59]. Across these South African studies $36 \%$ of selfidentified MSM reported a past history of vaginal sex [64], 63\% reported regular partnerships with women [63] and up to $6 \%$ in a Cape Town township study reported a current female sexual partner [59]. However, in South Africa, there are no data on the impact of these behavioural links on the MSM and generalised HIV epidemics.

\section{HIV-1 Subtypes among MSM in Africa}

A structured literature review was performed in order to describe HIV-1 subtypes identified among men who have sex with men, in Africa from the 1980s to date.

\subsection{Methods}

Included in the review were all epidemiological studies that described the HIV-1 subtype distribution within an African MSM cohort. Samples could be derived from country, community or clinic based studies, or from sample banks, such as blood bank specimens.

Studies of selected strains and review articles were excluded from the literature review. There were no exclusions based on participant age or subtyping methodology.

The PubMed and Africa-Wide Information electronic databases were searched. The following search terms were used in the PubMed search: ("HIV-1/classification" [MeSH 
term] OR "HIV-1/genetics" [MeSH term] OR "Phylogeny" [MeSH term]) AND ("homosexuality" [MeSH term] OR "homosexuality, male" [MeSH term]) AND (subtype OR clade) AND Africa. A filter for "human" studies was added. For the Africa-Wide Information database, the following search terms were used: [HIV-1 classification OR HIV-1 genetics] AND "homosexuality, male" AND "South Africa". Titles and abstracts identified by the search terms were screened for inclusion/exclusion criteria. Full paper review was performed on the remaining papers, and the reference lists were reviewed for additional papers.

An electronic data extraction form was developed and relevant data from the selected studies were captured on this form. Where possible, authors were contacted to clarify information.

\subsection{Results}

\subsubsection{Identification of studies}

The electronic database searches were performed on 10 June 2013. The PubMed yielded 8 results. Title and abstract review excluded five papers. Full review of the remaining three papers confirmed their eligibility.

The Africa-Wide Information database search yielded three results, one of which was excluded as a duplicate of the PubMed search results and two were deemed ineligible based on title and abstract review. No additional studies were identified via review of the papers' references.

In addition, three studies from the South African review reported HIV-1 subtypes by sexual orientation (including MSM) were not identified in the electronic search, but were included in the structured review.

Therefore the final literature review was performed on six studies (Table 2).

\subsubsection{Overview of studies:}

\subsubsection{Study Populations}

Four of the six studies occurred in South Africa. These four studies predominantly recruited patients from public healthcare services in Cape Town over a period ranging from 1984 to 2004. One study was performed among urban MSM in Senegal in 2004 and the sixth study reported on HIV-1 subtypes among MSM in and around a large city in Kenya from 2005 to 2006. 


\subsubsection{Study Designs}

Five of the studies were cross-sectional surveys. However, Tovanabutra et al reported on patients from an HIV incident cohort study: $43 \%$ of specimens were prevalent HIV infections identified at study baseline, and $57 \%$ were incident HIV-1 infections that occurred during the study period [66].

\subsubsection{Sampling}

A range of sampling methodologies were used across these studies: two studies did not report on sampling methodology, one study utilized a convenience sample of specimens available from South African public health care clinics, one study selected participants based on likely mode of HIV transmission, another study utilized snowball recruitment (a technique used to recruit hard to reach populations), and the final study utilized a combination of convenience sampling of prevalent cases and incident cases occurring in the study cohort. Sample sizes ranged from 14 to 107 across these six studies.

\subsubsection{Demographics}

One South African study did not report on participants' gender, although $97 \%$ of that study sample was reportedly heterosexual [28]. One South African study and the Senegalese study were performed in exclusively male participants, while the male representation in the remaining three studies ranged from $45 \%$ to $67 \%$.

Ndiaye et al recruited exclusively MSM [67], while MSM accounted for 3-71\% of study participants in the remaining studies. In the Kenyan study, $39 \%$ of participants were female sex workers [66].

Racial characteristics of participants were not reported in three of the studies. The three studies that did report on race were all South African based. In the South African study performed exclusively in MSM men, all 14 participants were white men. In the remaining two South African studies [34,35], MSM were predominantly white (54\% and $66 \%$ respectively), while the heterosexual participants were predominantly black (62\% and $96 \%$ respectively) and coloured ( $28 \%$ and $4 \%$ ). 


\subsubsection{HIV-1 Subtypes}

Across the four South African studies, 78\% (95\% Cl: 64-89\%) of MSM participants were infected with HIV-1 subtype B virus, compared to $5 \%(95 \% \mathrm{Cl}: 3-9 \%)$ of the heterosexual patients in the same surveys ( $p<0.001) ; 9 \%$ (95\% Cl: 2-21\%) of MSM were infected with subtype C, compared to $92 \%(95 \% \mathrm{Cl}$ : $87-96 \%)$ of the heterosexual participants $(p<0.001)$. In addition, $13 \%$ of MSM were infected with subtype D virus.

In the two studies that reported subtype by both race and sexual orientation, only two one black African MSM were included, one of which had an HIV-1 subtype C infection and the other subtype $B[34,40]$.

Ndiaye et al reported that $40 \%$ of the Senegal study's MSM participants were infected with subtype C, $24 \%$ with recombinant CRF02_AG, $19 \%$ with subtype $B$, and the remaining $8 \%$ with additional recombinant viruses. They noted that these subtypes were similar to those occurring in the country's general population and female sex workers, although in different proportions: over $50 \%$ of infections in Senegal's general population and female sex workers are attributed to CRF02_AG virus, and $<6 \%$ due to subtype $C$ or B [67].

Tovanabutra et al noted that HIV-1subtype A accounted for $62 \%$ of HIV infections among MSM participants in the Kenyan study, and $80 \%$ of the infections among female sex workers and heterosexual participants. The remaining infections in both groups were due to a variety of recombinant viruses. The authors note that a high proportion of recombinant viruses were noted in the incident infections versus prevalent infections [66].

\subsection{Limitations}

Only English language papers were included in this review, and as such studies reported in French from Francophone African countries may have been missed.

The majority of these studies were cross-sectional surveys and therefore likely reported on prevalent HIV infections. This may limit our ability to extrapolate these findings to the currently circulating HIV-1 subtypes, as illustrated by the increased representation of recombinant viruses noted among incident cases in the Kenyan study. 
The South African MSM data are largely restricted to white patients and thus the generalizability of these data to the wider MSM population may be limited.

\subsection{Discussion}

The South African studies reported a predominance of subtype B virus among MSM and the findings suggest that the MSM epidemic is independent of the generalized heterosexual epidemic [35]. However, three of these studies were performed early in the South African HIV epidemic (prior to 2000) and in predominantly white MSM. Across all four studies only one known black African MSM was enrolled. Therefore there remains a dearth of current data on HIV-1 subtypes among South African MSM, and particularly among black African men.

The 1999 van Harmelen study reported no subtype B viruses detected among Cape Town heterosexuals, but also noted the first subtype $C$ virus identified in a South African MSM [28]. As already noted, there is substantial behavioural data to support the concept of bridging between MSM and general populations in South Africa [59,63-65], and this phenomenon could impact the evolution of the HIV-1 epidemics in these population groups.

The Senegalese study also reported "bridging" behaviours across population groups: $56 \%$ of the study participants reported a regular female partner, with $82 \%$ reporting any heterosexual contacts. The HIV-1 subtypes identified in the MSM population were the same as those noted in the general population, and this may suggest linking of the HIV epidemics between the groups. However, the authors noted that the prevalence of the subtypes were very different in the different groups. As this was a cross-sectional study and the first of its kind in Senegal it is not possible to determine if the HIV-1 subtype proportions in these populations are in fact changing over time - and if so, whether that change is one of diversification or convergence. Similarly, in the Kenyan study $60 \%$ of the overall MSM cohort reported sex with a female partner [57], and $46 \%$ of the participants with genotype data available. However, in this study the distribution of subtypes were very similar among the MSM and FSW groups, suggesting that these HIV epidemics are not independent [66]. 
Of interest is that in the Kenyan studies, recombinant viruses were over-represented in the incident cases, compared to prevalent cases. It is therefore possible that recombination of different subtypes prevalent in different population groups may be indicative of recent bridging across epidemics [66].

\section{Summary}

While there are considerable data available on HIV-1 subtypes among the general South African population, there are few current data on HIV-1 subtypes among South African MSM. In addition, while there are numerous reports of behavioural links between the MSM and general populations in the country, there are no recent molecular epidemiological data assessing the impact of these behaviours on the previously independent epidemics in these two population groups.

The South African government has identified MSM as a key population for targeted interventions in the current National Strategic Plan on HIV, STIs and TB [68]. In order to plan and implement effective strategies an improved understanding of HIV-1 epidemic among MSM is required. Furthermore, insights into the possible interactions or bridging between different population groups and previously independent epidemics, may increase our understanding of the drivers of our local epidemic, and further inform local policy and resource allocation. 
Table 1: Summary of structured literature review of HIV-1 subtypes in South Africa

\begin{tabular}{|c|c|c|c|c|c|c|c|c|c|c|c|}
\hline & $\begin{array}{l}\text { Author, publication } \\
\text { year }\end{array}$ & $\begin{array}{l}\text { Sampling } \\
\text { Period }\end{array}$ & Province & Population & $\begin{array}{l}\text { Sampling } \\
\text { Method }\end{array}$ & $\begin{array}{c}\text { Sample } \\
\text { size }\end{array}$ & Race $^{*}$ & Gender & $\begin{array}{l}\text { Likely } \\
\text { transmission } \\
\text { route }^{*}\end{array}$ & $\begin{array}{l}\text { HIV-1 } \\
\text { Subtypes* }\end{array}$ & $\begin{array}{l}\text { Subtypes by } \\
\text { sexual } \\
\text { orientation }\end{array}$ \\
\hline 1 & $\begin{array}{l}\text { Engelbrecht [40], } \\
1995\end{array}$ & 1984-1992 & Western Cape & $\begin{array}{l}\text { HIV-infected } \\
\text { patients } \\
\text { attending public } \\
\text { hospital in Cape } \\
\text { Town }\end{array}$ & Not reported & 14 & $\begin{array}{l}7 \% \text { black African } \\
14 \% \text { coloured } \\
78 \% \text { white }\end{array}$ & $100 \%$ male & $\begin{array}{l}50 \% \text { homosexual } \\
21 \% \text { bisexual } \\
21 \% \text { heterosexual } \\
7 \% \text { blood } \\
\text { transfusion }\end{array}$ & $\begin{array}{l}\text { B: } 50 \% \\
\text { D: } 36 \% \\
\text { C: } 14 \%\end{array}$ & $\begin{array}{l}\text { Homosexual: } \\
\text { D:57\%; B:43\% } \\
\text { Bisexual: } \\
\text { B: } 66 \% ; \text { D: } \\
\text { 33\% } \\
\text { Heterosexual: } \\
\text { C:66\%; B:33\% }\end{array}$ \\
\hline 2 & Becker [33], 1995 & 1984-1992 & Western Cape & $\begin{array}{l}\text { HIV-infected } \\
\text { patients from } \\
\text { southern Africa }\end{array}$ & $\begin{array}{l}\text { Selected } \\
\text { based on } \\
\text { race, gender } \\
\text { and sexual } \\
\text { orientation }\end{array}$ & 13 & $\begin{array}{l}\text { South African } \\
\text { participants: } \\
63 \% \text { black African } \\
25 \% \text { coloured } \\
12 \% \text { white }\end{array}$ & $\begin{array}{l}\frac{S A}{\text { participants: }} \\
13 \% \text { female } \\
13 \% \text { not } \\
\text { specified }\end{array}$ & $\begin{array}{l}\text { Only reported for } 1 \\
\text { SA participant: } \\
1 \mathrm{MSM}\end{array}$ & $\begin{array}{l}\text { Overall: } \\
\text { C: } 83 \% \\
\text { B: } 8 \% \\
\text { D: } 8 \% \\
\text { SA participants: } \\
\text { C: } 88 \% \\
\text { B: } 13 \%\end{array}$ & $\underline{\text { MSM: }}$ B \\
\hline 3 & $\begin{array}{l}\text { van Harmelen [35], } \\
1997\end{array}$ & 1993-1994 & Western Cape & $\begin{array}{l}\text { HIV-infected } \\
\text { patients } \\
\text { attending public } \\
\text { hospitals in } \\
\text { Cape Town }\end{array}$ & $\begin{array}{l}\text { Selected } \\
\text { based on } \\
\text { mode of HIV } \\
\text { transmission }\end{array}$ & 61 & $\begin{array}{l}36 \% \text { black African } \\
33 \% \text { white } \\
31 \% \text { coloured }\end{array}$ & $\frac{\text { Heterosexual: }}{48 \% \text { female }}$ & $\begin{array}{l}48 \% \text { heterosexual } \\
39 \% \text { homosexual } \\
3 \% \text { bisexual } \\
5 \% \text { MTCT } \\
2 \% \text { blood } \\
\text { transfusion } \\
3 \% \text { unknown } \\
\end{array}$ & $\begin{array}{l}\text { B: } 52 \% \\
\text { C: } 43 \% \\
\text { D: } 3 \% \\
\text { E: } 1.5 \%\end{array}$ & $\begin{array}{l}\text { Heterosexual/ } \\
\text { Vertical: } \\
\text { C:81\%; B:13\% } \\
\text { MSM: } \\
\text { B: } 96 \% ; \text { D: } 4 \%\end{array}$ \\
\hline 4 & Bredell [32], 1998 & $\begin{array}{l}\text { Not } \\
\text { reported }\end{array}$ & Gauteng & $\begin{array}{l}\text { Migrant mine } \\
\text { workers from } \\
\text { rural SA and } \\
\text { surrounding } \\
\text { countries }\end{array}$ & $\begin{array}{l}\text { Proportionate } \\
\text { to } \\
\text { nationalities' } \\
\text { represented } \\
\text { in mines }\end{array}$ & 43 & Not reported & $100 \%$ male & Not reported & C: $100 \%$ & Not reported \\
\hline 5 & Moodley [69], 1998 & $\begin{array}{l}\text { Not } \\
\text { reported }\end{array}$ & Kwazulu-Natal & $\begin{array}{l}\text { HIV-infected } \\
\text { women } \\
\text { attending ANC }\end{array}$ & Not reported & 72 & Not reported & $100 \%$ female & Not reported & $\begin{array}{l}\text { C: } 97 \% \\
\text { A: } 1.5 \% \\
\text { B: } 1.5 \%\end{array}$ & Not reported \\
\hline 6 & $\begin{array}{l}\text { van Harmelen [28], } \\
1999\end{array}$ & 1994-1996 & $\begin{array}{l}\text { Gauteng; } \\
\text { Kwazulu- } \\
\text { Natal; Free } \\
\text { State, and } \\
\text { Western Cape }\end{array}$ & $\begin{array}{l}\text { HIV-infected } \\
\text { individuals } \\
\text { attending public } \\
\text { service clinics }\end{array}$ & $\begin{array}{l}\text { Convenience } \\
\text { sample of } \\
\text { available } \\
\text { specimens }\end{array}$ & 107 & Not reported & Not reported & $\begin{array}{l}97 \% \text { heterosexual } \\
1 \% \text { homosexual } \\
2 \% \text { bisexual }\end{array}$ & $\begin{array}{l}\text { C: } 92 \% \\
\text { B: } 7 \% \\
\text { A: } 2 \%\end{array}$ & $\begin{array}{l}\text { Heterosexual: } \\
\text { C: } 93 \% ; \text { B: } 5 \% \text {; } \\
\text { A: } 2 \% \\
\text { Homosexual: } \\
\text { B: } 100 \% \\
\text { Bisexual: } \\
\text { C:50\%; B:50\% }\end{array}$ \\
\hline
\end{tabular}




\begin{tabular}{|c|c|c|c|c|c|c|c|c|c|c|c|}
\hline 7 & $\begin{array}{l}\text { Engelbrecht [70], } \\
1999\end{array}$ & $\begin{array}{l}\text { Not } \\
\text { reported }\end{array}$ & $\begin{array}{l}\text { Gauteng, } \\
\text { Mpumalanga, } \\
\text { Kwazulu Natal } \\
\text { and Western } \\
\text { Cape }\end{array}$ & $\begin{array}{l}\text { HIV-infected } \\
\text { patients } \\
\text { attending public } \\
\text { hospitals and } \\
\text { ANC }\end{array}$ & Not reported & 81 & Not reported & $\begin{array}{l}62 \% \text { female } \\
6 \% \text { not } \\
\text { reported }\end{array}$ & $\begin{array}{l}\text { Only reported for } \\
\text { WC: } \\
84 \% \text { heterosexual } \\
4 \% \text { MSM } \\
12 \% \text { unknown }\end{array}$ & $\begin{array}{l}\text { C: } 94 \% \\
\text { B: } 4 \% \\
\text { BC recombinant: } \\
\quad 1 \% \\
\text { AB recombinant: } \\
\quad 1 \%\end{array}$ & $\begin{array}{l}\text { Not reported } \\
\text { by orientation }\end{array}$ \\
\hline 8 & Hunt [71], 2001 & 1996-1999 & Gauteng & $\begin{array}{l}\text { HIV-infected } \\
\text { patients } \\
\text { attending } \\
\text { private or public } \\
\text { hospitals/clinic }\end{array}$ & $\begin{array}{l}\text { Convenience } \\
\text { sample of } \\
\text { available } \\
\text { specimens }\end{array}$ & 60 & Not reported & Not reported & Not reported & $\begin{array}{l}\text { C: } 77 \% \\
\text { B: } 17 \% \\
\text { A: } 3 \% \\
\text { G: } 1.5 \% \\
\text { DC recombinant: } \\
\quad 1.5 \%\end{array}$ & Not reported \\
\hline 9 & Bessong [31], 2005 & 2001 & $\begin{array}{l}\text { Limpopo } \\
\text { Province }\end{array}$ & $\begin{array}{l}\text { HIV-infected } \\
\text { patients at } \\
\text { public sector } \\
\text { clinic }\end{array}$ & Not reported & 42 & Not reported & $79 \%$ female & $100 \%$ heterosexual & C: $100 \%$ & $\begin{array}{l}\text { Not reported } \\
\text { by orientation }\end{array}$ \\
\hline 10 & Jacobs [30], 2006 & $2002-2003$ & Western Cape & $\begin{array}{l}\text { HIV-infected } \\
\text { patients } \\
\text { attending an } \\
\text { HIV support } \\
\text { group in Cape } \\
\text { Town }\end{array}$ & $\begin{array}{l}\text { Nested in } \\
\text { Ascariasis } \\
\text { and HIV } \\
\text { cohort study }\end{array}$ & 127 & Not reported & $87 \%$ female & Not reported & $\begin{array}{l}\text { C: } 99 \% \\
\text { C/D } \\
\text { recombinant: } 1 \%\end{array}$ & Not reported \\
\hline 11 & Jacobs [39], 2008 & $2002-2004$ & Western Cape & $\begin{array}{l}\text { HIV-infected } \\
\text { patients } \\
\text { attending } \\
\text { private or public } \\
\text { hospitals/clinic } \\
\text { in Cape Town; } \\
\text { Western } \\
\text { Province Blood } \\
\text { Transfusion } \\
\text { Service donors; } \\
\text { Sex worker } \\
\text { cohort }\end{array}$ & Not reported & 140 & $\begin{array}{l}82 \% \text { black African } \\
14 \% \text { coloured } \\
4 \% \text { white }\end{array}$ & $66 \%$ female & $\begin{array}{l}\text { Reported a mix of } \\
\text { heterosexual, } \\
\text { homosexual, } \\
\text { bisexual and } \\
\text { MTCT-infected } \\
\text { individuals, but did } \\
\text { not report } \\
\text { proportional } \\
\text { representation }\end{array}$ & $\begin{array}{l}\text { C: } 95 \% \\
\text { B: } 4 \% \\
\text { G: } 1 \% \\
\text { CRF02_AG: } 1 \%\end{array}$ & $\begin{array}{l}\text { Not reported } \\
\text { by orientation }\end{array}$ \\
\hline 12 & Pillay [42], 2008 & $\begin{array}{l}2002 \text { and } \\
2004\end{array}$ & Gauteng & $\begin{array}{l}\text { Pregnant } \\
\text { women } \\
\text { participating in } \\
\text { anonymous } \\
\text { South African } \\
\text { National } \\
\text { Antenatal HIV } \\
\text { Survey }\end{array}$ & $\begin{array}{l}\text { All women in } \\
\text { their first } \\
\text { pregnancy } \\
\text { presenting in } \\
\text { October of } \\
\text { each study } \\
\text { year }\end{array}$ & 113 & $\begin{array}{l}97 \% \text { black African } \\
3 \% \text { unknown }\end{array}$ & $100 \%$ female & Not reported & C: $100 \%$ & Not reported \\
\hline
\end{tabular}




\begin{tabular}{|c|c|c|c|c|c|c|c|c|c|c|c|}
\hline 13 & Marconi [38], 2008 & $2005-2006$ & Kwazulu-Natal & $\begin{array}{l}\text { HIV-infected } \\
\text { patients } \\
\text { accessing public } \\
\text { sector ARV } \\
\text { treatment and } \\
\text { failing first ARV } \\
\text { regimen }\end{array}$ & $\begin{array}{l}\text { All eligible } \\
\text { adult patients } \\
\text { at the two } \\
\text { study clinics } \\
\text { were invited } \\
\text { to participate }\end{array}$ & 115 & $\begin{array}{l}94 \% \text { black African } \\
6 \% \text { not reported }\end{array}$ & $52 \%$ female & $\begin{array}{l}97 \% \text { heterosexual } \\
3 \% \text { not reported }\end{array}$ & $\begin{array}{l}\text { C: } 97 \% \\
\text { A: } 1 \% \\
\text { B: } 1 \% \\
\text { C/J recombinant: } \\
\quad 1 \%\end{array}$ & $\begin{array}{l}\text { Not reported } \\
\text { by orientation }\end{array}$ \\
\hline 14 & Jacobs [43], 2009 & $2000-2001$ & Western Cape & $\begin{array}{l}\text { HIV-infected } \\
\text { patients } \\
\text { attending } \\
\text { private or public } \\
\text { hospitals/clinic } \\
\text { in Cape Town; } \\
\text { Western } \\
\text { Province Blood } \\
\text { Transfusion } \\
\text { Service donors; } \\
\text { Sex worker } \\
\text { cohort }\end{array}$ & Not reported & 320 & $\begin{array}{l}64 \% \text { black African } \\
31 \% \text { coloured } \\
5 \% \text { white }\end{array}$ & $66 \%$ female & $\begin{array}{l}91 \% \text { heterosexual } \\
4 \% \text { MSM } \\
3 \% \text { MTCT } \\
2 \% \text { unknown }\end{array}$ & $\begin{array}{l}\text { C: } 89 \% \\
\text { B: } 7 \% \\
\text { A: } 3 \% \\
\text { F1: } 0.3 \% \\
\text { U: } 0.3 \% \\
\text { G: } 0.3 \% \\
\text { CH recombinant: } \\
\quad 0.3 \%\end{array}$ & $\begin{array}{l}\text { Not fully } \\
\text { reported by } \\
\text { orientation, } \\
\text { but }>64 \% \\
\text { MSM were B } \\
\text { (all white and } \\
\text { coloured) }\end{array}$ \\
\hline 15 & Romani [34], 2009 & $2002-2004$ & Western Cape & $\begin{array}{l}\text { HIV-infected } \\
\text { patients from } \\
\text { Cape Town } \\
\text { Metropole }\end{array}$ & Not reported & 58 & $\begin{array}{l}91 \% \text { black African } \\
5 \% \text { coloured } \\
3 \% \text { white }\end{array}$ & $55 \%$ female & $\begin{array}{l}93 \% \text { heterosexual } \\
5 \% \text { MSM } \\
2 \% \text { unknown }\end{array}$ & $\begin{array}{l}\text { C: } 93 \% \\
\text { B: } 7 \%\end{array}$ & $\begin{array}{l}\text { MSM: } \\
\text { B:66\%; C:33\% } \\
\text { Heterosexual: } \\
\text { C: } 96 \%\end{array}$ \\
\hline 16 & Naidoo [36], 2009 & 2005 & Kwazulu-Natal & $\begin{array}{l}\text { HIV-infected } \\
\text { patients } \\
\text { accessing public } \\
\text { sector ARV } \\
\text { treatment } \\
\text { program }\end{array}$ & $\begin{array}{l}\text { Random } \\
\text { selection of } \\
\text { samples from } \\
\text { eligible } \\
\text { patients on } \\
\text { the ARV } \\
\text { program }\end{array}$ & 83 & Not reported & $\begin{array}{l}65 \% \text { female } \\
4 \% \text { not } \\
\text { reported }\end{array}$ & Not reported & C: $100 \%$ & Not reported \\
\hline 17 & Huang [44], 2009 & 2006 & Free State & $\begin{array}{l}\text { HIV-infected } \\
\text { patients } \\
\text { accessing public } \\
\text { sector ARV } \\
\text { treatment } \\
\text { program }\end{array}$ & $\begin{array}{l}\text { New patients } \\
\text { at ARV } \\
\text { treatment } \\
\text { clinics }\end{array}$ & 390 & Not reported & Not reported & Not reported & C: $100 \%$ & Not reported \\
\hline 18 & $\begin{array}{l}\text { Papathanasopoulos } \\
\text { [29], } 2010\end{array}$ & $2006-2007$ & Gauteng & $\begin{array}{l}\text { Participants in } \\
\text { an HIV-positive } \\
\text { cohort study }\end{array}$ & $\begin{array}{l}10 \% \text { random } \\
\text { selection } \\
\text { from cohort } \\
\text { study } \\
\text { participants }\end{array}$ & 32 & Not reported & $75 \%$ female & Not reported & $\begin{array}{l}\text { C: } 94 \% \\
\text { A1/C } \\
\text { recombinants: } \\
\quad 6 \%\end{array}$ & Not reported \\
\hline
\end{tabular}




\begin{tabular}{|c|c|c|c|c|c|c|c|c|c|c|c|}
\hline 19 & $\begin{array}{l}\text { Nwobegahay [41], } \\
2011\end{array}$ & 2008 & $\begin{array}{l}\text { Limpopo } \\
\text { Province }\end{array}$ & $\begin{array}{l}\text { HIV-infected } \\
\text { patients } \\
\text { attending } \\
\text { HIVIAIDS } \\
\text { Wellness clinic }\end{array}$ & $\begin{array}{l}\text { HIV-infected, } \\
\text { ARV drug } \\
\text { naïve } \\
\text { patients } \\
\text { sequentially } \\
\text { recruited at } \\
\text { HIVIAIDS } \\
\text { Wellness } \\
\text { clinic }\end{array}$ & 57 & $100 \%$ black African & Not reported & Not reported & $\begin{array}{l}\text { C: } 98 \% \\
\text { BC recombinant: } \\
\quad 2 \%\end{array}$ & Not reported \\
\hline 20 & $\begin{array}{l}\text { Nwobegahay [72], } \\
2011\end{array}$ & 2008 & $\begin{array}{l}\text { Limpopo } \\
\text { Province }\end{array}$ & $\begin{array}{l}\text { Patients who } \\
\text { tested HIV- } \\
\text { infected at } \\
\text { public hospital } \\
\text { VCT clinic }\end{array}$ & $\begin{array}{l}\text { HIV-infected, } \\
\text { ARV drug } \\
\text { naïve } \\
\text { patients } \\
\text { sequentially } \\
\text { recruited at } \\
\text { VCT clinic }\end{array}$ & 54 & $100 \%$ black African & $\begin{array}{l}\text { 73\% female } \\
1 \% \text { not } \\
\text { reported }\end{array}$ & Not reported & $\begin{array}{l}\text { C: } 96 \% \\
\text { B: } 2 \% \\
\text { J: } 2 \%\end{array}$ & Not reported \\
\hline 21 & Musyoki [45], 2012 & 2006-2007 & Gauteng & $\begin{array}{l}\text { HIV-infected } \\
\text { patients } \\
\text { accessing public } \\
\text { sector ARV } \\
\text { treatment } \\
\text { program }\end{array}$ & Not reported & 123 & Not reported & Not reported & Not reported & C: $100 \%$ & Not reported \\
\hline 22 & Iweriebor [37], 2012 & 2007-2008 & $\begin{array}{l}\text { Limpopo } \\
\text { Province }\end{array}$ & $\begin{array}{l}\text { Patients who } \\
\text { tested HIV- } \\
\text { infected at } \\
\text { public clinic and } \\
\text { hospital VCT } \\
\text { centres }\end{array}$ & $\begin{array}{l}\text { All clients } \\
\text { testing HIV- } \\
\text { infected at } \\
\text { VCT clinics } \\
\text { were invited } \\
\text { to participate }\end{array}$ & 82 & Not reported & $90 \%$ female & $\begin{array}{l}99 \% \text { heterosexual } \\
1 \% \text { MTCT }\end{array}$ & C: $100 \%$ & Not reported \\
\hline
\end{tabular}

* Percentages in cells may not sum to $100 \%$, due to rounding up.

Note: ARV = Antiretroviral; ANC = Antenatal clinic; VCT = Voluntary Counselling and HIV Testing; SA = South Africa; $M$ TCT =

Mother to child transmission; WC = Western Cape 
Table 2: Summary of structured literature review of HIV-1 subtypes among MSM in Africa

\begin{tabular}{|c|c|c|c|c|c|c|c|c|c|c|}
\hline & $\begin{array}{l}\text { Author, } \\
\text { publication year }\end{array}$ & $\begin{array}{l}\text { Sampling } \\
\text { period }\end{array}$ & Country & Population & $\begin{array}{l}\text { Sampling } \\
\text { method }\end{array}$ & $\begin{array}{l}\text { Sample } \\
\text { size }\end{array}$ & Race $^{*}$ & Gender ${ }^{*}$ & $\begin{array}{l}\text { Sexual } \\
\text { orientation* }\end{array}$ & $\begin{array}{l}\text { Subtypes by } \\
\text { orientation* }\end{array}$ \\
\hline 1 & $\begin{array}{l}\text { Engelbrecht [40], } \\
1995\end{array}$ & 1984-1992 & South Africa & $\begin{array}{l}\text { HIV-infected patients } \\
\text { attending public } \\
\text { hospital in Cape Town }\end{array}$ & Not reported & 14 & $\begin{array}{l}\frac{\text { Homosexual: }}{100 \% \text { white }} \\
\text { Bisexual: } \\
100 \% \text { white }\end{array}$ & $100 \%$ male & $\begin{array}{l}50 \% \text { homosexual } \\
21 \% \text { bisexual } \\
21 \% \text { heterosexual } \\
7 \% \text { unknown }\end{array}$ & $\begin{array}{l}\text { Homosexual: } \\
43 \% \text { B; } 57 \% \text { D } \\
\text { Bisexual: } \\
66 \% \text { B; 33\% D } \\
\text { Heterosexual: } \\
66 \% \text { C; 33\% B }\end{array}$ \\
\hline 2 & $\begin{array}{l}\text { van Harmelen } \\
\text { [35], } 1997\end{array}$ & 1993-1994 & South Africa & $\begin{array}{l}\text { HIV-infected patients } \\
\text { attending public } \\
\text { hospitals in Cape } \\
\text { Town }\end{array}$ & $\begin{array}{l}\text { Selected based } \\
\text { on mode of HIV } \\
\text { transmission }\end{array}$ & & $\begin{array}{l}\text { Homosexual: } \\
58 \% \text { white } \\
42 \% \text { coloured } \\
\text { Bisexual: } \\
100 \% \text { white } \\
\text { Heterosexual: } \\
62 \% \text { black } \\
\text { African } \\
28 \% \text { coloured } \\
10 \% \text { white }\end{array}$ & $67 \%$ male & $\begin{array}{l}48 \% \text { heterosexual } \\
39 \% \text { homosexual } \\
3 \% \text { bisexual } \\
10 \% \text { unknown }\end{array}$ & $\begin{array}{l}\text { Heterosexual/Vertical } \\
81 \% \mathrm{C} ; 13 \% \mathrm{~B} \\
\text { MSM: } \\
96 \% \mathrm{~B} ; 4 \% \mathrm{D}\end{array}$ \\
\hline 3 & $\begin{array}{l}\text { van Harmelen } \\
{[28], 1999}\end{array}$ & 1994-1996 & South Africa & $\begin{array}{l}\text { HIV-infected } \\
\text { individuals attending } \\
\text { public service clinics }\end{array}$ & $\begin{array}{l}\text { Convenience } \\
\text { sample of } \\
\text { available } \\
\text { specimens }\end{array}$ & 107 & Not reported & $\begin{array}{l}\text { Not } \\
\text { reported }\end{array}$ & $\begin{array}{l}97 \% \text { heterosexual } \\
1 \% \text { homosexual } \\
2 \% \text { bisexual }\end{array}$ & 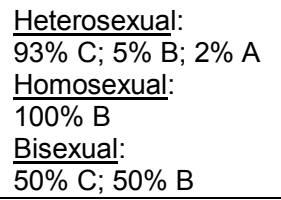 \\
\hline 4 & $\begin{array}{l}\text { Romani [34], } \\
2009\end{array}$ & 2002-2004 & South Africa & $\begin{array}{l}\text { HIV-infected patients } \\
\text { from Cape Town } \\
\text { Metropole }\end{array}$ & Not reported & 58 & $\begin{array}{l}\text { MSM: } \\
66 \% \text { white } \\
33 \% \text { black } \\
\text { Heterosexual: } \\
96 \% \text { black } \\
\text { African } \\
4 \% \text { coloured }\end{array}$ & $45 \%$ male & $\begin{array}{l}93 \% \text { heterosexual } \\
5 \% \text { MSM } \\
2 \% \text { unknown }\end{array}$ & $\begin{array}{l}\text { MSM: } 66 \% \text { B; } 33 \% \text { C } \\
\text { Heterosexual: } 96 \% \text { C }\end{array}$ \\
\hline 5 & $\begin{array}{l}\text { Ndiaye [67], } \\
2009\end{array}$ & 2004 & Senegal & Urban MSM & $\begin{array}{l}\text { Snowball } \\
\text { technique }\end{array}$ & 70 & Not reported & $100 \%$ male & $100 \% \mathrm{MSM}$ & $\begin{array}{l}\text { C: } 40 \% \\
\text { CRF02_AG: } 24 \% \\
\text { B: } 19 \% \\
\text { CRF09_cpx: } 4 \% \\
\text { Unique recombinants: } \\
4 \%\end{array}$ \\
\hline
\end{tabular}


6 Tovanabutra [66],
2005-2006

Kenya
Prospective Incidence

Cohort study an

MSM and FSW in and

around Mombasa
All sero-

convertors and a

convenience

sample of

prevalent cases
MSM:

A: $62 \%$

AA2CD: $15 \%$

AD recombinant: $8 \%$

AC recombinant: $8 \%$

DG recombinant: $8 \%$

FSW \& heterosexual:

A: $88 \%$

AA2D: $11 \%$

AD recombinant: $11 \%$

* Percentages in cells may not sum to $100 \%$, due to rounding up.

Note: FSW = female sex worker 


\section{References}

1. Serwadda D, Mugerwa RD, Sewankambo NK, Lwegaba A, Carswell JW, Kirya GB et al. Slim disease: a new disease in Uganda and its association with HTLV-III infection. Lancet 1985; 2: 849-852.

2. Centers for Disease Control. Pneumocystis pneumonia - Los Angeles. Morb Mortal Wkly Rep 1981; 30: 1-3.

3. Centers for Disease Control. A Cluster of Kaposi's Sarcoma and Pneumocystis carinii Pneumonia among Homosexual Male Residents of Los Angeles and range Counties, California. Morb Mortal Wkly Rep 1982; 31: 305-307.

4. Marx JL. New disease baffles medical community. Science 1982; 217: 618-621.

5. Barre-Sinoussi F, Chermann JC, Rey F, Nugeyre MT, Chamaret S, Gruest J et al. Isolation of a T-lymphotropic retrovirus from a patient at risk for acquired immune deficiency syndrome (AIDS). Science 1983; 220: 868-871.

6. Zhu T, Korber BT, Nahmias AJ, Hooper E, Sharp PM, Ho DD. An African HIV-1 sequence from 1959 and implications for the origin of the epidemic. Nature 1998; 391: 594-597.

7. UNAIDS. Global HIVIAIDS Response. Epidemic update and health sector progress towards Universal Access. 2011. 2011.

http://www.who.int/hiv/pub/progress report2011/hiv full report 2011.pdf

8. Keele BF, Giorgi EE, Salazar-Gonzalez JF, Decker JM, Pham KT, Salazar MG et al. Identification and characterization of transmitted and early founder virus envelopes in primary HIV-1 infection. Proc Natl Acad Sci U S A 2008; 105: 7552-7557.

9. Korber B, Muldoon M, Theiler J, Gao F, Gupta R, Lapedes A et al. Timing the ancestor of the HIV-1 pandemic strains. Science 2000; 288: 1789-1796.

10. Santiago ML, Range F, Keele BF, Li Y, Bailes E, Bibollet-Ruche F et al. Simian immunodeficiency virus infection in free-ranging sooty mangabeys (Cercocebus atys atys) from the Tai Forest, Cote d'Ivoire: implications for the origin of epidemic human immunodeficiency virus type 2. J Virol 2005; 79: 12515-12527. 
11. Lemey P, Pybus OG, Wang B, Saksena NK, Salemi M, Vandamme AM. Tracing the origin and history of the HIV-2 epidemic. Proc Natl Acad Sci U S A 2003; 100: 65886592.

12. Ishikawa K, Janssens W, Banor JS, Shinno T, Piedade J, Sata T et al. Genetic analysis of HIV type 2 from Ghana and Guinea-Bissau, West Africa. AIDS Res Hum Retroviruses 2001; 17: 1661-1663.

13. Pieniazek D, Ellenberger D, Janini LM, Ramos AC, Nkengasong J, Sassan-Morokro $M$ et al. Predominance of human immunodeficiency virus type 2 subtype $B$ in Abidjan, Ivory Coast. AIDS Res Hum Retroviruses 1999; 15: 603-608.

14. Munoz JL, Parks WP, Wolinsky SM, Korber BT, Hutto C. HIV-1 reverse transcriptase. A diversity generator and quasispecies regulator. Ann N Y Acad Sci 1993; 693: 6570.

15. Stebbing J, Moyle G. The clades of HIV: their origins and clinical significance. AIDS Rev 2003; 5: 205-213.

16. Robertson DL, Anderson JP, Bradac JA, Carr JK, Foley B, Funkhouser RK et al. HIV1 nomenclature proposal. Science 2000; 288: 55-56.

17. Ayouba A, Souquieres S, Njinku B, Martin PM, Muller-Trutwin MC, Roques $P$ et al. HIV-1 group N among HIV-1-seropositive individuals in Cameroon. AIDS 2000; 14 : 2623-2625.

18. Lemey P, Pybus OG, Rambaut A, Drummond AJ, Robertson DL, Roques P et al. The molecular population genetics of HIV-1 group O. Genetics 2004; 167: 1059-1068.

19. Virology. In: Handbook of HIV Medicine. Wilson D, Naidoo S, Bekker LG, Cotton MF, Maartens G (eds) Oxford University Press. 2002: 15-21.

20. Los Alamos National Laboratory. HIV Database. 2012. http://www.hiv.lanl.gov/

21. Fleischmann WR. Viral Genetics. In: Medical Microbiology. Baron S (ed). Galveston, Texas, University of Texas Medical Branch at Galveston. 1996. Available at: http://www.ncbi.nlm.nih.gov/books/NBK8439/

22. Robertson DL, Anderson JP, Bradac JA, Carr JK, Foley B, Funkhouser RK et al. HIV1 nomenclature proposal. Science 2000; 288: 55-56. 
23. Peeters M, Sharp PM. Genetic diversity of HIV-1: the moving target. AIDS 2000; 14 Suppl 3: S129-S140.

24. Hemelaar J, Gouws E, Ghys PD, Osmanov S. Global trends in molecular epidemiology of HIV-1 during 2000-2007. AIDS 2011; 25: 679-689.

25. Dalai SC, de Oliveira T, Harkins GW, Kassaye SG, Lint J, Manasa J et al. Evolution and molecular epidemiology of subtype C HIV-1 in Zimbabwe. AIDS 2009; 23: 25232532.

26. McCormack GP, Glynn JR, Crampin AC, Sibande F, Mulawa D, Bliss L et al. Early evolution of the human immunodeficiency virus type 1 subtype $C$ epidemic in rural Malawi. J Virol 2002; 76: 12890-12899.

27. Bredell H, Williamson C, Sonnenberg P, Martin DJ, Morris L. Genetic characterization of HIV type 1 from migrant workers in three South African gold mines. AIDS Res Hum Retroviruses 1998; 14: 677-684.

28. Van Harmelen JH, Van der RE, Loubser AS, York D, Madurai S, Lyons S et al. A predominantly HIV type 1 subtype C-restricted epidemic in South African urban populations. AIDS Res Hum Retroviruses 1999; 15: 395-398.

29. Papathanasopoulos MA, Vardas E, Wallis C, Glashoff R, Butto S, Poli G et al. Characterization of HIV type 1 genetic diversity among South African participants enrolled in the AIDS Vaccine Integrated Project (AVIP) study. AIDS Res Hum Retroviruses 2010; 26: 705-709.

30. Jacobs GB, de Beer C, Fincham JE, Adams V, Dhansay MA, van Rensburg EJ et al. Serotyping and genotyping of HIV-1 infection in residents of Khayelitsha, Cape Town, South Africa. J Med Virol 2006; 78: 1529-1536.

31. Bessong PO, Larry OC, Cilliers T, Choge I, Phoswa M, Pillay C et al. Characterization of human immunodeficiency virus type 1 from a previously unexplored region of South Africa with a high HIV prevalence. AIDS Res Hum Retroviruses 2005; 21: 103-109.

32. Bredell H, Williamson C, Sonnenberg P, Martin DJ, Morris L. Genetic characterization of HIV type 1 from migrant workers in three South African gold mines. AIDS Res Hum Retroviruses 1998; 14: 677-684. 
33. Becker ML, De Jager G, Becker WB. Analysis of partial gag and env gene sequences of HIV type 1 strains from southern Africa. AIDS Res Hum Retroviruses 1995; 11: 1265-1267.

34. Romani B, Glashoff R, Engelbrecht S. Molecular and phylogenetic analysis of HIV type 1 vpr sequences of South African strains. AIDS Res Hum Retroviruses 2009; 25: 357-362.

35. van Harmelen J, Wood R, Lambrick M, Rybicki EP, Williamson AL, Williamson C. An association between HIV-1 subtypes and mode of transmission in Cape Town, South Africa. AIDS 1997; 11: 81-87.

36. Naidoo AF, Parboosing R, Gordon ML. Dual HIV Infection Uncommon in Patients on Antiretroviral Therapy in a Region with High HIV Prevalence. AIDS Res Hum Retroviruses 2009; 25: 1225-1230.

37. Iweriebor BC, Mavhandu LG, Masebe T, Rekosh D, Hammarskjold ML, Mphahlele $\mathrm{JM}$ et al. Molecular epidemiology of HIV in two highly endemic areas of northeastern South Africa. Arch Virol 2012; 157: 455-465.

38. Marconi VC, Sunpath H, Lu Z, Gordon M, Koranteng-Apeagyei K, Hampton J et al. Prevalence of HIV-1 drug resistance after failure of a first highly active antiretroviral therapy regimen in KwaZulu Natal, South Africa. Clin Infect Dis 2008; 46: 1589-1597.

39. Jacobs GB, Laten A, van Rensburg EJ, Bodem J, Weissbrich B, Rethwilm A et al. Phylogenetic diversity and low level antiretroviral resistance mutations in HIV type 1 treatment-naive patients from Cape Town, South Africa. AIDS Res Hum Retroviruses 2008; 24: 1009-1012.

40. Engelbrecht S, Laten JD, Smith TL, van Rensburg EJ. Identification of env subtypes in fourteen HIV type 1 isolates from south Africa. AIDS Res Hum Retroviruses 1995; 11: $1269-1271$.

41. Nwobegahay J, Bessong $\mathrm{P}$, Masebe T, Mavhandu L, Manhaeve C, Ndjeka N et al. Prevalence of drug-resistant mutations in newly diagnosed drug-naive HIV-1-infected individuals in a treatment site in the waterberg district, limpopo province. S Afr Med $J$ 2011; 101: 335-337. 
42. Pillay V, Ledwaba J, Hunt G, Rakgotho M, Singh B, Makubalo L et al. Antiretroviral drug resistance surveillance among drug-naive HIV-1-infected individuals in Gauteng Province, South Africa in 2002 and 2004. Antivir Ther 2008; 13 Suppl 2: 101-107.

43. Jacobs GB, Loxton AG, Laten A, Robson B, van Rensburg EJ, Engelbrecht S. Emergence and diversity of different HIV-1 subtypes in South Africa, 2000-2001. J Med Virol 2009; 81: 1852-1859.

44. Huang $\mathrm{KH}$, Goedhals $\mathrm{D}$, Fryer $\mathrm{H}$, van Vuuren $\mathrm{C}$, Katzourakis $\mathrm{A}$, de Oliveira $\mathrm{T}$ et al. Prevalence of HIV type-1 drug-associated mutations in pre-therapy patients in the Free State, South Africa. Antivir Ther 2009; 14: 975-984.

45. Musyoki A, Mothapo K, Rakgole J, Lukhwareni A, Bessong P, Selabe G et al. Genetic characterization of HIV before widespread testing of HIV vaccine candidates at a clinical trial site in Pretoria, South Africa. AIDS Res Hum Retroviruses 2012; 28 : 1131-1138.

46. Bredell H, Williamson C, Sonnenberg P, Martin DJ, Morris L. Genetic characterization of HIV type 1 from migrant workers in three South African gold mines. AIDS Res Hum Retroviruses 1998; 14: 677-684.

47. Perrin L, Kaiser L, Yerly S. Travel and the spread of HIV-1 genetic variants. Lancet Infect Dis 2003; 3: 22-27.

48. Jochelson K, Mothibeli M, Leger JP. Human immunodeficiency virus and migrant labor in South Africa. Int J Health Serv 1991; 21: 157-173.

49. Lurie MN, Williams BG, Zuma K, Mkaya-Mwamburi D, Garnett GP, Sweat MD et al. Who infects whom? HIV-1 concordance and discordance among migrant and nonmigrant couples in South Africa. AIDS 2003; 17: 2245-2252.

50. Bredell H, Williamson C, Sonnenberg P, Martin DJ, Morris L. Genetic characterization of HIV type 1 from migrant workers in three South African gold mines. AIDS Res Hum Retroviruses 1998; 14: 677-684.

51. Jackson DJ, Rakwar JP, Richardson BA, Mandaliya K, Chohan BH, Bwayo JJ et al. Decreased incidence of sexually transmitted diseases among trucking company workers in Kenya: results of a behavioural risk-reduction programme. AIDS 1997; 11: 903-909. 
52. Quinn TC. Population migration and the spread of types 1 and 2 human immunodeficiency viruses. Proc Natl Acad Sci U S A 1994; 91: 2407-2414.

53. Tatem AJ, Hemelaar J, Gray RR, Salemi M. Spatial accessibility and the spread of HIV-1 subtypes and recombinants in sub-Saharan Africa. AIDS 2012.

54. Sher R. HIV infection in South Africa, 1982-1988--a review. S Afr Med J 1989; 76: 314-318.

55. Varghese B, Maher JE, Peterman TA, Branson BM, Steketee RW. Reducing the risk of sexual HIV transmission: quantifying the per-act risk for HIV on the basis of choice of partner, sex act, and condom use. Sex Transm Dis 2002; 29: 38-43.

56. Vittinghoff E, Douglas J, Judson F, McKirnan D, MacQueen K, Buchbinder SP. Percontact risk of human immunodeficiency virus transmission between male sexual partners. Am J Epidemiol 1999; 150: 306-311.

57. Sanders EJ, Graham SM, Okuku HS, van der Elst EM, Muhaari A, Davies A et al. HIV-1 infection in high risk men who have sex with men in Mombasa, Kenya. AIDS 2007; 21: 2513-2520.

58. Wade AS, Kane CT, Diallo PA, Diop AK, Gueye K, MBoup S et al. HIV infection and sexually transmitted infections among men who have sex with men in Senegal. AIDS 2005; 19: 2133-2140.

59. Baral S, Burrell E, Scheibe A, Brown B, Beyrer C, Bekker LG. HIV risk and associations of HIV infection among men who have sex with men in peri-urban Cape Town, South Africa. BMC Public Health 2011; 11: 766.

60. Baral S, Trapence G, Motimedi F, Umar E, lipinge S, Dausab F et al. HIV prevalence, risks for HIV infection, and human rights among men who have sex with men (MSM) in Malawi, Namibia, and Botswana. PLoS One 2009; 4: e4997.

61. Baral S, Sifakis F, Cleghorn F, Beyrer C. Elevated risk for HIV infection among men who have sex with men in low- and middle-income countries 2000-2006: a systematic review. PLoS Med 2007; 4: e339.

62. UNAIDS. Country Fact Sheet. South Africa. 2011. http://www.unaids.org/en/regionscountries/countries/southafrica/ 
63. Lane T, Raymond HF, Dladla S, Rasethe J, Struthers H, McFarland W et al. High HIV prevalence among men who have sex with men in Soweto, South Africa: results from the Soweto Men's Study. AIDS Behav 2011; 15: 626-634.

64. Rispel LC, Metcalf CA, Cloete A, Reddy V, Lombard C. HIV prevalence and risk practices among men who have sex with men in two South African cities. J Acquir Immune Defic Syndr 2011; 57: 69-76.

65. Burrell E, Mark D, Grant R, Wood R, Bekker LG. Sexual risk behaviours and HIV-1 prevalence among urban men who have sex with men in Cape Town, South Africa. Sex Health 2010; 7: 149-153.

66. Tovanabutra S, Sanders EJ, Graham SM, Mwangome M, Peshu N, McClelland RS et al. Evaluation of HIV type 1 strains in men having sex with men and in female sex workers in Mombasa, Kenya. AIDS Res Hum Retroviruses 2010; 26: 123-131.

67. Ndiaye HD, Toure-Kane C, Vidal N, Niama FR, Niang-Diallo PA, Dieye T et al. Surprisingly high prevalence of subtype $\mathrm{C}$ and specific HIV-1 subtype/CRF distribution in men having sex with men in Senegal. J Acquir Immune Defic Syndr 2009; 52: 249-252.

68. Department of Health. National Strategic Plan on HIV, STIs and TB. 2011. http://www.doh.gov.za/docs/stratdocs/2012/NSPfull.pdf

69. Moodley D, Smith TL, van Rensburg EJ, Moodley J, Engelbrecht S. HIV type 1 V3 region subtyping in KwaZulu-Natal, a high-seroprevalence South African region. AIDS Res Hum Retroviruses 1998; 14: 1015-1018.

70. Engelbrecht S, Smith TL, Kasper P, Faatz E, Zeier M, Moodley D et al. HIV type 1 V3 domain serotyping and genotyping in Gauteng, Mpumalanga, KwaZulu-Natal, and Western Cape Provinces of South Africa. AIDS Res Hum Retroviruses 1999; 15 : 325-328.

71. Hunt GM, Johnson D, Tiemesse CT. Characterisation of the long terminal repeat regions of South African human immunodeficiency virus type 1 isolates. Virus Genes 2001; 23: 27-34.

72. Nwobegahay JM, Bessong PO, Masebe TM, Mavhandu LG, Iweriebor BC, Selabe G. Prevalence of antiretroviral drug resistance mutations and HIV-I subtypes among 
newly-diagnosed drug-naive persons visiting a voluntary testing and counselling centre in northeastern South Africa. J Health Popul Nutr 2011; 29: 303-309. 
PART C: Manuscript 
Epidemiology of HIV-1 subtypes among men who have sex with men in Cape Town, South Africa

Keren MIDDELKOOP, MBChB, $\mathrm{PhD}^{\mathrm{a}}$

Cecilia RADEMEYER, MSc (Med) ${ }^{b}$

Ben B BROWN, BSc ${ }^{a}$

Tamaryn J CASHMORE, B.MedSc(Hons) ${ }^{b}$

Jinny C MARAIS, MSc (Med) ${ }^{b}$

Andrew $\mathrm{P}$ SCHEIBE, MBChB ${ }^{\mathrm{a}}$

Gama P BANDAWE, MSc ${ }^{b}$

Landon MYER, MBChB, $\mathrm{PhD}^{\mathrm{a}, \mathrm{c}}$

Jonathan D FUCHS, MD, MPH

Carolyn WILLIAMSON, PhD ${ }^{\text {b,e }}$

Linda-Gail BEKKER, MBChB, FCP PhD

a) Desmond Tutu HIV Centre, Institute of Infectious Disease and Molecular Medicine and Department of Medicine, University of Cape Town, Cape Town, South Africa

b) Division of Medical Virology and Institute of Infectious Disease and Molecular Medicine, University of Cape Town, Cape Town, South Africa

c) Centre for Infectious Diseases Epidemiology \& Research, School of Public Health \& Family Medicine, University of Cape Town, Cape Town, South Africa

d) Center for Learning and Innovation, San Francisco Department of Public Health, and University of California, San Francisco, United States of America

e) National Health Laboratory Services, South Africa

Short title: HIV subtypes among Cape Town MSM

Word count (abstract):250

Word count (manuscript): 3,366

Corresponding author:

Keren Middelkoop

PO Box 13801

Mowbray

Observatory, Cape Town

7705 
South Africa

(tel) +27216506960

(fax) +27216506963

Email: keren.middelkoop@hiv-research.org.za

\section{Financial Support}

This study was made possible by funding provided by the International AIDS Vaccine Initiative, the Developmental Center for AIDS Research at the University of Rochester, and US Centers for Disease Control and Prevention, with funding from the President's Emergency Plan for AIDS Relief. 


\section{Abstract}

Objective: Early studies in Cape Town identified independent HIV-1 epidemics, with distinct viral subtypes, among men who have sex with men (MSM) and the heterosexual population. However few recent HIV-1 subtype data are available for MSM in South Africa. We examined circulating HIV-1 subtypes among MSM in Cape Town.

Design: Cross-sectional survey

Methods: Self-identified MSM were recruited from geographically and racially disparate communities across Cape Town. Participants completed behavioural questionnaires and underwent HIV testing. Virus isolated from infected participants underwent complete env gp160 sequencing and HIV-1 subtypes were assigned via phylogenetic analysis.

Results: In total 194 HIV-infected MSM were enrolled: 67\% black African, 24\% coloured, and $9 \%$ white men. More black African men identified as bisexual or heterosexual compared to other races. Overall $31 \%-66 \%$ of men reported a recent partner of another race. HIV-1 subtypes were confirmed for 143 participants: $81 \%$ were subtype $C, 14 \% B, 1 \% A 1,1 \% F 2$, and three recombinant viruses. Subtype $C$ virus was associated with black African race ( $p=0.003$ compared to coloured; $p<0.001$ compared to white), men who identified as bisexual/heterosexual $(p=0.01)$, and reported a female sexual partner in the last year $(p=0.02)$. Compared to previous studies, an increasing prevalence of subtype $C$ virus was noted among white MSM.

Conclusions: This molecular epidemiological study provides novel evidence of sexual network links between the heterosexual and MSM epidemics and between historically racially disparate communities. These findings provide insights into the drivers of HIV epidemics in different population groups and may have implications for prevention strategies.

\section{Key words}

HIV-1; phylogeny; subtypes; men who have sex with men; homosexuality 


\section{Introduction}

South Africa has one of the largest HIV epidemics world-wide, with an estimated prevalence of $17 \%$ [1]. The first documented South African cases of acquired immunodeficiency syndrome (AIDS) were identified in men who have sex with men (MSM) in 1982 [2], and the HIV prevalence among primarily white MSM peaked in the mid-1980s [3]. However by the early 1990s it was clear that this MSM epidemic was rapidly giving way to a far larger heterosexual epidemic, predominantly among black Africans who comprise the majority of the South African population [4]. An early molecular epidemiological study of circulating HIV strains in Cape Town in the late 1980s and early 1990s suggested that the two epidemics were independent of one another: the MSM epidemic was comprised almost exclusively of HIV-1 subtype B virus, and was associated with travel to high income countries [5]. The heterosexual epidemic, by contrast, comprised mainly HIV-1 subtype $\mathrm{C}$ virus and most likely spread to South Africa through local or regional travel [5].

Independent HIV epidemics in different population groups have also been identified in Thailand, and it has been postulated that the "epidemiological segregation" of subtypes may be due to demographic and social network factors that extend beyond sexual preference [6]. Indeed, the importance of societal structures has also been noted in the spread of other sexually transmitted diseases in South Africa [7]. In South Africa, the political segregation of apartheid, including legally enforced racial segregation of residential areas and prohibition of inter-racial sexual relationships may have limited social mixing and amplified this phenomenon. Furthermore, the different cultural backgrounds of South African MSM communities may influence how these groups identify and engage in MSM activity, as well as the interaction across these communities [8].

The current emphasis of HIV prevention and treatment policies and research programmes in South Africa are overwhelmingly focused on heterosexual and vertical transmission of HIV. As a result, research among MSM, and HIV prevention policies for this group have been largely neglected. Yet, there is evidence that HIV prevalence remains high in MSM groups in South Africa [9]. While the impact of MSM transmission of HIV on the South African epidemic may be minor, these transmission patterns may contribute disproportionally to incident HIV infections among males generally [10].

Little is known about the HIV-1 subtypes currently circulating among MSM in Cape Town or indeed in South Africa, or how the changing socio-political landscape over the past two decades may have impacted this epidemic. Yet HIV subtypes may have implications for HIV 
testing, transmission, natural history of the disease, treatment and prevention, particularly HIV vaccine designs $[11,12]$. We aimed to describe the circulating HIV-1 subtypes among MSM in Cape Town, and explore possible differences and links between both the generalised epidemic and historically geographic and racially defined communities.

\section{Methods}

Participants: Self-identified MSM were recruited from urban and peri-urban sites in Cape Town in 2009 and 2010, over an eight-month period. Historically, Cape Town was divided into geographical, racially-defined areas [13]. For the purposes of this study, urban areas were defined as Cape Town's Central Business District (CBD) and surrounding communities that were historically designated as white communities. Peri-urban areas were defined as township or low-income communities that were historically designated as black African and/or coloured communities. The racial categories of black African, coloured and white were used as per the terms employed in the latest South African census [14]. In South Africa, "coloured" refers to individuals of mixed race or of Khoisan or Malay descent [15]. Participants were recruited from organizations and venues frequented by MSM, subsequent referrals from enrolled participants (quasi-snowballing technique [16]), and recruitment via other studies and internet advertising. Men were considered eligible for the study if they were of male sex at birth, 16 years of age or older, resided in the greater Cape Town area, had engaged in sexual activity with another man in the last 12 months and were willing to undergo an HIV test.

Following enrollment, participants completed interviewer-administered questionnaires in their home language that captured demographic data and information on sexual orientation and disclosure. Information was also gathered on participants' sexual history, in particular regarding sexual history with female partners, as well as the participant's three most recent sexual partners in the past six months. HIV testing was performed using finger-prick rapid antibody screening tests and followed the national HIV Counselling and Testing guidelines [17]. Men who tested HIV-positive had blood samples drawn for CD4 T-cell count testing and HIV subtyping. The study was conducted in accordance with the Declaration of Helsinki (2008) and was approved by the Human Research Ethics Committee of the University of Cape Town. Participants provided written informed consent.

In order to show a $25 \%$ difference in the representation of subtype $\mathrm{C}$ virus among MSM in urban versus peri-urban communities, a sample size of 200 was required. This allowed for 
an approximately $15 \%$ loss of specimens due to difficulties in amplification of cDNA or indeterminate sequencing results.

Viral RNA extraction, cDNA synthesis and amplification: HIV-1 subtyping was performed by DNA amplification followed by sequencing of the HIV-1 env gene. RNA was extracted from 200-400 $\mu$ l plasma using the QIAamp Viral RNA Mini Kit (Qiagen). Reverse transcription of RNA to single-stranded cDNA was performed with SuperScript III Reverse Transcriptase using primer Oligo (dT)20 (Invitrogen Life Technologies) based on manufacturerrecommended, previously described methods [18].

In order to ensure that single genomes were amplified, cDNA was serially diluted to determine the exact dilution at which no more than $30 \%$ positive amplification reactions was present per dilution batch. Amplification of gp160 was then performed according to a method described elsewhere [19].

For Gag p17p24 amplification and sequencing a One-Step RT-PCR was performed (SuperScript ${ }^{\circledR}$ III One-Step RT-PCR System with Platinum ${ }^{\circledR}$ Taq DNA Polymerase High Fidelity, Invitrogen Life Technologies), which was adapted from a method described elsewhere [20]. This consisted of $1 \times$ Reaction Mix (0.2 mM of each dNTP and $1.6 \mathrm{mM}$ $\mathrm{MgSO}_{4}$ ), $0.2 \mu \mathrm{M}$ of each primer DT1 5' ATGGGTGCGAGAGCGTCAGTATT '3 (nt 790-812 HXB2) and DT7 5' CCCTGACATGCTGTCATCATTTCTTCT '3 (nt 1818-1844 HXB2), and $1 \mu$ of the SuperScript $₫$ III RT/ Platinum $®$ Taq Mix in a $50 \mu$ l reaction. PCR cycling parameters were: 1 cycle of $55^{\circ} \mathrm{C}$ for 30 minutes; 1 cycle of $94^{\circ} \mathrm{C}$ for 2 minutes, 10 cycles of a denaturing step of $94^{\circ} \mathrm{C}$ for 15 seconds, an annealing step of $55^{\circ} \mathrm{C}$ for 30 seconds, an extension step of $68^{\circ} \mathrm{C}$ for 1 minute; 25 cycles of a denaturing step of $94^{\circ} \mathrm{C}$ for 15 seconds, an annealing step of $55^{\circ} \mathrm{C}$ for 30 seconds, an extension step of $68^{\circ} \mathrm{C}$ for 1 minute with a 5 second increase for each cycle thereafter and followed by a final extension of $68^{\circ} \mathrm{C}$ for 7 minutes. The second round PCR consisted of 1x Expand High Fidelity Buffer, 1.5mM MgCl2, $0.2 \mathrm{mM}$ each dNTP, $0.3 \mu \mathrm{M}$ of each primer DT3 5' CATCTAGTATGGGCAAGCAGGGA '3 (nt 886-908 HXB2) and DT6 5’ ATGCTGACAGGGCTATACATTCTTAC '3 (nt 1609-1634 HXB2), and 2.6 units Expand High Fidelity polymerase (Roche) in a 100 $\mu$ reaction. Second round cycling parameters: 1 cycle of $94^{\circ} \mathrm{C}$ for 2 minutes; 10 cycles of $94^{\circ} \mathrm{C}$ for 15 seconds, $57^{\circ} \mathrm{C}$ for 30 seconds, $72^{\circ} \mathrm{C}$ for 1 minute; 25 cycles of $94^{\circ} \mathrm{C}$ for 15 seconds, $57^{\circ} \mathrm{C}$ for 30 seconds, $72^{\circ} \mathrm{C}$ for 1 minute with 5 seconds increase per cycle; $72^{\circ} \mathrm{C}$ for 7 minutes.

Sequencing and Sequence Analysis: PCR products were directly sequenced using BigDye Terminator chemistry as recommended by the manufacturer (Applied Bio-systems, 
Foster City, CA). The sequences were determined by using an ABI 3730xl genetic analyzer (Applied Biosystems, Foster City, CA) and edited by using the Sequencher program (Gene Codes, Ann Arbor, MI).

The complete env gp160 sequences ( $2500 \mathrm{bp})$ of study participants were aligned using CLUSTAL $W^{[21]}$, and subtypes were assigned by inferring gp160 phylogenetic relatedness of participant sequences to an HIV-1 subtype reference set from the HIV Sequence Database [22]. Maximum Likelihood phylogenetic trees were generated using MEGA v5.04 software [23] based on the Tamura-Nei model [24]. Reliability of the tree topology was assessed by 500 bootstrap replicates. Sequences which clustered together were further investigated to exclude any possibility of contamination or sample mix-up. Sequences from all phylogenetic clusters were confirmed by re-isolation of RNA and sequenced in gp160 and/or a region in gag p17p24 (748 bp). In all cases except one (in which clustering could not be confirmed in gag), cluster patterns were confirmed true.

Sequences were screened for evidence of inter-subtype recombination by the Recombination Identification Program (RIP 3.0) (http://www.hiv.lanl.gov/content/sequence/RIP/RIP.html), REGA HIV-1 Subtyping ToolVersion 2.0 (http://www.bioafrica.net/rega-genotype/html/subtypinghiv.html) and jumping profile Hidden Markov Model (jpHMM) (http://jphmm.gobics.de/) ${ }^{[25]}$. Recombinant viruses were analyzed for subtype assignment and breakpoint identification by SimPlot software v3.5.1 (http://sray.med.som.jhmi.edu/SCRoftware). Specifically, neighbour-joining bootscan analysis was performed with a sliding window of 200 bp incremented by 20 bp across the entire alignment that included sequences of nine HIV-1 subtypes-A, B, C, D, F, G, H, J, and $\mathrm{K}$, obtained from the Los Alamos HIV database (http://www.hiv.lanl.gov/). Phylogenetic trees were generated from portions of gp160 on either side of Simplot identified breakpoints in order to confirm HIV-1 inter-subtype recombinant viruses.

Data were analyzed using STATA 10.0 (StataCorp, College Station, Texas). Bivariate analyses employed Wilcoxon rank sum, chi-squared tests and Fisher exact tests, as appropriate. Bivariate and multivariate logistic regression models were developed to examine factors associated with HIV-1 subtypes. All statistical tests were 2-sided at alpha=0.05. 


\section{Results}

In this study, 197 HIV-infected MSM were enrolled. Three participants were subsequently excluded: one was confirmed ineligible, and two were enrolled twice in the study (data from second enrolment were excluded). Of the remaining 194 participants, 93 (48\%) were from urban areas.

\section{Demographics and sexual history}

The median age of participants was 32 years (interquartile range [IQR]: 26-39), and 47 (25\%) were employed. Overall 129 (67\%) were black African, 47 (24\%) were coloured, and $17(9 \%)$ were white men. The demographic characteristics, sexual orientation and relationship histories are reported by race (Table 1 ). In total $72 \%$ of men identified as homosexual or gay, $21 \%$ identified as bisexual, and $3 \%$ as heterosexual. Black men were more likely to identify as bisexual or heterosexual compared to other races (33\% compared to $6 \%$ in both coloured and white men; $p<0.001$ ). Black men were less likely to have disclosed their same sex activity to family or friends compared to coloured and white MSM $(p=0.01)$.

Overall, 96 (49\%) men reported having a female sexual partner in the past, with black African and white men more likely to have ever had a female partner compared to coloured men $(p<0.001)$. Overall, $50 \%$ of participants were currently in a relationship with a man, $9 \%$ with both a male and a female partner, $5 \%$ with a female partner, and $36 \%$ were not currently in a relationship. Black men were more likely to be in relationship with both men and women (not statistically significant). When asked about their three most recent male sexual partners, $31 \%$ (95\% confidence interval [Cl]: 10-61\%) of white participants, $66 \%$ (95\% Cl: $50-80 \%)$ of coloured and $32 \%$ (95\% Cl: $24-41 \%)$ of black participants reported a partner of a different race.

\section{HIV-1 subtypes}

HIV-1 subtypes were confirmed phylogenetically for 143 of the 194 participants. There was no difference in those participants with and without subtyping data in terms of residential location $(p=0.42)$, race $(p=0.51)$ or previous or recent female sexual partner $(p=0.22$ and $p=0.87$, respectively). However, participants who identified as homosexual/gay were more likely to have subtyping data available $(p=0.01)$. Overall $116(81 \%)$ samples were subtype $C$, $20(14 \%)$ subtype $B$, two (1\%) were subtypes $A 1$, two (1\%) F2, and three (3\%) were recombinants $\mathrm{AC}, \mathrm{BC}$, and $\mathrm{BF}$ (one of each). The availability of subtyping data and the 
distribution of HIV subtypes among racial groups are shown in Figure 1. In total, $85 \%$ of participants with subtype $B$ virus and $43 \%$ of those with subtype $C$ were from urban sites.

The phylogenetic trees for the viruses in each race group are presented in Figure 2. Subtype $C$ virus was more likely to occur in black African men (odds ratio [OR]: $4.5 ; 95 \%$ $\mathrm{Cl}: 1.7-12.5$ compared to coloured men and OR:18.8; $95 \% \mathrm{Cl}: 4.5-78.3$ compared to white men) and men who identified as bisexual/heterosexual $(p=0.01)$. While subtype $C$ was not associated with a previous history of female sexual partner, it was associated with a female sexual partner in the last year (OR: 6.8; 95\% Cl: 01.4-33.3 "within last year" compared to ">1 year ago"). The association of demographic, sexual orientation and sexual history with subtype $C$ is reported in Table 2 . When adjusted for location, race $(p=0.001)$ remained positively associated with subtype $C$ virus, but location did not $(p=0.39)$. Among white men, the median age of individuals with subtype $C$ virus was 34 years (IQR:27-41) versus 40 years (IQR: $36-40)$ among men with subtype $B(p=0.77)$.

Some subtypes and recombinant forms that occur at low frequencies globally were detected, including two subtype F2 viruses in black African men and one BF recombinant virus in a white man. The subtype F2 viruses clustered with viruses from Cameroon and were very closely related to each other (Figure 3) suggestive of recent transmission from a common source in South Africa rather than two independent introductions of this subtype into the community. The participant with BF virus reported recently returning from Dubai, where he had had at least two sexual partners. Two additional recombinant strains were identified, namely recombinant $A C$ (from a black participant) and BC (from a coloured participant). Both these participants reported no sexual history with a woman, and reported that their last three sexual partners were all in South Africa. The three recombinant viruses were not recognized circulating recombinant forms (CRFs).

In addition to the F2 cluster, there were a further 17 participants in seven clusters of low diversity (range: 2-4 individuals/cluster) suggestive of recent transmission events (Figure 3). From the available sexual network data, possible epidemiological links were identified between 15 (79\%) participants occurring in clusters (ie, reported residing in or having recent sexual partners from the same communities), and no epidemiological link was found for the remaining four participants. While there were no differences in race within clusters, in three of these clusters, participants resided in different locations to one another (ie urban or periurban). 


\section{Discussion}

In the early 1990s studies reported two independent HIV-1 epidemics in Cape Town: a predominantly subtype B epidemic among MSM and a subtype $C$ epidemic in the heterosexual population $[5,26]$. While a number of studies have assessed the circulating HIV subtypes of predominantly the heterosexual epidemic since then [27-29], this study is the first dedicated study of subtypes among MSM in Cape Town in the last two decades. This study demonstrates that the two epidemics are no longer independent, and reports evidence of bridging between the generalized heterosexual and concentrated MSM HIV epidemics in Cape Town.

While subtype B virus remains more prevalent among MSM compared to the generalized epidemic (14\% vs $1-7 \%$ respectively [29-31]), the majority of MSM in this study had subtype $C$ virus. Subtype $C$ was significantly associated with men from peri-urban locations, and more specifically with black African race. Subtype $C$ was also strongly associated with bisexual orientation as well as reported sex with a female in the last year. We found that half of the self-identified MSM participants reported high levels of sex with women. In particular, black African MSM were more likely to identify as bisexual or heterosexual compared to white or coloured MSM, and were more likely to have a current female partner. This may be related to the finding that black African men were less likely to have disclosed their sexual preference to anyone, possibly due to high levels of stigma and discrimination within these communities [32]. Together, the higher levels of bisexual activity and the association with subtype $\mathrm{C}$ virus among black African MSM may be evidence of bridging between the heterosexual and homosexual populations in Cape Town. This hypothesis is strengthened by reports of an increasing representation of subtype B in South Africa's heterosexual population [29]. In addition, two of the three recombinants detected in this study included subtype $\mathrm{C}$ sequences (including one $\mathrm{BC}$ sequence), further supporting the theory of bridging between the MSM and heterosexual epidemics. This finding is in keeping with literature from Kenya where it has also been reported that MSM are predominantly infected with the same HIV subtype as the general population [33].

While predominately associated with black African MSM, an increasing prevalence of subtype $C$ virus was noted among white MSM - no subtype $C$ viruses were identified among this group in the 1990s [5], but subtype C accounted for $36 \%$ of HIV infections among white MSM in this study. A trend toward subtype $C$ virus occurring in younger white MSM was also noted, although this was not statistically significant (possibly due to the small sample size in this racial group). Together with the high reported levels of inter-racial relationships, this 
finding may reflect a breaking down of historical social barriers in Cape Town in the recent past, with mixing across previously racially defined urban and peri-urban communities, and a bridging of epidemics across these districts.

Research from Cape Town over the past decade have reported overwhelmingly subtype $C$ epidemics (>90\%) with variable representation of subtypes $B$, as well as $A$ and $G$ (one study each) and occasional recombinants [31,34]. This study reported an unusually high diversity of HIV subtypes. These subtypes may have been introduced to Cape Town MSM networks through international tourism [5] and the migration of other African MSM to South Africa, seeking the protection afforded by the country's constitution. Furthermore, while there were insufficient specimens to exclude a founder effect among subtype B viruses, the lack of structure among the subtype $\mathrm{C}$ component of the overall phylogenetic tree is evidence of the absence of a founder effect in this group. This is in keeping with literature that suggest multiple introductions of subtype B and C viruses into South Africa [5,31].

This study has several limitations. First, due to the hard to reach nature of the MSM population, a number of recruitment strategies were used, as is commonplace when working with MSM [16], and this non-random recruitment strategy may limit the generalizability of our findings. Behavioural data was obtained by interviewer-administrated questionnaire, and may suffer from typical problems of self-reported information, including social desirability bias. Due to the cross-sectional study design we are more likely to have identified prevalent, rather than incident HIV-positive cases, limiting our ability to make inferences regarding currently circulating HIV-1 strains. The large number of linked cases identified in this study may be due to the high frequency of multiple concurrent partners among MSM $[35,36]$. In this study, the evidence of possible recent transmission links may be a result of the peerbased recruitment strategy. However we were unable to confirm transmission events, as we did not collect in-depth sexual network data. Furthermore, we did not investigate the likely route of HIV acquisition. It is possible that some participants acquired HIV infection through non-sexual routes, such as blood transfusions or intravenous drug use (IDU). However IDU is reportedly low (<3\%) among South African MSM [32].

In conclusion, this study presents novel data on the molecular epidemiology of HIV-1 subtypes among MSM in South Africa. A substantially higher proportion of subtype C infections was found in this sample compared to previous studies and evidence of transmission of relatively rare subtypes such as F2 and BF recombinants was also found. These data provide biological confirmation of behavioural data of the links between the heterosexual and MSM epidemics [33], as well as between the urban and peri-urban 
communities in Cape Town, and providing insights into the drivers of HIV epidemics in different population groups. As the generalized HIV epidemic stabilizes emphasis is shifting towards "hot-spot" populations and this study illustrates the value of molecular epidemiology for understanding sexual networks and transmission dynamics in key groups. Public health implications of this study's findings include informing HIV prevention strategies such as risk reduction counselling. Counsellors should be trained to enquire and counsel men about same-sex activity, even if married or reporting relationships with members of the opposite sex. These findings may also have implications for ongoing HIV-related research, particularly the development of locally efficacious HIV vaccines. Over the next several years, vaccine products based on subtype $\mathrm{C}$ constructs will be entering clinical trials, including in South Africa. Given that MSM who report sex with women have a significant risk of subtype C infection, they should be eligible for participation in these studies.

\section{Acknowledgements}

We would like to acknowledge Earl Burrell for his contribution to the early design of this study and both Sheetal Manicklal and Ruwayhida Thebus for their assistance in processing study samples. This study was made possible by funding provided by the International AIDS Vaccine Initiative, the Developmental Center for AIDS Research at the University of Rochester, and US Centers for Disease Control and Prevention, with funding from the President's Emergency Plan for AIDS Relief.

\section{Principal contributions of authors:}

KM: Study conception and design, analysis and interpretation of data; drafting the article and final approval of the manuscript.

CR: Processing of specimens and interpretation of data; assistance with drafting the article, critical revision of article for important intellectual content; and final approval of the manuscript.

BB: Acquisition of data; critical revision of article for important intellectual content; and final approval of the manuscript.

TB: Processing of specimens; critical revision of article for important intellectual content; and final approval of the manuscript.

JM: Processing of specimens; critical revision of article for important intellectual content; and final approval of the manuscript.

AS: Acquisition of data; critical revision of article for important intellectual content; and final approval of the manuscript.

GB: Establishment of laboratory methodology, processing of specimens; critical revision of article for important intellectual content; and final approval of the manuscript. 
LM: Study conception and design; critical revision of article for important intellectual content and final approval of the manuscript.

JF: Study design; critical revision of article for important intellectual content and final approval of the manuscript.

$\mathrm{CW}$ : Interpretation of data; critical revision of article for important intellectual content; and final approval of the manuscript.

LGB: Study conception and design, interpretation of data; critical revision of article for important intellectual content; and final approval of the manuscript.

\section{Financial Support}

All authors report no conflict of interest.

KM was supported by a Hasso Plattner Foundation award via University of Cape Town. 
Table 1: Demographic, sexual orientation and relationship history, reported by race

\begin{tabular}{lcccc}
\hline $\begin{array}{c}\text { Black African } \\
\mathrm{n}=129\end{array}$ & $\begin{array}{c}\text { Coloured } \\
\mathrm{n}=47\end{array}$ & $\begin{array}{c}\text { White } \\
\mathrm{n}=17\end{array}$ & p-value \\
\hline $\begin{array}{l}n(\%) \text { or } \\
\text { median (IQR) }\end{array}$ & $\begin{array}{c}n(\%) \text { or } \\
\text { median (IQR) }\end{array}$ & $\begin{array}{c}n(\%) \text { or } \\
\text { median }(I Q R)\end{array}$ & \\
Demographics & & & & \\
\hline Age & $32(25-37)$ & $32(26-38)$ & $40(32-42)$ & $<0.001$ \\
Peri-urban & $91(71)$ & $10(21)$ & 0 & $<0.001$ \\
Employed & $19(15)$ & $16(34)$ & $11(65)$ & $<0.001$ \\
Education level & & & & \\
$\quad$ No secondary level education & $12(9)$ & $8(17)$ & 0 & \\
$\quad$ Secondary level education & $91(71)$ & $29(62)$ & $9(53)$ & \\
Tertiary education & $26(20)$ & $10(21)$ & $8(47)$ & 0.13 \\
\hline
\end{tabular}

\section{Sexual Orientation}

\begin{tabular}{lcccl}
\hline Heterosexual/Straight & $5(4)$ & $1(2)$ & 0 & \\
Homosexual/gay & $83(66)$ & $39(83)$ & $15(88)$ & \\
Bisexual & $37(29)$ & $2(4)$ & $1(6)$ & \\
Other & $1(1)$ & $5(10)$ & $1(6)$ & $<0.001$ \\
\hline
\end{tabular}

\section{Sexual History}

Have ever had sex with a

woman

$76(59)$

$9(19)$

$10(59)$

$<0.001$

Had sex with a woman in the

last year

42 (58)

$3(30)$

0

$<0.001$

Current relationship status

Male partner

Female partner

Both male and female partner

Not in a relationship

Disclosed sexual involvement

with other men to anyone

89 (69)

7 (5)

17 (13)

38 (30)
19 (40)

2 (4)

1 (2)

25 (53)

6 (38)

0 (63)

38 (81)

17 (100)

0.01

Columns may not always sum to $n$, due to missing data points

One participant declined to identify his race and is therefore excluded from this table $(n=193)$.

$I Q R=$ interquartile range 
Table 2: Demographic, sexual orientation and relationship factors associated with subtype C virus.

\section{Bivariate analysis $\quad \mathrm{p}$-value}

Association with subtype C

OR $(95 \% \mathrm{Cl})$

\section{Demographics}

\begin{tabular}{lcc}
\hline Age & $0.96(0.9-1.0)$ & 0.08 \\
Location & 1 & \\
Urban & $4.6(1.7-12.3)$ & 0.002 \\
Peri-urban & & \\
Race & 1 & \\
White & $4.1(1.0-17.1)$ & 0.05 \\
Coloured & $18.8(4.5-78.3)$ & $<0.001$ \\
Black African & $0.2(0.1-0.6)$ & 0.001 \\
Employed & & \\
\hline
\end{tabular}

\section{Sexual orientation}

\begin{tabular}{ll} 
Homosexual & 1 \\
Bisexual/heterosexual & $*$ \\
\hline
\end{tabular}

\section{Sexual history}

Ever had sex with a woman

$1.1(0.5-2.5) \quad 0.88$

Last sexual intercourse with a woman

More than 1 year ago

1

Within last year

$6.8(1.4-33.3)$

0.02

Currently in relationship

With a man

1

With a woman

$1.8(0.2-15.9)$

0.59

With a man and a woman

Disclosed sexual involvement with other men to anyone

$0.1(0.01-0.7) \quad 0.03$

\footnotetext{
* Perfectly predicts subtype $C$ infection

$\mathrm{OR}=$ odds ratio

$\mathrm{Cl}=$ confidence interval
} 
Figure 1: Consort diagram of subtyping data, by race

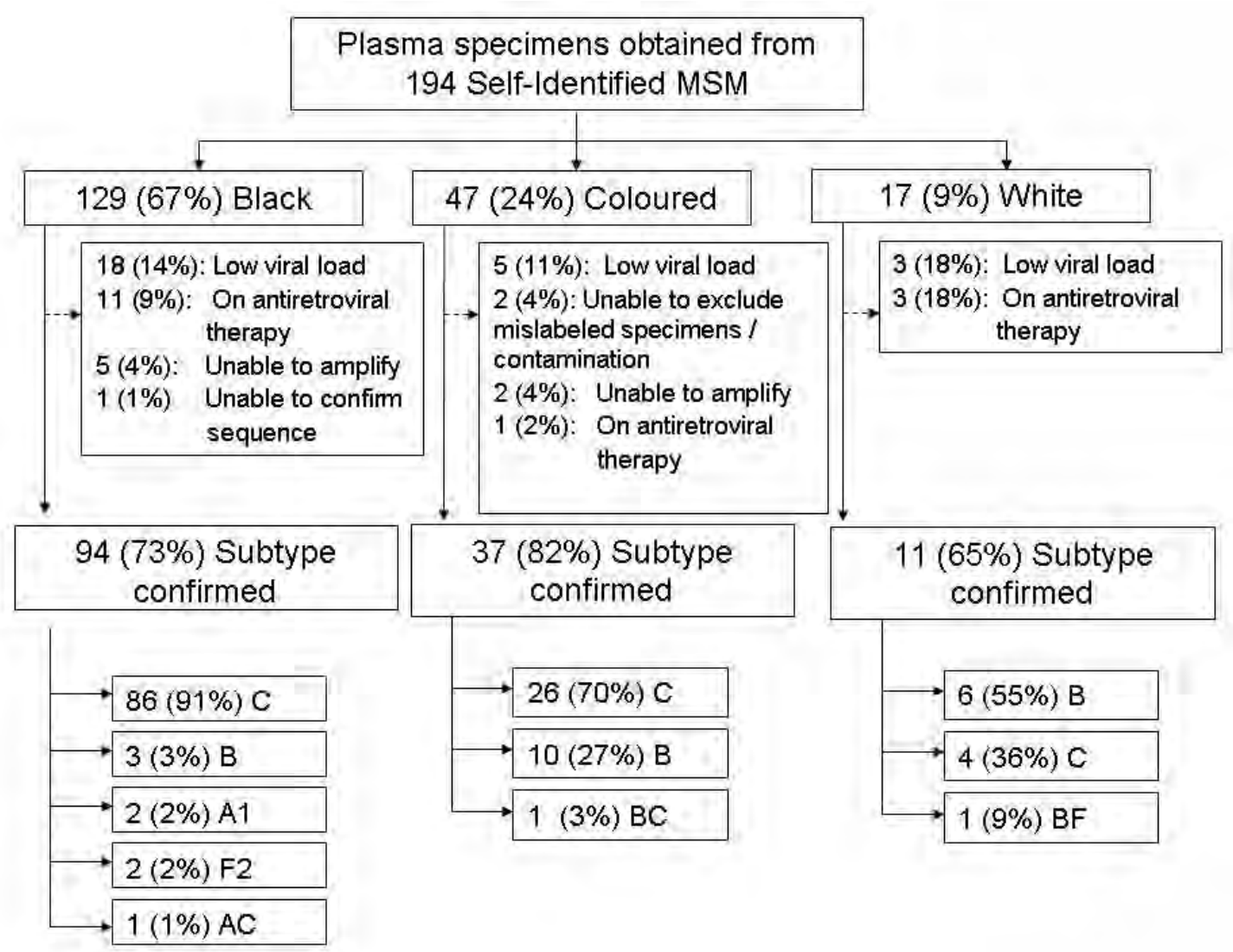

* One participant with an HIV-1 subtype B virus declined to identify his race ( $n=193)$. 
Figure 2: Maximum likelihood trees of study sequences together with 19 reference sequences (obtained from the HIV Sequence Database) presented by race. The scale bar represents $2 \%$ divergence. Proportional representation of subtypes in black African (A), coloured (B) and white MSM (C) in Cape Town are also presented.
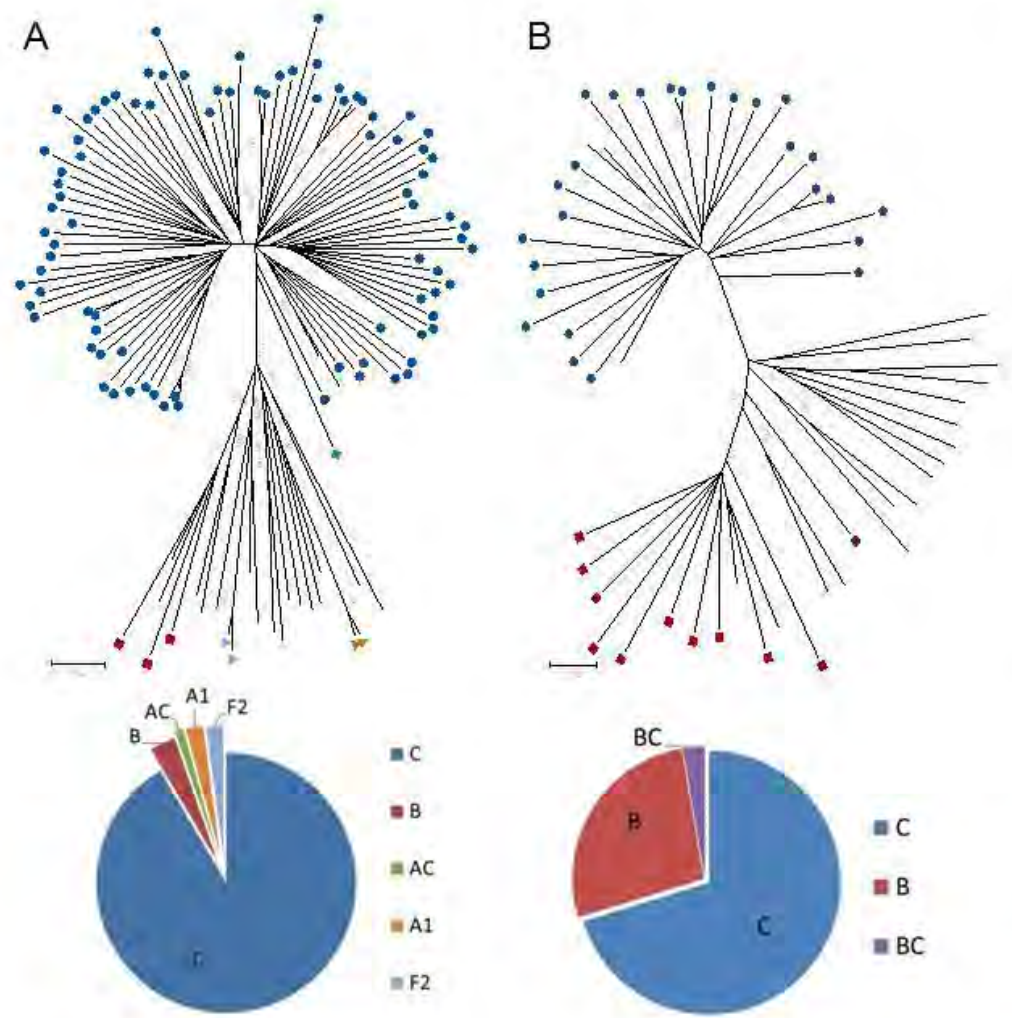

B

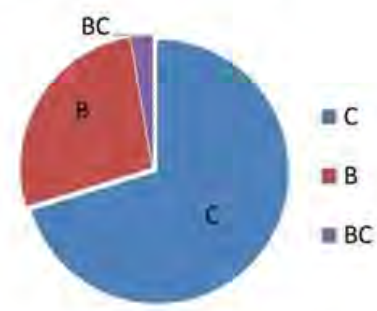

C
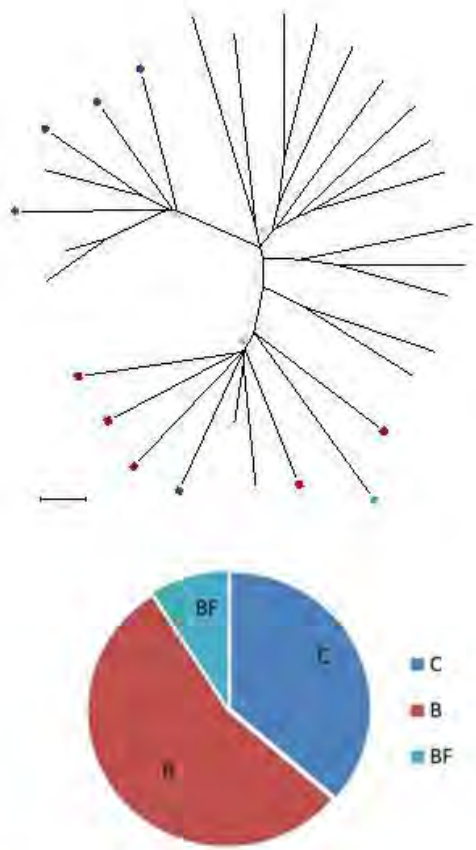
Figure 3: Gp160 Maximum likelihood tree depicting phylogenetic relatedness of the 143 MSM study sequences. Eight putative clusters are bolded. The scale bar represents $2 \%$ divergence and bootstrap values of $>80 \%$ are shown.

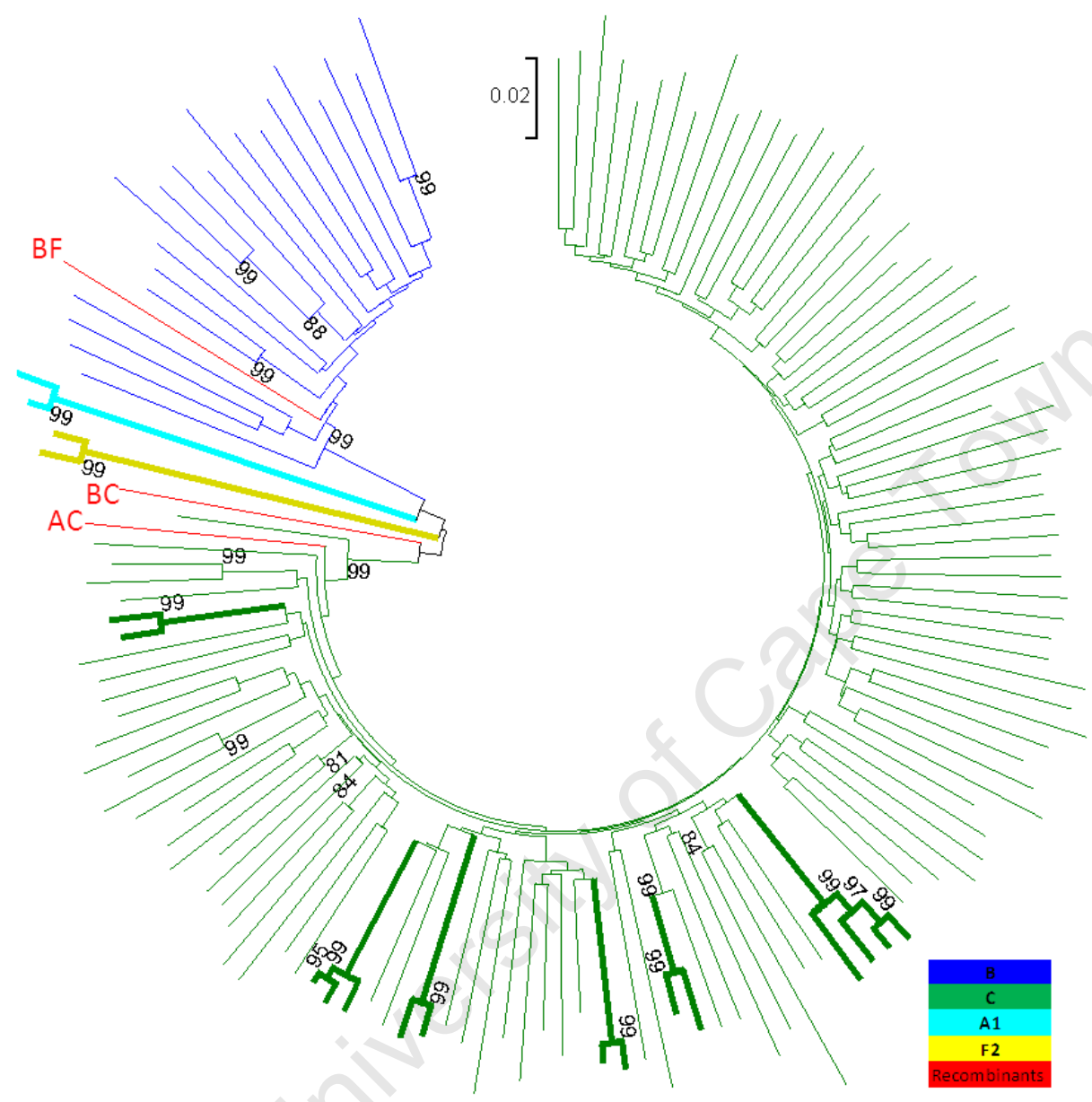




\section{References}

1. UNAIDS. Global Report. UNAIDS report on the global AIDS epidemic. 2012.

http://www.unaids.org/en/media/unaids/contentassets/documents/epidemiology/2012/g $\underline{\text { r2012/20121120 UNAIDS Global Report } 2012 \text { en.pdf }}$

2. Ras GJ, Simson IW, Anderson R, Prozesky OW, Hamersma T. Acquired immunodeficiency syndrome. A report of 2 South African cases. S Afr Med J 1983; 64: 140-142.

3. Sher R. HIV infection in South Africa, 1982-1988--a review. S Afr Med J 1989; 76: 314318.

4. Wood R, O'Keefe EA, Maartens $G$. The changing pattern of transmission and clinical presentation of HIV infection in the Western Cape region of South Africa (1984-1995). Southern African Journal of Epidemiology and Infection 1996; 11: 96-98.

5. van Harmelen J, Wood R, Lambrick M, Rybicki EP, Williamson AL, Williamson C. An association between HIV-1 subtypes and mode of transmission in Cape Town, South Africa. AIDS 1997; 11: 81-87.

6. Mastro TD, Kunanusont C, Dondero TJ, Wasi C. Why do HIV-1 subtypes segregate among persons with different risk behaviors in South Africa and Thailand? AIDS 1997; 11: $113-116$

7. Kark S. The social pathology of syphilis in Africans. S Afr Med J 1949; 23: 77-84.

8. Tucker A. Queer Visibilities: Space, Identity and Interaction in Cape Town. WileyBlackwell. 2009. 
9. Rispel LC, Metcalf CA, Cloete A, Reddy V, Lombard C. HIV prevalence and risk practices among men who have sex with men in two South African cities. J Acquir Immune Defic Syndr 2011; 57: 69-76.

10. South African Centre for Epidemiological Modelling and Analysis (commissioned for SA National AIDS Council). The Modes of Transmission of HIV in South Africa. 2009.

11. Stebbing J, Moyle G. The clades of HIV: their origins and clinical significance. AIDS Rev 2003; 5: 205-213.

12. Rambaut A, Posada D, Crandall KA, Holmes EC. The causes and consequences of HIV evolution. Nat Rev Genet 2004; 5: 52-61.

13. Group Areas Act, No.41 of 1950. Cape Town. Parliament of South Africa.

14. Statistics South Africa. South African Census Questionnaire. 2011. https://www.statssa.gov.za/census2011/CensusQuestionnaire.asp

15. Boonzaier E, Sharp J. South African keywords: the uses \& abuses of political concepts. Cape Town, David Philip. 1988.

16. Magnani R, Sabin K, Saidel T, Heckathorn D. Review of sampling hard-to-reach and hidden populations for HIV surveillance. AIDS 2005; 19 Suppl 2: S67-S72.

17. Department of Health RoSA. National HIV Counselling and Testing (HCT) Policy Guidelines. 2010.

http://www.uj.ac.za/EN/CorporateServices/ioha/Documentation/Documents/hct policy guidelines\%202010.pdf

18. Keele BF, Giorgi EE, Salazar-Gonzalez JF, Decker JM, Pham KT, Salazar MG et al. Identification and characterization of transmitted and early founder virus envelopes in primary HIV-1 infection. Proc Natl Acad Sci U S A 2008; 105: 7552-7557. 
19. Salazar-Gonzalez JF, Bailes E, Pham KT, Salazar MG, Guffey MB, Keele BF et al. Deciphering human immunodeficiency virus type 1 transmission and early envelope diversification by single-genome amplification and sequencing. J Virol 2008; 82: 39523970.

20. McCormack GP, Glynn JR, Crampin AC, Sibande F, Mulawa D, Bliss L et al. Early evolution of the human immunodeficiency virus type 1 subtype $\mathrm{C}$ epidemic in rural Malawi. J Virol 2002; 76: 12890-12899.

21. Thompson JD, Higgins DG, Gibson TJ. CLUSTAL W: improving the sensitivity of progressive multiple sequence alignment through sequence weighting, positionspecific gap penalties and weight matrix choice. Nucleic Acids Res 1994; 22: 46734680.

22. Los Alamos National Laboratory. HIV Database. 2012. http://www.hiv.lanl.gov/

23. Tamura K, Peterson D, Peterson N, Stecher G, Nei M, Kumar S. MEGA5: molecular evolutionary genetics analysis using maximum likelihood, evolutionary distance, and maximum parsimony methods. Mol Biol Evol 2011; 28: 2731-2739.

24. Tamura K, Nei M. Estimation of the number of nucleotide substitutions in the control region of mitochondrial DNA in humans and chimpanzees. Mol Biol Evol 1993; 10: $512-526$.

25. Schultz AK, Zhang M, Leitner T, Kuiken C, Korber B, Morgenstern B et al. A jumping profile Hidden Markov Model and applications to recombination sites in HIV and HCV genomes. BMC Bioinformatics 2006; 7: 265.

26. Williamson C, Engelbrecht S, Lambrick M, van Rensburg EJ, Wood R, Bredell W et al. HIV-1 subtypes in different risk groups in South Africa. Lancet 1995; 346: 782. 
27. Van Harmelen JH, Van der RE, Loubser AS, York D, Madurai S, Lyons S et al. A predominantly HIV type 1 subtype C-restricted epidemic in South African urban populations. AIDS Res Hum Retroviruses 1999; 15: 395-398.

28. Engelbrecht S, Smith TL, Kasper P, Faatz E, Zeier M, Moodley D et al. HIV type 1 V3 domain serotyping and genotyping in Gauteng, Mpumalanga, KwaZulu-Natal, and Western Cape Provinces of South Africa. AIDS Res Hum Retroviruses 1999; 15: 325328.

29. Jacobs GB, Loxton AG, Laten A, Robson B, van Rensburg EJ, Engelbrecht S. Emergence and diversity of different HIV-1 subtypes in South Africa, 2000-2001. J Med Virol 2009; 81: 1852-1859.

30. Nwobegahay JM, Bessong PO, Masebe TM, Mavhandu LG, Iweriebor BC, Selabe G. Prevalence of antiretroviral drug resistance mutations and HIV-I subtypes among newly-diagnosed drug-naive persons visiting a voluntary testing and counselling centre in northeastern South Africa. J Health Popul Nutr 2011; 29: 303-309.

31. Romani B, Glashoff R, Engelbrecht S. Molecular and phylogenetic analysis of HIV type $1 \mathrm{vpr}$ sequences of South African strains. AIDS Res Hum Retroviruses 2009; 25: $357-$ 362.

32. Baral S, Burrell E, Scheibe A, Brown B, Beyrer C, Bekker LG. HIV risk and associations of HIV infection among men who have sex with men in peri-urban Cape Town, South Africa. BMC Public Health 2011; 11: 766.

33. Smith AD, Tapsoba P, Peshu N, Sanders EJ, Jaffe HW. Men who have sex with men and HIVIAIDS in sub-Saharan Africa. Lancet 2009; 374: 416-422.

34. Jacobs GB, Laten A, van Rensburg EJ, Bodem J, Weissbrich B, Rethwilm A et al. Phylogenetic diversity and low level antiretroviral resistance mutations in HIV type 1 
treatment-naive patients from Cape Town, South Africa. AIDS Res Hum Retroviruses 2008; 24: 1009-1012.

35. Beyrer C, Trapence G, Motimedi F, Umar E, lipinge S, Dausab F et al. Bisexual concurrency, bisexual partnerships, and HIV among Southern African men who have sex with men. Sex Transm Infect 2010; 86: 323-327.

36. Baral S, Trapence G, Motimedi F, Umar E, lipinge S, Dausab F et al. HIV prevalence, risks for HIV infection, and human rights among men who have sex with men (MSM) in Malawi, Namibia, and Botswana. PLoS One 2009; 4: e4997. 


\section{Appendices}

\section{Informed Consent}

MSM HIV Subtype Study

Informed Consent

Version 1.0

18 Apr 2013

\section{Epidemiology of HIV-1 subtypes among Cape Town MSM \\ An Exploratory Study to Determine Identity, Social Networks and Circulating HIV Subtypes Among Men Who Have Sex With Men in Cape Town}

Dear Participant

The Desmond Tutu HIV Foundation is conducting a study to gain an improved understanding of men-who-have-sex-with-men (MSM) in the greater Cape Town area. You are being invited to participate in this study because you have identified yourself as a man who has sex with men. This information leaflet describes the study. Please ask a member of the research team any questions you may have regarding the study. The doctor in charge of this study is $\mathrm{Dr}$ Keren Middelkoop.

Participation in this study is voluntary. You can refuse to take part in this study.

\section{Why are we doing this study?}

We wish to better understand the social and sexual networks among MSM in the greater Cape Town area. In addition we are studying the main HIV subtypes in HIV-positive MSM in this area. There are several different types of HIV virus. We call these "subtypes". You can think of them as "cousins" in the same family. Scientists think that the type most commonly transmitted by heterosexual contact may be different from the type most commonly transmitted by MSM contact in South Africa.

We hope that this information will help to develop local policy and HIV prevention strategies, particularly for the MSM communities.

\section{Who can take part in the study?}

This study will include men who were born male, identify themselves as MSM and are 16 years or older. All study participants should reside in the greater Cape Town area, and must either have a documented HIV-positive test result or be willing to have an HIV test as part of the study. In total, there will be approximately 200 HIV-positive participants. 


\section{What will the participants need to do on the study?}

If you take part in this study we will ask you to:

- Answer a questionnaire that will ask about basic demographic details, your sexual orientation and past and current sexual partners.

- The questionnaire will take about 30 minutes to complete.

- You will have about $20 \mathrm{ml}$ of blood drawn (approximately 2 tablespoons) for:

○ an HIV test

- You will get the results back at the same visit

- If you test HIV-negative:

- You will receive post-test counselling, including risk reduction counselling

- The remaining blood drawn from your arm will be discarded.

- If you test HIV-positive:

- You will have a second HIV test to confirm the diagnosis

- you will receive post-test counselling

- Some of your blood will be stored for HIV-subtype testing

- We will also send some of your blood for a CD4 count test. You may come back for a second visit to receive further counselling and get your CD4 result.

- We will refer you to an appropriate centre for medical care.

This part of the study will take approximately another hour.

\section{Where does your blood go?}

The blood for the CD4 count will be sent to a local laboratory for testing. The blood for the HIV subtyping will be sent to a research laboratory at the University of Cape Town. The blood will be labeled only with your unique study number and not with your name to be sure that no one, other than the clinical staff, know who you are.

\section{What about confidentiality?}

All information you give us and all results of laboratory tests will be kept private and will only be disclosed to your medical care provider with your permission. Your name will not be written on the questionnaire. The completed consent forms will be kept in a separate locked filing cabinet that can only be opened by the study staff. Your name will not be used in any publication or presentation of this study.

Your study records may be reviewed by study staff and study monitors, as well as representatives of the sponsors or the University of Cape Town Research Ethics Committee. 


\section{What are the possible risks of this study?}

Some questions in the questionnaire might make you feel uncomfortable. You have the right to refuse to answer any question. Another risk is that confidentiality may be broken. We cannot guarantee participant's confidentiality, but every effort will be made to protect confidentiality.

There is some risk in drawing blood from a vein for the laboratory tests. You will probably have pain and may have some bruising where the needle goes into your arm. Very rarely, you may develop an infection at the site of the blood draw.

\section{What are the benefits of the study?}

You will benefit by learning your HIV status. You will receive risk reduction counselling. If you are HIV-positive you will receive the results the CD4 test and you will be referred for appropriate medical care. The knowledge that we gain from this study may help with HIV research, treatments, and prevention strategies.

\section{What are my rights during the study?}

Participation in the study is voluntary. You are free to withdraw from the study at any time without any disadvantage to you. Participants can decide at any time to leave the study after starting. In this case we will ask the reasons for no longer wishing to be part of the study.

\section{Will being in the study cost anything?}

Participation in the study will not cost you any money.

\section{Will I be paid to be in this study?}

No, you will not be paid. You will be given R100 to reimburse you for time and transport.

\section{What are my alternatives?}

You can chose not to take part in this study. If you are concerned that you have HIV you can get tested at any HIV testing clinic or centre. The researcher can give you more information as to your closest available testing centre.

\section{Who do I call if I have questions?}

If you need more information or you have any questions regarding the study, please feel free to contact Dr Keren Middelkoop, Desmond Tutu HIV Foundation at 0216506966.

If you have a question about your rights as a research volunteer you can contact $\mathrm{Dr}$ Blockman at 021406 6492. He is the head of the University of Cape Town Human Research Ethics Committee, the committee that provided ethical approval for this study. 
Epidemiology of HIV-1 subtypes among Cape Town MSM

An Exploratory Study to Determine Identity, Social Networks and Circulating HIV Subtypes Among Men Who Have Sex With Men in Cape Town

\section{Consent Form}

I hereby confirm that I have been told about the design and purpose of this study. I have received and understood the above information regarding the research. I understand that my participation in the study is voluntary. I have had sufficient opportunity to ask questions and my questions have been answered. I agree to participate in the research as described in the information leaflet above.

I will receive a copy of this consent form and information leaflet.

\section{Participant's Name:}

Printed Name Signature Date

Study Staff Member's Name:

Printed Name Signature Date

Witness's Name (if appropriate): 


\section{Study Questionnaire}

\section{Epidemiology of HIV-1 subtypes among Cape Town MSM Study Questionnaire}

\begin{tabular}{|c|c|c|c|c|}
\hline \multirow[t]{2}{*}{ PID } & \multicolumn{4}{|c|}{ D D / M M M / Y Y Y Y } \\
\hline & Part 1: & & $\begin{array}{l}\text { Response Guide } \\
88 \text { Unsure/don't know } \\
99 \text { No response }\end{array}$ & $\begin{array}{l}\text { Response } \\
\text { (Numerical } \\
\text { Answer) }\end{array}$ \\
\hline 1 & How old are you? & & Number of Years & \\
\hline 2 & What race do you identify as? & & $\begin{array}{l}1 \text { Black African } \\
2 \text { Colored } \\
3 \text { White } \\
4 \text { Other (specify) }\end{array}$ & \\
\hline 3 & Which township or suburb do you live in? & & Name & \\
\hline 4 & How long have you lived in this township/suburb? & & Number of Years & \\
\hline 5 & Which township or suburb do you live in before you move & here? & Name & \\
\hline 6 & What level of education have you completed? & & $\begin{array}{l}1 \text { No formal Education } \\
2 \text { Primary School } \\
3 \text { Secondary School } \\
4 \text { College or University }\end{array}$ & \\
\hline 7 & Are you currently employed/working? & & $\begin{array}{l}1 \text { Yes } \\
2 \mathrm{No} \\
\end{array}$ & \\
\hline 8 & $\begin{array}{l}\text { Are you currently married to or in a relationship with a ma } \\
\text { partner? }\end{array}$ & or female & $\begin{array}{l}1 \text { Male } \\
2 \text { Female } \\
3 \text { Both a male \& a female } \\
77 \text { Not married or in a } \\
\text { relationship }\end{array}$ & \\
\hline 9 & Have you ever had vaginal sex with a woman? & & $\begin{array}{l}1 \text { Yes } \\
2 \mathrm{No}\end{array}$ & \\
\hline 10 & If YES to 9, When did you last have vaginal sex with a wo & an? & $\begin{array}{l}\text { This week } \\
2 \text { This month } \\
3 \text { In the last } 6 \text { months } \\
4 \text { In the last year } \\
5 \text { Over a year ago }\end{array}$ & \\
\hline 11 & How many men have you had anal sex with in the last $6 r$ & nths? & Number & \\
\hline 12 & Which of the following terms best describes your sexual 0 & entation? & $\begin{array}{l}1 \text { Heterosexual/Straight } \\
2 \text { Homosexual/Gay } \\
3 \text { Bisexual } \\
4 \text { Other (specify) }\end{array}$ & \\
\hline 13 & $\begin{array}{l}\text { Have you told anyone about your sexual involvement with } \\
\text { If YES to 14:, Choose all options that apply }\end{array}$ & ther men? & $\begin{array}{l}\text { 1 yes } \\
\text { 2. No } \\
\text { 1a Family member } \\
\text { 1b Gay Friends } \\
\text { 1c Straight Friends } \\
\text { 1d Wife/girlfriend } \\
\text { 1e Casual girlfriend } \\
\text { 1f Co-worker } \\
\text { 1g Religious leader } \\
\text { 1h Hospital/clinic staff }\end{array}$ & \\
\hline
\end{tabular}




\section{Part 2:}

I'm now going to ask about the 3 most recent partners you have had sex with in the last 6 months.

You do not have to use any names.

Let's start with the MOST RECENT partner you have had sex with in the last 6 months.

\begin{tabular}{|l|l|l|l|l|l|}
\hline & Question & Response Guide & $\mathbf{1}^{\text {st }}$ Partner & & $\mathbf{3}^{\text {nd }}$ Partner \\
\hline 14 & $\begin{array}{l}\text { Is this partner male, female, } \\
\text { or trans? }\end{array}$ & $\begin{array}{l}\text { 1 Male } \\
\text { 2 Female } \\
\text { 3Transexual (specify) }\end{array}$ & & & \\
\hline 15 & $\begin{array}{l}\text { What is the race or ethnic } \\
\text { group of this partner? }\end{array}$ & $\begin{array}{l}\text { 1 Black African } \\
\text { 2 Colored } \\
\text { 3 White } \\
\text { 4 Other (specify) }\end{array}$ & & & \\
& & & & \\
\hline 16 & $\begin{array}{l}\text { Was/ls this partner a main or } \\
\text { 1 Main } \\
\text { 2 Casual }\end{array}$ & & & \\
\hline 17 & $\begin{array}{l}\text { Where did you meet this } \\
\text { partner? }\end{array}$ & (name township/suburb) & & \\
& & & & \\
\hline 18 & $\begin{array}{l}\text { Where does this partner } \\
\text { live? } \\
\text { (name township/suburb) }\end{array}$ & (name township/suburb) & & & \\
\end{tabular}




\section{Ethics Committee Approval (latest annual renewal of approval)}

UNAVERSITY OF CAPE TOWN

FACULTY OF HEALTH SCIENCES

Human Research Ethics Committee

Annual Progress Report

\begin{tabular}{|l|l|}
\hline REC REF Number & \begin{tabular}{l}
$276 / 2006$ \\
\hline Title
\end{tabular} \\
& $\begin{array}{r}\text { Exploratory Study to Determine Identity, Social Networks and Circulating HIV } \\
\text { Clades Among Men-Who-Have-Sex-With-Men (MSM) in Cape Town }\end{array}$ \\
\hline Principal Investigator & Dr K Middelkoop \\
\hline
\end{tabular}

List of documentation

Protocol Version 3.1 Dated 21 June 2010

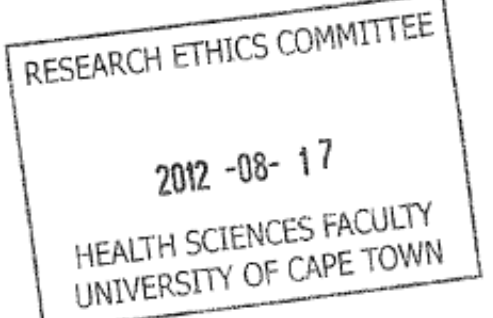

HREC office use only (FWA00001637; IRB00001938)

\begin{tabular}{|c|c|c|c|}
\hline á Approved & \multicolumn{3}{|c|}{$\begin{array}{l}\text { This serves as notification of annual approval, including all documentation described } \\
\text { above. }\end{array}$} \\
\hline$\square$ Not approved & \multicolumn{3}{|c|}{ See attached comments. } \\
\hline Type of review & $\nabla$ Expedited & \multicolumn{2}{|c|}{ Full committee } \\
\hline \multicolumn{4}{|l|}{ Expiry date } \\
\hline $\begin{array}{l}\text { Signature } \\
\text { Chairperson of the HREC }\end{array}$ & pp TRugess & Date & 17108120 \\
\hline
\end{tabular}




\title{
IV. Author Instructions
}

\author{
From: http://edmgr.ovid.com/aids/accounts/ifauth.htm
}

\section{AIDS}

\section{Online Submission and Review System}

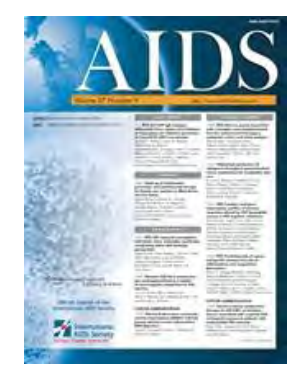

\section{Guidance for Authors on the Preparation and Submission of Manuscripts to AIDS}

Note: These instructions comply with those formulated by the International Committee of Medical J ournal Editors. For further details, authors should consult the "Uniform Requirements for Manuscripts Submitted to Biomedical Journals" at www.icmje.org.

\section{Scope}

AIDS publishes papers reporting original scientific, clinical, epidemiological, and social research which are of a high standard and contribute to the overall knowledge of the field of the acquired immune deficiency syndrome. The J ournal publishes Original Papers, Concise Communications, Field Notes, Research Letters, and Correspondence, as well as invited Editorial Reviews, Opinion Pieces, and Editorial Comments. All manuscript submissions to the regular issues and supplements of the journal are peer-reviewed. Papers may be subject to a statistical analysis and for flow cytometry results by a group of experts in the field. Case Reports are not encouraged but may be considered as Correspondence letters.

\section{Original papers}

Manuscripts should be concise and not be more than 3500 words, with up to five figures or tables. Papers will be returned if they exceed the maximum stated. The word limit refers to the main body of the text and does not include the abstract, references or figure legends.

\section{POINTS TO CONSIDER BEFORE SUBMISSION}

\section{Conflicts of interest}

Authors must state all possible conflicts of interest in the manuscript, including financial, consultant, institutional and other relationships that might lead to bias or a conflict of interest. If there is no conflict of interest, this should also be explicitly stated as none declared. All sources of funding should be acknowledged in the manuscript. All relevant conflicts of interest and sources of funding should be included on the title page of the manuscript with the heading "Conflicts of Interest and Source of Funding:". For example:

Conflicts of Interest and Source of Funding: A has received honoraria from Company Z. B is currently receiving a grant (\#12345) from Organization $Y$, and is on the speaker's bureau for Organization $\mathrm{X}$ - the CME organizers for Company A. For the remaining authors none were declared.

In addition, each author must complete and submit the journal's copyright transfer agreement, which includes a section on the disclosure of potential conflicts of interest based on the recommendations of the International Committee of Medical Journal Editors, "Uniform Requirements for Manuscripts Submitted to Biomedical Journals" (www.icmje.org/update.html). The form is readily available on the manuscript submission page http://edmgr.ovid.com/aids/accounts/copyrightTransfer.pdf and can be completed and submitted 
electronically. Please note that authors may sign the copyright transfer agreement form electronically. For additional information about electronically signing this form, go to http://links.Iww.com/ZUAT/A106.

\section{Permissions to reproduce previously published material}

Authors should include with their submission, copies of written permission to reproduce material published elsewhere (such as illustrations) from the copyright holder. Authors are responsible for paying any fees to reproduce material. We cannot send your paper to press without these permissions!

\section{Subject consent forms}

Subjects have a right to privacy that should not be infringed without informed consent. Identifying details (written or photographic) should be omitted if they are not essential, but subject data should never be altered or falsified in an attempt to attain anonymity. Complete anonymity is difficult to achieve, and a consent form should be obtained if there is any doubt. For example, masking the eye region in photographs of subjects is inadequate protection of anonymity. When informed consent has been obtained, it should be indicated in the published article. A sample patient consent form is available here if required.

\section{Ethics committee approval}

All authors must sign a declaration that the research was conducted within the guidelines below and under the terms of all relevant local legislation. Please also look at the latest version of the Declaration of Helsinki. The Editors reserve the right to judge the appropriateness of the use and treatment of humans or animals in experiments for publication in the journal.

Human experiments: All work must be conducted in accordance with the Declaration of Helsinki. Papers describing experimental work on human participants which carries a risk of harm must include (1) a statement that the experiments were conducted with the understanding and the consent of each participant, and (2) a statement that the responsible ethical committee has approved the experiments.

\section{Authorship}

All authors must sign the document accompanying their submission to confirm that they have read and approved the paper, that they have met the criteria for authorship as established by the International Committee of Medical J ournal Editors, that they believe that the paper represents honest work, and that they are able to verify the validity of the results reported.

The corresponding author should list the principal contributions made by each of the authors to the article in the Acknowledgements section of the submission. The journal discourages a long list of authors and does not recommend more than 12. In rare instances, a maximum of 15 is permitted if well-justified. Persons listed as authors must be able to justify their participation in the study and should have substantially contributed to the study's conception, design, and performance. An Appendix of additional study sites and participants, in addition to the authors, may be included after the References.

\section{Copyright assignment}

Please note that the inclusion of a signed copyright transfer and disclosure form is required for the submission of all manuscripts. This is irrespective of whether an author chooses the Open Access option when an article is accepted for publication. 


\section{Authors retain copyright}

Authors retain their copyright for all articles they opt to publish open access. Authors grant LWW a license to publish the article and identify itself as the original publisher.

\section{Submissions}

Authors are strongly encouraged to submit their manuscripts through the web-based tracking system at http://aids.edmgr.com/. Signed author forms may be included in the submission as a 'supporting document' or mailed to the journal office. The site contains instructions and advice on how to use the system. Authors should NOT in addition then post a hard copy submission to the editorial office, unless you are supplying artwork, letters or files that cannot be submitted electronically, or have been instructed to do so by the editorial office. For those authors who have no option but to submit by mail please send one copy of the article, plus an electronic version on disk or CD-ROM to: The Editors, AIDS, AIDS Editorial Office, 250 Waterloo Road, London SE1 8RD, UK, Tel: +44 20 7981-0600, Fax: +44 20 7981-0601. Or alternatively via: AIDS Editorial Office (London), Lippincott Williams \& Wilkins, Penn Mutual Building, 530 Walnut Street, Philadelphia, PA 19106, USA. Include the following where appropriate: subject consent forms; transfer of copyright form; permission to reproduce previously published material.

Double spacing should be used throughout the manuscript, which should include the following sections, each starting on a separate sheet: Title Page, abstract (when required) and keywords, text, acknowledgements, references, individual tables and captions. Margins should be at least 3 $\mathrm{cm}$. Pages should be numbered consecutively, beginning with the Title Page, and the page number should be placed in the top right-hand corner of each page. Abbreviations should be defined on their first appearance in the text; those not accepted by international bodies should be avoided. The word count should be clearly stated on the Title Page. Manuscripts sent by post should be submitted on high quality white paper and on a word-processing disk.

Authors are invited to list up to four potential reviewers, including their full addresses, telephone and fax numbers, and e-mail addresses.

\section{PRESENTATION OF PAPERS Title Page}

The Title Page should carry the full title of the paper (not more than 120 characters) and a short title (not more than 40 characters) to be used as a 'running head' (and which should be so identified). The given or first name, middle initial and family name (surname) of each author should appear. The family name (surname) must appear in CAPITAL letters. If the work is to be attributed to a department or institution, its full name should be included. Total number of words used should be clearly stated on the Title Page. Any disclaimers should appear on the Title Page, as should the name and address (and email) of the author responsible for correspondence concerning the manuscript and the name and address of the author to whom requests for reprints should be made. Finally, the Title Page should include the sources of any support for the work in the form of grants, equipment, drugs, or any combination of these. Disclose funding received for this work from any of the following organizations: National Institutes of Health (NIH); Wellcome Trust; Howard Hughes Medical Institute (HHMI); and other(s).

Abstracts

The abstract should not exceed 250 words and should follow one of the following two styles:

a. Articles concerning original scientific research should include a structured abstract with the following headings and information: 
Objective(s): State the primary objective of the paper (if appropriate).

Design: State the principal reasoning for the procedures adopted.

Methods: State the procedures used.

Results: State the main results of the study. Numerical data should be kept to a minimum.

Conclusions: State the conclusions that can be drawn from the data given.

\section{Key Words}

The abstract should be followed by a list of 5-7 keywords or short phrases which will assist the cross-indexing of the article and which may be published. The terms used should be from the Medical Subject Headings list of the US National Library of Medicine

(http://www.nlm.nih.gov/mesh/meshhome.html). Include terms from the AIDS classifications that appear on the Fast Track submission form at the back of each journal issue, and on the submission website at http://aids.edmgr.com/.

\section{Text}

Full papers of an experimental or observational nature may be divided into sections headed Introduction, Methods (including ethical and statistical information), Results, and Discussion (including a conclusion), although reviews may require a different format.

\section{Acknowledgements}

The corresponding author should list the principal contributions made by each of the authors to the article. Acknowledgements should be made only to those who have made a substantial contribution to the study. Authors are responsible for obtaining written permission from people acknowledged by name in case readers infer their endorsement of data and conclusions. Sources of funding should be placed in this section.

\section{References}

References should be numbered consecutively in the order in which they first appear in the text. They should be assigned Arabic numerals, which should be given in brackets, e.g. [17]. References should include the names of all authors when six or fewer; when seven or more, list only the first six names and add et al. References should also include full title and source information. Journal names should be abbreviated as in the MEDLINE (http://www. nlm.nih.gov).

\section{Articles in journals}

Standard journal article:

Valori RM, Kumar D, Wingate DL. Effects of different types of stress and of 'prokinetic' drugs on the control of the fasting motor complex in humans. Gastroenterology 1986; 90: $1890-1900$.

More than six authors:

Gentilini P, Laffi G, La Villa G, Romanelli RG, Buzzelli G, Casini-Raggi V, et al. Long course and prognostic factors of virus-induced cirrhosis of the liver. Am J Gastroenterology 1997; 92: $1-7$. 
Supplements:

Goulis J, Burroughs AK. Role of vasoactive drugs in the treatment of bleeding oesophageal varices. Digestion 1999; 60(Suppl 3): 25-34.

Letter/Abstract:

Ozsoylu S, Kocak N. Naloxone in hepatic encephalopathy [Letter]. Am J Dis Child 1985;

139: 749-750.

Lankisch PG, Assmus D, Pflichtohofer D.: The burden of pancreatic disease in a welldefined population [Abstract]. Gastroenterology 1998; 114:A24.

\section{Books}

Book:

Whitehead WE, Schuster MM, Gastrointestinal Disorders. Behavioral and Physiological Basis for Treatment. Orlando: Academic Press; 1985.

Chapter in a book:

Blackshaw AJ. Non-Hodgkin's lymphomas of the gut. In: Recent Advances in

Gastrointestinal Pathology. Wright R (editor). New York: Saunders; 1980. pp. 213-240.

Personal communications and unpublished work should not feature in the reference list but should appear in parentheses in the text. Unpublished work accepted for publication but not yet released should be included in the reference list with the words 'in press' in parentheses beside the name of the journal concerned. References must be verified by the author(s) against the original documents.

\section{Tables}

Each table should be typed on a separate sheet in double spacing. Tables should not be submitted as photographs. Each table should be assigned an Arabic numeral, e.g. (Table 3) and a brief title. Vertical rules should not be used. Place explanatory matter in footnotes, not in the heading. Explain in footnotes all non-standard abbreviations that are used in each table. Identify statistical measures of variations, such as standard deviation and standard error of the mean.

Be sure that each table is cited in the text. If you use data from another published or unpublished source, obtain permission and acknowledge the source fully.

\section{Illustrations}

References to figures and tables should be made in order of appearance in the text and should be in Arabic numerals in parentheses, e.g. (Fig. 2). If hard copies of figures are submitted they should have a label pasted to the back bearing the figure number, the title of the paper, the author's name and a mark indicating the top of the figure. Illustrations should not be mounted. Half-tone illustrations should be presented as glossy prints to a width of $82 \mathrm{~mm}$; line illustrations should be presented as original artwork or prints to a width of $82 \mathrm{~mm}$ or, when the illustration demands it, to a width of $173 \mathrm{~mm}$. 
Figures may be reduced, cropped or deleted at the discretion of the editor. Colour illustrations are acceptable but authors will be expected to cover the extra reproduction costs (for current charges, contact the publisher).

\section{Digital Artwork}

\section{A) Creating Digital Artwork}

http://links.Iww.com/ES/A42

1. Create, Scan and Save your artwork and compare your final figure to the Digital Artwork Guideline Checklist (below).

2. Upload each figure to Editorial Manager in conjunction with your manuscript text and tables.

\section{B) Digital Artwork Guideline Checklist}

Here are the basics to have in place before submitting your digital artwork:

- Artwork should be saved as TIFF, EPS, or MS Office (DOC, PPT, XLS) files. High resolution PDF files are also acceptable.

- Crop out any white or black space surrounding the image.

- Diagrams, drawings, graphs, and other line art must be vector or saved at a resolution of at least $1200 \mathrm{dpi}$. If created in an MS Office program, send the native (DOC, PPT, XLS) file.

- Photographs, radiographs and other halftone images must be saved at a resolution of at least 300 dpi.

- Photographs and radiographs with text must be saved as postscript or at a resolution of at least $600 \mathrm{dpi}$.

- Each figure must be saved and submitted as a separate file. Figures should not be embedded in the manuscript text file.

\section{Remember:}

- Cite figures consecutively in your manuscript.

- Number figures in the figure legend in the order in which they are discussed.

- Upload figures consecutively to the Editorial Manager web site and enter figure numbers consecutively in the Description field when uploading the files.

\section{Legends for illustrations}

Captions should be typed in double spacing, beginning on a separate sheet of paper. Each one should have an Arabic numeral corresponding to the illustration to which it refers. Internal scales should be explained and staining methods for photomicrographs should be identified. 


\section{Units of measurement}

Measurements of length, height, weight, and volume should be reported in metric units (metre, kilogram, or litre) or their decimal multiples. Temperatures should be given in degrees Celsius. Blood pressures should be given in millimetres of mercury.

All haematologic and clinical chemistry measurements should be reported in the metric system in terms of the International System of Units (SI). Editors may request that alternative or non-SI units be added by the authors before publication.

\section{Abbreviations and symbols}

Use only standard abbreviations. Avoid abbreviations in the title and abstract. The full term for which an abbreviation stands should precede its first use in the text unless it is a standard unit of measurement. 